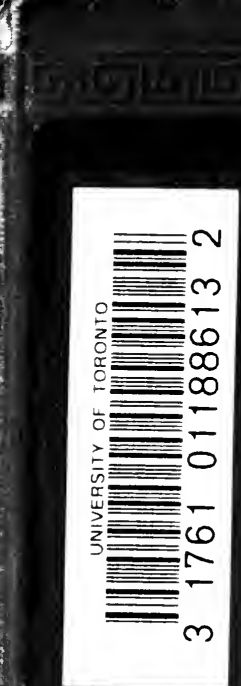


IVP 2.

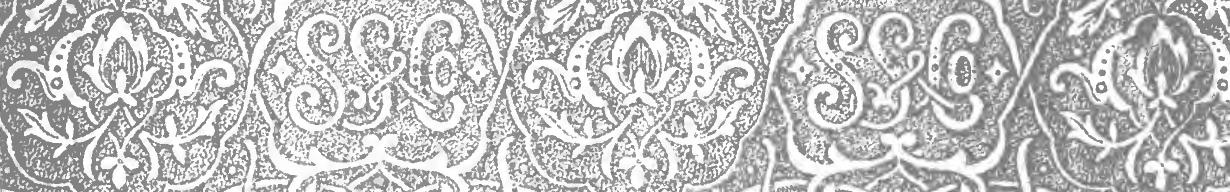

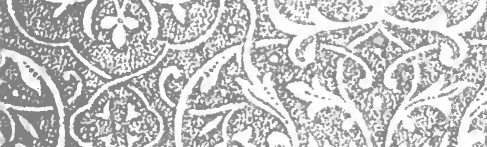

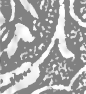

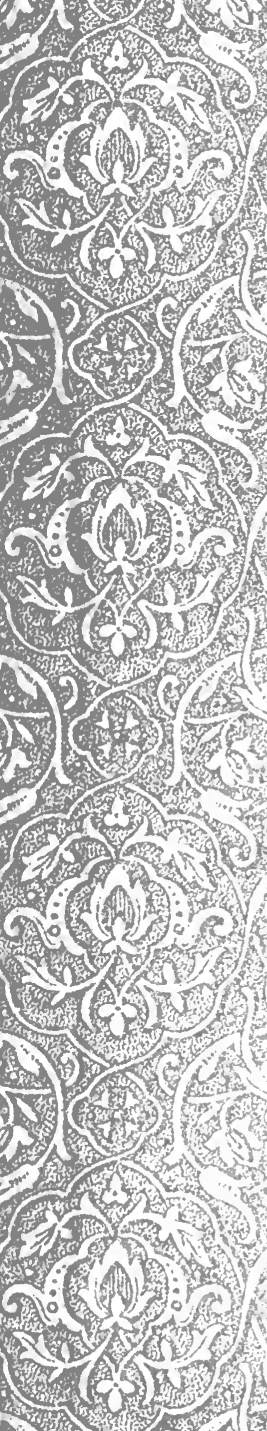

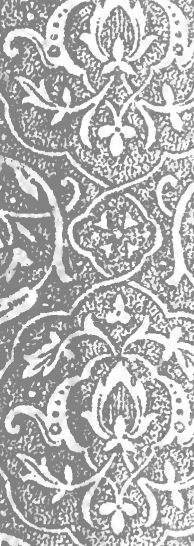

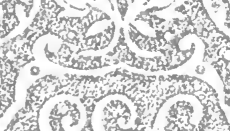

M. (1) (6)

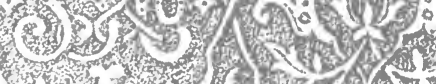
$(6)$ 1.4.

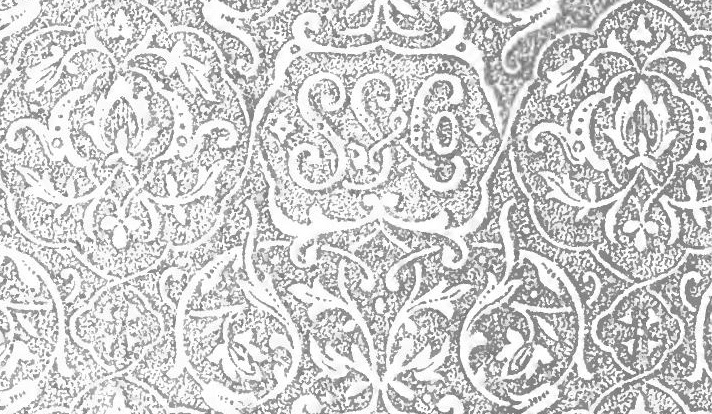
,

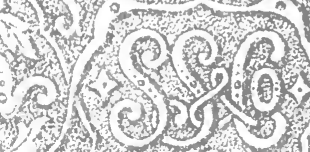
0.

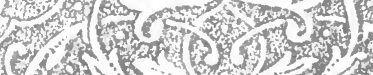
7 . (1) 4

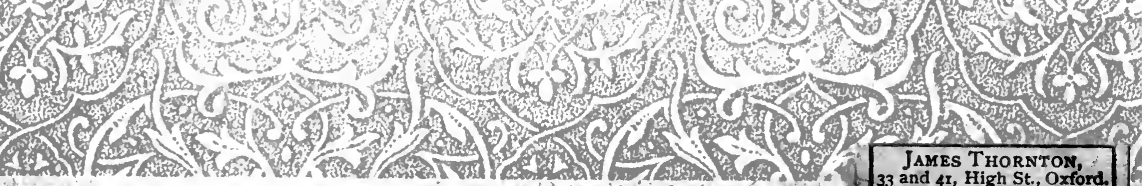

JAMES THORNTON,
33 and $4 \mathrm{I}$, High St., Oxford. 


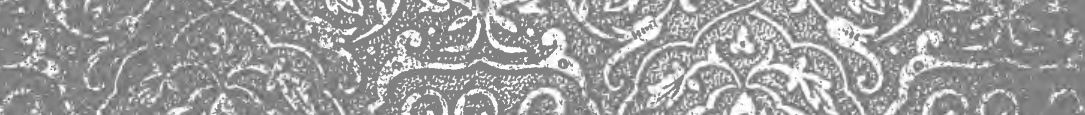
6
4

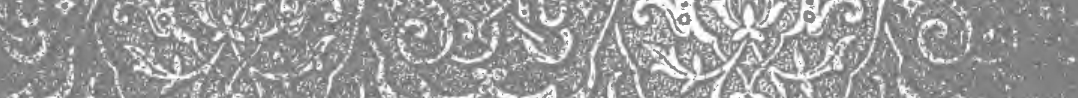

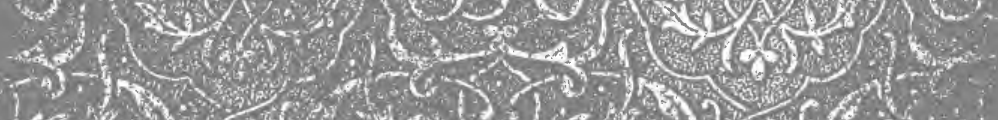

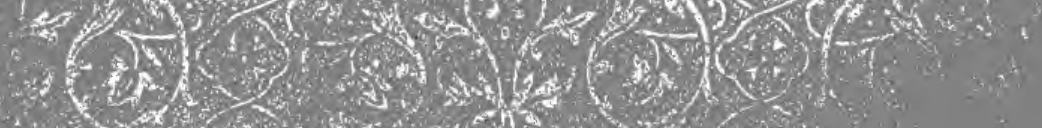

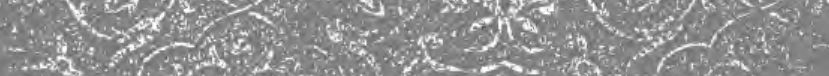

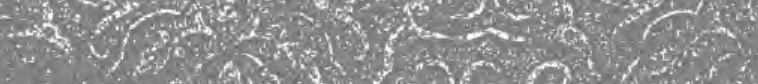




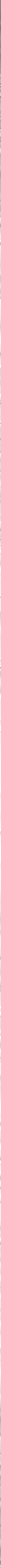
f

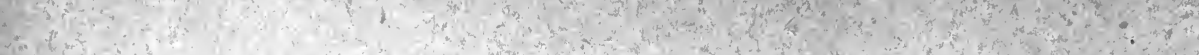
$\frac{3}{3}$ 


$$
\begin{aligned}
& \text { a.9. Eagleston. } \\
& \text { Balliol College }
\end{aligned}
$$

\section{DARWIN AND HEGEL}

ETC. 
Eagleston 


\section{DARWIN AND HEGEL}

\section{WITH OTHER PHILOSOPHICAL STUDIES}

BY

DAVID G. RITCHIE, M.A.

Fellow and Tutor of Jesus College, Oxford; Author of "Darwinism and Po'itics," "The Principles of State Interference," etc.

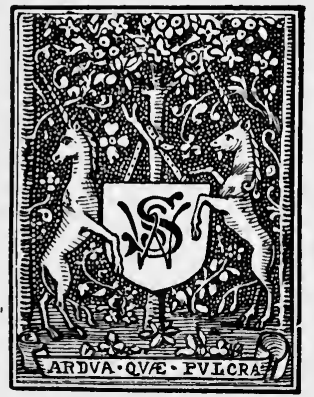

3ัanชon

SWAN SONNENSCHEIN \& CO. NEW YORK: MACMILLAN \& CO. 
BUTLER \& TANNER,

The Selwood Printing Works,

FROME, AND LONDON.

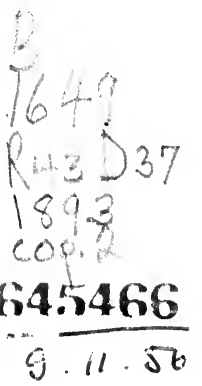




\section{P REF A CE.}

THE papers collected in this volume have previously appeared in Mind, The Proceedings of the Aristotelian Society, The Philosophical Review, The Economic Review, The Political Science Quarterly, The Annals of the American Academy of Political and Social Science, and The International Journal of Ethics; and I have to thank the respective Editors for their kindness and courtesy in permitting republication. The "Notes" at the end of the first and third essays have not been printed before.

Corrections and alterations of varying importance have been made; but I have not attempted to give these essays, written at different times, an appearance of greater unity than belongs to them from the fact that the diverse subjects are looked at from a common point of view. I have put in the title of the volume the title of the second essay, because it indicates with sufficient emphasis what that point of view is ; it expresses my endeavour to reconcile a qualified acceptance of the general principles of that idealist 
philosophy which is based on Kantian criticism (but which, at the same time, carries us back to Plato and Aristotle) with a full recognition of the revolutionary change in our intellectual universe which is due to the historical method of studying ideas and institutions, and, in particular, to the influence of the biological theory of natural selection.

"Idealism" and "Materialism" are commonly spoken of as antagonistic types of philosophy; and, in a sense, they are, I have tried to show that one form of idealism is quite compatible with that materialistic monism which is now-a-days the working hypothesis of every scientific explorer in every department, whatever other beliefs or denials he may, more or less explicitly and more or less consistently, superadd. Materialistic monism, it seems to me, only becomes false when put forward as a complete philosophy of the universe, because it leaves out of sight the conditions of human knowledge, which the special sciences ${ }^{1}$ may conveniently disregard, but which a candid philosophy cannot ignore. It is too probable that my Eirenicon, like other efforts at peacemaking, may only result in provoking a twofold hostility, and that "Darwinians" and "Hegelians" will both look on me as a heretic. But I cannot, as yet, see any other way out of a hopeless controversy than that towards which I

1 Including, perhaps, even Psychology, as that is commonly understood. Cf. below, p. 104, and p. 9, note. 
have been led, especially by the teaching of the late Thomas Hill Green on the one side, and by the influence of scientific friends on the other. And this Idealist Evolutionism (if a label is necessary) seems to me to give the best starting point for an examination of the concrete problems of ethics and politics, which are, after all, the most urgent difficulties with which we have to deal. In venturing to trespass to some extent on the proper domains of the economist, the lawyer and the historian, I trust that lack of special knowledge and special training has not led me into grave errors. I consider such applications of philosophical criticism to be at once the best test of the value of general philosophical theories and the most useful service which the student of philosophy can render to those who are pursuing special studies.

I hope the "benevolent reader" will pardon this brief explanation. I must not make it longer, lest by preliminary prolixity I should only add to the offence (as it is often supposed to be) of publishing a few detached essays instead of waiting to inflict a big treatise on the public. I will only ask those, who may do me the honour of considering carefully what I have to say, to remember that I wish these papers, though written at intervals, to be taken as a whole; so that statements in one essay must be understood as qualifying those in another. A certain amount of repetition will perhaps be excused, and may even be useful, if it serves to remind the 
viii PREFACE.

reader of this unity of purpose. It is not possible to put the whole of one's philosophic creed, especially when it is but partially formulated, into every page or into every article. In fact, a formula that professed to exhaust the truth would excite very reasonable suspicion.

OXFORD,

May ist, I 893 . 


\section{CONTENTS.}

I. Origin and Validity $. \quad . \quad . \quad . \quad \cdot$ I-3 I

Origin supposed to determine worth, in popular thought, I, 2, and in the "metaphysical" stage of reflection, 3-6. The philosophical problem distinct from the historical and psychological, 6-8. What is of most permanent value in Kant's Critical Philosophy, 8-14. The relation between Critical Philosophy (Theory of Knowledge) and Speculative Metaphysics, I4, I5. Illustrations of the importance of distinguishing questions of origin and validity, in Logic, 16-22. (Axioms, 17 ; the Syllogism, I8-20; Connotation of proper names, 20 ; Analytic and synthetic judgments, 21 ; Inconceivability of the opposite, 2I, 22); in other philosophical sciences that are concerned with Ideals, 22-25; in Æsthetics, 25, 26; in Ethics, 26, 27 ; in Politics, 27-30 ; in Religion, 30, 31 .

Note on Heredity as a Factor in KnowLEDGE • • • . . . . $32-37$

The biological controversy between Lamarckian and Weismannite, 32-35. Application to problem of knowledge, 35. Relation of the Evolution theory to the Kantian theory of knowledge, 36, 37 . 
II. Darwin and Hegel . . . . . $38-76$

Philosophy always affected by the predominant science of the time, 38-4I. The idea of development, especially in biology, prevalent during Hegel's youth, 4I-44. His preference for Emanation over Evolution, 44 ; Element of truth in this-the lower must be explained by the higher, 45-47. Hegel to be "read backwards"; illustration from categories of "Becoming" and "Similarity," 47-49. Risk of misunderstanding, when a thought process is stated as if it were a time-process, 50, 5 I. Hegel's mode of exposition due to (I) influence of idea of Emanation, and (2) of his interpretation of history, especially of the history of philosophy, $5 \mathrm{I}-53$.

Hegel's philosophy of nature, 53, 54. How it could be adjusted to Darwin's theory of natural selection, 55 , 56. The seeming irrationality of nature $=$ the indefinite variability presupposed by natural selection, 57,58 . Modern science assumes that nature is not alogical, 59. Restored value of the Aristotelian concept of Final Cause, 6o-62.

Application of "natural selection" in ethics : Utilitarianism corrected, 62, 63. History in the light of natural selection-a dialectic movement, clearer in the higher stages, 63-66. Mr. S. Alexander's analysis of Punishment, at once Darwinian and Hegelian, 66, 67. Hegel agrees with evolutionist ethics (I) in denying an ultimate distinction between "ought" and "is"-with some exaggeration, 68; "The Real is the Rational," $69-72 ;(2)$ in repudiating individualism in ethics, 72, 73. Self-consciousness the highest category, 74. Hegel's system as a hypothesis; reconciliation of "materialistic" science with "mystical" theology, 75, 76. 


\section{What is Reality?}

Ambiguity in the term: (I.) "Real" used for every actual psychical event (subjective reality), but generally with suggestion of an objective reference, 77-80. (II.) Objective reality tested by coherence in our own experience and by coherence of our own experience with that of others, 80 . Are feelings more real than thoughts? $8 \mathrm{I}-83$. Is the real what occupies space? 83,84 . (III.) Difference between reality for ordinary belief and for science, 84,85 . The inconceivability of the opposite as a test, 86,87 . Identity of thought and being ; in what sense assumed by science, 87-89. Ordinary antithesis of thought and things, 89, $9 \mathrm{r}$. Matter, 9o. (IV.) The "real" circle = the perfect circle, 9I, 92. (V.) "Real," in the ethical sense, opposed to "sham," 92, 93. What is an atom ? 93, 94. The "other" of thought, 94, 95. Distinction of thought and things falls within thought, 95,96 .

Objection that the individual alone is the real, 96. What is the "individual?" ( $\mathrm{I}$ ) Everything that can be spoken of as one? 96, 97. (2) That which can be expressed by a singular term ? 97,98 . (3) Are qualities real as individual sensations? 98. (4) Is the conscious self the "real?" What is the "real person"? 98-Ior. (5) The transcendental ego or unity of the cosmos? 10I. Thought implies a subject, IOI, 102. The ultimate subject of the logical judgment, 102, 103. The self as subject and as object, 103, 104. Psychology and Philosophy, 104. What is implied in saying, e.g., that Matter is the potentiality of Thought, I05.

Note on Logical Necessity . . . io6-108

(I) The necessity of the causal nexus, 106 ; (2) The necessity of axioms, 106, 107 ; (3) Necessity in regard to human actions, 108 . 


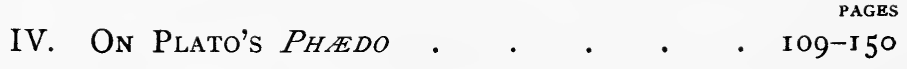

(I.). Plato's "myths," how to be understood, I09126. The doctrines of (I) Recollection, I IO-I I4 ; (2) Pre-existence, II4-II7 ; (3) Transmigration, II7-I 20. The "myths" to be understood as approximations to the truth, I20-123. Distinction between Platonism, as interpreted and developed by Aristotle, and as it may have existed for the mind of Plato himself, 123-126.

(II.). The arguments in the Phado: (I) (a) The alternation of opposites, 127-129; and (b) Recollection, 129. (2) The soul simple, not composite (Plato does not say it is a substance), I30-135. Objection that the soul is a Harmony, I35-I37. (3) The soul partakes in the Idea of life, 137, 138. Relation of the soul to the Ideas, 138-I42. The Arguments of the Phado compared with those of the Phadrus, 142 ; and with those of the Republic, 143-146.

(III.). In what sense did Plato hold the immortality of the soul? I46-I 50.

\section{What aRe Economic Laws?} - $\quad$ 5 I-I 77

(I.). Prof. Cunningham's objections to the use of the terms "cause" and "law" in econornics, I 5 I. Ricardo's analysis of Rent involves the conception of "cause," 1 52, 1 53. [Note on Causation, I53, 154.] (I) What is the nature of scientific laws? 155,156 . (2) What is the position of economics among the sciences? 156-159. (3) In what sense there can be laws in a historical science, I59, 160. All scientific laws, in different degrees, abstract and hypothetical, 160-163. False antithesis between deductive and inductive (or historical) methods, 163-165. 
(II.). Difference between physical and sociological laws: the element of conscious purpose in human phenomena, 165-167. Illustration from history of language, 167-169; from history of political institutions, 169, 170. The volitional element (moral factor) in economic evolution, 170-173. The "spiritual principle" in Nature, 173.

(III.). Economic laws, how related to moral laws, 174-177.

\section{Locke's Theory of Property . . . $178-195$}

Locke derives property from labour, 178, I79. Relation of the Law of Nature to the positive laws of particular societies, $180-185$. The theories of Hobbes and Locke viewed in the light of the events of their lifetime, 185, 186. Their theories not to be treated as historical but as logical, 187. Logical difficulties in Locke's theory of property, 188, 189. Property the product, not of individual, but of social labour, 190-192. Locke's theory no real improvement on the theories of Grotius and Puffendorf, the distribution of wealth depending on arrangements ("compacts") of particular societies, 193-195.

ViI. Contributions to the History of the Social

\section{Contract Theory} $196-226$

(I.). The theory held by some Greek Sophists and by Epicurus, not by Plato and Aristotle, 196-199.

(II.). In the middle ages the idea of a contract between king and people due to influence of Old Testament and of Roman Law, 200-203. This form of the theory the popular one in the sixteenth and seventeenth centuries, 203-205. 
(III.). Locke's theory not that of a contract between king and people, 205, 206; but essentially the same as Rousseau's, 206-208; an unconscious return to that of the Greek Sophists, 208, 209; this change in the form of the theory connected with Hooker, 210-212; the Scottish Covenant, 212, 213; the "Mayflower" compact, 213, 214; Grotius, 21 5 ; Milton, 21 5, 216 . Hobbes reverses the application of the theory, 216, 217. Spinoza's criticism of Hobbes, 217 . Was Hobbes inconsistent ? 218. Locke's difference from Hobbes and similarity to Rousseau, 219, 220. Rousseau's theory adopted by Kant, 220-222 ; and by Fichte, 222, 223.

(IV.) Criticism of the theory by Hume, 223, 224 ; by Bentham, 224. Decay of the theory through growth of the historical spirit, 224, 225; Burke quoted, 225. Relative truth of the theory recognised by Hegel and M. Fouillée, 226.

\section{On the Conception of Sovereignty • 227-264}

Austin's definitions of Sovereignty and Law, 227. These conceptions peculiar to English Jurisprudence, 228, 229. Historical objections, 229, 230. Attempts to obviate them, 230-233. Value of analytic method, 23I ; but danger of abstraction, 232, 233.

Austin's conception applied to the British Constitution, 234-242. Necessity of distinguishing between the nominal, legal, and political sovereigns, as Locke does, 238, 239. Hobbes's theory of sovereignty, 239, 240. The ultimate political sovereign not a determinate body of persons, 24I, 242. Austin's conception of legal sovereignty applied to the United States of America : difficulty in finding the "determinate persons," 242246. The nominal sovereign not always a determinate person or body of persons, 246, 247. Mr. Spencer's 
objections to the view that Sovereignty is unlimited, 247-249. Austin's conception of sovereignty as unlimited avoids confusions such as those of Bluntschli, 249, 250.

The ultimate political sovereign - "Opinion" or "Sovereignty of the people," 250-252. Distinction between sovereignty de facto and de jure, 252, 253. How the "General Will" may express itself, 253-255. Confusion about "tyranny of majority" and "rights of minority," 255, 256. Public opinion, 257. Might and Right, 258-260.

Limits of political sovereignty, 260-264. Sovereignty in its external aspects, 260-262. International law, 262, 263. The problem of the Philosophy of History, 263, 264.

IX. The Rights of Minorities $26_{5}-28_{5}$

In the past, majorities have had to struggle for freedom, 265, 266. As against modern democracy, rights are claimed for minorities, 266-268. Distinction between authority of the few in scientific and in practical matters, 269, 270. Difference in practical matters with respect to means and ends, 271, 272. Difficulties in schemes for representation of minorities, 273, 274. Public opinion, its power and organs, 275. The right of spreading opinions, 276, 277. Toleration, and use of discussion, 277-280. Prof. Bryce on "the tyranny of the majority" and "the fatalism of the multitude," $280-$ 282. Resistance to law never a right, sometimes a duty, 282-284. Individual responsibility in regard to opinions, 284,285 . 



\section{DARWIN AND HEGEL:}

WITH OTHER PHILOSOPHICAL STUDIES.

\section{I. \\ ORIGIN AND VALIDITY. ${ }^{1}$}

When Aristotle, after tracing the progress of human society from the patriarchal family to the city-state of the Hellenes, says that the city-state comes into being for the sake of life, but has its being for the sake of the good life, he gives an admirable illustration of a distinction, which he is always ready to recognise, between the origin of anything (its ma-

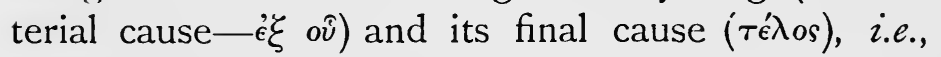
the end which it comes to serve: this latter must be known if we are to know the true nature of a thing

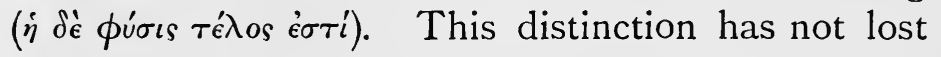
its significance, though it has been overlooked in many philosophical and other controversies. The question that sometimes arises in social circles which are careful of their dignity: "Who is so-and-so?" is frequently solved by consultation of the Peerage or, at a lower elevation, of some old lady: and the oracle answers by telling who his great-grandfather or great-grandmother was, the value of a man (or

1 Reprinted from Mind, Vol. XIII., No. 49 (I888).

D. $\mathrm{H}$. 
woman) for certain purposes of society being supposed to depend not on what he himself is, but on what some ancestor had the reputation of being. Pride of birth is, indeed, sometimes supported by the scientific doctrine of heredity, though it is apt to be forgotten that the kind of eminence which has qualified men in times past for elevation to the peerage has not always been such as to make the transmission of it desirable in the interests of the whole social organism as that now is. And, further, it is forgotten that, if a man's great-great-grandfather was a really great person, the man is probably only in respect of one-sixteenth part of himself the hereditary representative of that ancestor. And, yet again, it is forgotten that not merely inherited capacity, but a favourable environment in which it can be exercised, is requisite for the production of the best type of individual; and that such favourable environment is not always provided by an atmosphere of adulation and the absence of the stimulus to industry. The popular respect for pedigrees involves to a great extent the confusion of origin and worth. "He is nobody" means, being translated, he is without father or mother-of note: and when such a person really impresses the world, it is often found expedient to discover for him some dignified descent, in order to satisfy the popular prejudice. This prejudice has invaded more important spheres. The great men, not of Hellas only, came to be looked on as the sons of gods and demigods. People have found it difficult to believe that those, whom they 
felt to be immeasurably above them, could be born of ordinary parents and according to the ordinary laws of human generation.

There are many estimable persons who derive great comfort from abusing metaphysics; and it is a pity that they should not be able to indulge their inclinations in a harmless way. Therefore it would be desirable if we could mark off a certain meaning of "metaphysics" and "metaphysical" in which they shall denote what is bad, reserving the liberty to employ these terms also for something that is not only unobjectionable, but necessary. Let us say then that, from an Idealist point of view, we are ready to admit all the hard things that Comte has said of the old Ontologies, and to declare that we are as anxious as he to eliminate the influence of them from theory and practice; but that we consider such clearing of the ground will be even more effectually carried out, if we do not shirk an investigation of the conditions under which knowledge and nature and conduct are possible. Nay, we are prepared to argue that just those persons who disclaim metaphysics are sometimes the most apt to be infected with the disease they profess to abhor-and not to know when they have it.

One of the chief characteristics of the "metaphysical " stage of thought is its anxiety to vindicate the value of moral and other ideas by tracing them back to an origin which can be regarded as in itself great and dignified, whether the greatness and 
dignity be such as come from the clearness of reason or such as is supposed to come from the darkness of mystery. Thus, the true religion has been represented as a primitive revelation from which man afterwards fell away. "Degraded savages" have been supposed to be all degraded in the literal sense -degenerate from an originally better condition. There has been a preference for regarding man " as a fallen archangel, not as an elevated ape." The natural rights of man, i.e., those rights which it is felt man ought to have guaranteed to him in a wellordered society, have been thought of, or at least spoken of, as if they had been originally possessed by him and stolen away by the wickedness of tyrants and oppressors. The poet uses the language of such "Vorstellungen" to express ideas: and so we find Heine saying that the Holy Spirit "renews ancient rights" (erneut das alte Recht). Reform has been again and again brought in under the guise of restoration, sometimes indeed (as in the struggles of the English Parliament in the seventeenth century) with some degree of historical truth. So also with regard to the individual mind. Ideas, whether in logic or in morals, which are of peculiar importance, have been called "innate." They have been "implanted by God (or Nature) in our breasts." We have only to look deep enough to find them beneath the super-imposed crust of prejudice, experience and conventional belief. The voice of God and Nature may be heard if we go back to primitive simplicity : and thus we have the "noble savage" of eighteenth 
century imagination and the pseudo-Platonism of Wordsworth's "Ode on Intimations of Immortality from Recollections of Early Childhood." But very little can be found by the searcher after primitive, uncorrupted intuitions, either in the infant or in the savage, except what he manages to read into their undeveloped minds out of his own theories. Yet the temptation is strong to regard the inexplicable (or at least the unexplained), the unanalysable (or at least the unanalysed), with peculiar veneration, and to feel jealousy and suspicion of any attempt to examine the elements and origin of anything that is valued or admired.

"I ask not proud philosophy to teach me what thou art,"

says Campbell, as if the colours of the rainbow became less beautiful when we knew scientifically how they arose, than they seemed when supposed to be provided by a mechanical miracle at the disembarcation of Noah. To the poet, certainly, the physical cause of the rainbow is less attractive than its use as the symbol of a message of peace and promise. But such feelings are out of place when they intrude themselves, as they sometimes do, into the estimate of the truth of a scientific theory. The prejudice against the Darwinian theory implies that, if the higher organism be the product of the lower, the higher loses in worth and dignity, as if " man came from a beast" implied "therefore man is only a beast." The prejudice against anthropological investigation of the origin of religious ideas and 
customs and of institutions such as marriage has a similar source-a prejudice to be found even amongst those who have themselves done notable service in the application of comparative and historical methods to the study of human society and ideas. It is supposed that religion would lose all meaning if even its highest forms had an ancestry so low as fetishworship, and that marriage would lose its ethical value if "primitive marriage" turned out to be a euphemism for promiscuous sexual relations. ${ }^{1}$

Perhaps, however, there is an element of truth in the suspicion with which scientific analysis is regarded by most poets and by some philosophers. It is a true instinct which warns us, that we have not sufficiently disposed of a subject when we have given an historical account of how it came to be what it is: but this takes a false form, when it becomes a denial of the historical account. As against the "metaphysical" theories of Nature, Innate Ideas, Inexplicable Intuitions (which may happen to be only local or personal prejudices), the scientific methods of analysis and theories of evolution may be completely accepted, and it may yet be maintained that the real importance of ideas in logic, in ethics or in religion is not affected, though it has been shown that they have a history in the minds of the race and of the individual. This history is

1 The theory of an original "promiscuity" is rendered extremely doubtful by the habits of many of the higher animals. But if such theories were completely proved, they would decide nothing as to the social and ethical questions of our day. 
important for our knowledge, and may alter many things in the way in which ideas have been accepted and institutions regarded; but, over and above this natural history, we have the task of philosophy-of "metaphysics" in the sense in which the world never can and never must dispense with it. This is, of course, a proposition which may be disputed. Either it may be denied that we need anything more than an explanation of how things have come to be, in order rightly to understand what they are, or it may be denied that we can discover any answer to the questions which we inevitably find ourselves asking after the sciences have spoken their last word. To the latter position (that of the Positivist) the objection is the same as that which may be made to all theories of absolute phenomenalism : How can you know the limitations of the mind, unless you who are limited are also in some way outside your limitation? It may be said: "We find out our limitations only too surely by beating fruitlessly against the bars of our prison-house." But why do we do so? Why have mankind always done so, if it is not from the instinct that a larger life is their natural one, in the sense of being their due? "Yes," it may be said, "but we learn wisdom with time and shall give up trying to avoid the inevitable." But how, if in every step of advance made within the limits, there are already involved assumptions which imply that we in some way set our own limits? With the complete sceptic it is impossible to argue: he must be left to doubt his 
own scepticism, and so to contradict himself. Assume the validity of the processes of scientific knowledge. Assume, as the mathematician does, the absolute certainty of his processes and of his results, so far as they conform to his processes. Assume, as the student of nature does, the relative certainty of his methods and results. How can we make these assumptions about the necessities of thought, about space, about the orderliness of the physical universe? J. S. Mill boldly faced this objection to the satisfactoriness of psychological analysis : he denied the certainty of mathematics, and based the most trustworthy of inductive processes upon the least certain-the inductio per enumerationem simplicem. But this mode of defence really leads to a complete scepticism or to a complete surrender of the problem to be solved.

The lasting and permanent contribution of Kant to philosophy is his recognition of what the real problem of the theory of knowledge is, and what are the conditions of its solution. Assuredly there are different interpretations of Kant and different estimates of the relative importance of different parts of his system : but I consider that the point on which we must all always go "back to Kant" and on which we cannot go back behind him, if we are profitably to face the problems of philosophy now, is his conception of a "transcendental proof," and his view of the a priori element in all knowledge. The Kantian recognition of an a priori element in knowledge has almost nothing in common with psychological theo- 
ries of intuitionism, which are only revivals or survivals of the old "metaphysical" (in the bad sense) doctrines of innate ideas. The name a priori is unfortunate because it suggests a reference to time, which is irrelevant and misleading. Kant does not mean that the individual begins with certain mental forms and then goes on to fill them up with a content derived from experience. If that were the $a$ priori theory, as it is often supposed to be, it would be a theory very easy to refute, and a very absurd delusion to maintain. "The baby new to earth and sky" does not start with a knowledge of geometrical or other axioms. The psychologist has every right in saying that knowledge begins as sensation. That is true as a matter of mental history. $\mathrm{He}$ is only wrong when he goes on to say that knowledge is nothing but sensation and the products of sensation, unless in the term "products" (or any equivalent term) he has tacitly implied the recognition of thought as what makes the development of knowledge out of sensation possible. Kant's individualist mode of treating the problem of knowledge certainly seems to countenance a psychological ${ }^{\mathrm{I}}$ interpretation. But so far as it does, that must be put aside as the perishable part of Kant's theory. I may be interpreting wrongly; but I take the essence of the transcendental proof to be what I am going to state, and I cannot see that such a proof admits of any refutation,

1 If the meaning of Psychology were so extended as to cover Kant's theory of knowledge, that would involve an inconvenient deviation from the general use of the word. 
except from the consistent sceptic, who, as said before, must be left to refute himself. It is not entirely a discovery of Kant's: Plato and Aristotle were at least on the verge of it; and the various systems of Metaphysical Idealism may all be considered as, amid many errors, feeling after it.

If knowledge be altogether dependent on sensation, knowledge is impossible. But knowledge is possible, because the sciences exist. Therefore knowledge is not altogether dependent on sensation. It is no refutation of this argument to say: "Here is a history of the genesis of knowledge from sensation"; because the argument is not a statement of a fact in psychology (psychogenesis), but is entirely logical. The denial of it involves all our experience in contradiction. That is the ultimate argument, and, as we have said, it can be denied only by the complete sceptic.

What this non-sensational element is, must be discovered by taking the different stages and kinds of knowledge separately. And there is no reason why Kant should be right at every step here. The details of the Kantian philosophy may come to have little more than an antiquarian interest. The simplest act of knowledge is the judgment. Judging involves comparison. Comparison requires that the different sensations should be held together in unity. (This follows logically without any reference to psychology, though psychological experience may well come in as a test.) If I say "It (i.e., anything what is presented to my senses) is warm," I am 
asserting an identity along with difference, as existing for me. One sensation could make no knowledge, nor one series of uniform sensations; nor a series of different sensations, unless they could be brought together for comparison, and this bringing together cannot be actual, but must be ideal, i.e., a Self is implied in the simplest act of knowledge. If it is said, "It is true that as we know now, a conscious self is implied in our knowledge, but that conscious self is the result of a long process"that may be accepted (or not) as a true statement of the history of mental development; but that does not do away with the logical force of the argument. It is not asserted that at an elementary stage human beings have any conception of selfconsciousness or any word for it, nor that they have reflected on it, but only that the self-consciousness must be there potentially, implicitly. "But what about the lower animals? If we cannot draw a hard and fast line between lower and higher, is not the recognition that man may be developed from lower animal forms fatal to the recognition of a non-sensational element in human knowledge?" To this it may be answered: (I) All inferences about the "knowledge" possessed by the lower animals are rendered extremely uncertain, because we have no means whatever of communicating with them by language, and consequently interpret their actions on the analogy of externally similar actions done by ourselves. All tales about the cleverness of dogs, etc., are full of unscientific anthropomor- 
phism. It is well known how difficult it is fairly to interpret the ideas of lower human races, because of the imperfections of their language. When language is wanting, the difficulty becomes insuperable. (2) There seems no objection to admitting that, so far as lower animals possess anything that can be called knowledge, i.e., so far as they can be imagined actually to make judgments, as in applying human analogies to them we always suppose them to do, so far they must have a consciousness of a self, though at a lower and less explicit stage. If we say their life is one of mere sensation, and yet ascribe to them a power of making judgments, their "sensation" must be a sort of "obscure thinking."

Thus, when all has been said that can be said by physiology and psychology about the way in which thought arises out of sense, this, however true as a statement of historical facts, does not solve the problem of what knowledge is, unless it be regarded as a process in which consciousness (thought) is coming to itself. What we find at the higher stage is no new element suddenly inserted alongside of other elements, nor is it a mere chemical product of elements different from it (chemical analogies lie at the base of many current psychological theories), but it is what we are logically bound to regard as present throughout, though only fully realised and known at the higher stages. If it be said that this is only importing a mystical metaphysics into what was already clear, then we must answer that with- 
out this mystical metaphysics the theory was not clear, because it could only be expressed by the use of a number of terms which had not been explained. It is sometimes thought that, by saying "The lower is potentially the higher," or "contains the potency and promise of the higher," all has been said that need be said. But what is meant by saying " $\mathrm{A}(e . g$., the acorn) is potentially $\mathrm{B}(e . g .$, the oak")? If it merely means "Here you have A, afterwards you will have B," it would be better simply to say so; for then it would be made obvious that no explanation of $\mathrm{B}$ has been given, and that neither A nor $B$ is understood. " $A$ is potentially $\mathrm{B}$," if it means anything, must mean that in some way $A$ already is $B$, and that $B$ is needed to explain A. The late G. H. Lewes was not prejudiced in favour of old philosophies, but he most fully recognised the fact that we can only understand the lower from the point of view of the higher: "We can only understand the Amoeba and the Polype by a light reflected from the study of Man." 1 So that even within the sciences it is not really possible to "begin at the beginning." The attempt to do so will generally mean that some dimly accepted view about the "end" is influencing the observations of the beginning; for, as Lewes reminds us, "our closest observation is interpretation." Even for the study of origins an examination of the end or most complete state as it exists is not superfluous, and

1 Study of Psychology, p. 122. 
such an examination, apart from historical methods, must be analytic, or, in Kant's phrase, critical. Before we proceed to ask what history tells us, it may be worth while to ask what history can tell us. By knowing what something was, we do not always know what it is, sometimes only what it (now) is not.

To discover the a priori element in knowledge, i.e., that element which, though known to us only in connection with sense-experience, cannot be dependent upon sense-experience for its validity, is the business of a philosophical theory of knowledge. And if we call that a part of Metaphysics, it is a Metaphysics with which we cannot dispense. Suppose that "Self-consciousness," “Identity," "Substance," "Cause," “Time," “Space," be amongst the "Categories" so discovered, to arrange these categories in a system, to see their relations to one another and to the world of nature and of human action, will be the business of Philosophy or Metaphysics in a wider sense. "Speculative Metaphysics," as distinct from Critical, we might call it, because the method it must adopt can never have the logical precision and certainty of the Critical Method. The only test of the validity of a system of Speculative Metaphysics must be its adequacy to the explanation and arrangement of the whole Universe as it becomes known to us. Thus this Metaphysics can never be complete, but must always be attempted anew by each thinker. The Critical examination of the nature of knowledge 
may logically precede any or all of the special sciences, although it is only the advance of science that has suggested the need of such an examination; but the Metaphysician in this second sense can never be independent of any of the sciences or of any branch of human knowledge or effort. They are his material. ${ }^{1}$

To make knowledge possible there must (in Green's phrase) be "a comparing and distinguishing self"; but since Time, though relatively a form is yet also one of the contents of knowledge, this self must in some way be independent of Time. I know I am a series of experiences in Time. Therefore, in some way, I am not in Time-but an eternal (i.e., time-less) self-consciousness. But the Critical Philosophy can tell us nothing further, can tell us nothing as to what this eternal self-consciousness is or how it is related to our individual selves, which are the subject matter of Psychology. The attempt to find some expression for this relation, i.e., to show how an eternal self-consciousness reveals itself in Time and in Space is the business of Speculative Philosophy or Metaphysics. That there is an eternal self-consciousness we are logically compelled to believe, and that it is in some way present in our individual selves; but in what way is a matter of speculation: and it is still quite com-

1 It will be seen, from this, that while ready to recognise a distinction between Epistemology and Metaphysics, I recognise no Metaphysics as sound which is not based upon Epistemology. Ontology, as an independent science, is a sham science. 
petent to any one who accepts the main result of the critical examination of knowledge to maintain that this latter problem is altogether insoluble; although it is a problem (or rather series of problems) which we cannot leave alone, because we are met by it at every step in our ordinary experience, if we once begin to reflect on the meaning and mutual relations of the conceptions we are obliged to use.

It is not my present concern to give an exhaustive list of the a priori conceptions and principles which are involved in ordinary knowledge and in the procedure of scientific investigation and proof. An Intuitionist Philosophy, which professes to get at these principles by a simple introspection into the contents of consciousness, may fairly be met with the challenge to produce its list of intuitive principles. But if the term a priori be understood in the way which has been explained above, no such challenge can be justly made. It is only as experience progresses that we can become fully aware of and can formulate the conceptions and principles which that experience logically involves. Only if knowledge were completed could we know all that knowledge implied: and it is only as knowledge approximates to that apparently ever-receding goal that we can enlarge our view of what has been there implicitly from the first. Thus, in the very simplest acts of thought the principle of Identity and the principle of Contradiction ( $\mathrm{A}$ is $\mathrm{A}$; $\mathrm{A}$ is not not-A) are involved; and yet it was late in the 
history of mankind when the science of Logic was first enabled to discover and formulate these principles. Nevertheless they are $a$ priori in the sense that without them all knowledge would be impossible. So it is with the axioms of the science of quantity. That "Things which are equal to the same thing are equal to one another" is implied in all the experience which Mill thought went to prove the principle. Every carpenter who uses a foot-rule, every barmaid who draws off half-a-pint, implies the principle and acts on it, though totally ignorant of the elements of Geometry. Similarly, the rudest ideas about Nature imply the conception of $a$ Cosmos, of an order of nature, though that order may include gods, demons, fairies, and goblins, of whom the modern scientific man takes no account, and may exclude gravitation, electricity, and other forces which he has come to recognise. The principle that every event has a cause, i.e., is related to some other event (or events) without which it would not happen and with which it must happen,- the two clauses of this definition of cause are sometimes mistakenly separated as the principles of Causation and Uniformity of Nature respectively,-is involved in the mental action of the savage who hears the thunder and looks round for an explanation, though he may be quite wrong in his explanation, and though it may be late in time before any human being comes to reflect on the processes of experience and to formulate its principles. But the history of how men came to recognise Uniformity of Nature and D. $H$. 
how their conceptions of Cause and of Nature have varied is one thing: the logical character of the presupposition of all inductive inference is another. The former is a question of historical psychology; the latter is a question of philosophical criticism. The proposition, "Every event must have a cause" is not a priori because it convinces every person the moment he understands it, but because no knowledge of natural events is possible without a connection of them with other events as belonging to one system of nature. That nature is a system is the assumption underlying the earliest mythologies : to fill up this conception is the aim of the latest science. A capacity for discovering true causes may be capable of development as the race advances; so may be a capacity for philosophical analysis; but the presupposition of all investigation of causes cannot itself be derived from the experience either of the individual or of the race. ${ }^{1}$

The question for the logician is not: "How have I (or mankind generally) come to believe this?" That is a question for the psychologist and the sociologist. The logical question is : "Why am I or any one else justified in believing this ?" A confusion between these two questions underlies Mill's famous attack on the Syllogism. The essential and permanently significant portion of the Aristotelian doctrine of the Syllogism is the recognition that all inference (and $\sigma v \lambda \lambda o \gamma\llcorner\sigma \mu o$ s just means "inference") implies a

${ }^{1}$ See Note on "Heredity as a Factor in Knowledge" at the end of this Essay. 
Universal. As a psychological fact there may (though even this may be questioned) be in our minds a particular proposition and then immediately afterwards another particular proposition suggested by it. But, if the one can be described as an inference from the other, we must be able to answer the question, how we get the one from the other. And the answer to the question must, if we formulate it, take the form of a universal proposition, of which, till we have to face the question, we may be perfectly unconscious, and it will constitute the major premiss of the Aristotelian Syllogism (Barbara or Darii being taken as typical), the middle term being, in the scientific inference, the cause or ground (sufficient reason) of the conclusion. Thus the death of some one I know may suggest to me my own mortality; but the reason of the inference is our common possession of the attributes of human and so of animal life. It is always with a question of validity that the logician as such has to deal: "Are we justified in inferring that?"-not with the psychological process through which any particular person or persons have gone in arriving at their beliefs. Psychological introspection can, therefore, never solve logical difficulties. The formula of the Syllogism (major premiss, minor premiss, conclusion) is not an exposition of what actually takes place in any one's mind, but a logical exposition of that to which any actual inference must conform in order to be correct. It would not even be accurate to say it is the form 
according to which the normal reasoner actually reasons; because a man may reason quite correctly and be the normal reasoner, while quite unconscious of logical analysis. The reasonings of the normal reasoner are those which will conform best to the strict syllogistic form when they are so analysed by the logician. The incorrectness of an apparent inference becomes clear, when the reasoner is compelled to formulate the universal according to which he is reasoning though without being aware of it. If he were fully aware of it, he could not commit fallacies. If we were fully aware of everything that every proposition implies, we could not assert false propositions.

Take another logical illustration, a minor matter. Mill says that proper names have no connotation. It may be true enough that the name "John Smith" suggests nothing to me or to you; but, if I am a philological ethnologist, it may suggest a good deal ; if I have a friend of that name, it may suggest a good deal more. These are matters of psychological interest, and no definite answer independent of time, place, circumstances and persons can be given. But the name of an individual, not as a mere word, but as the name of an individual, as appropriated (and that is what "proper name" ought to mean) must logically have an infinite connotation. That we can say quite definitely, and that is the reason why the proper name cannot be defined. Any given person may be unable to say anything about any given proper name; whether he can or not is a matter of 
fact. But logic has to do with the ideal possibilities of definition. And we can answer quite certainly: We never can exhaust the signification of the individual.

The controversy whether mathematical judgments are analytic or synthetic is of a similar kind. As a psychological question it is a matter of degree, and, in the case of arithmetic, will depend solely on the extent to which a person has learned the multiplication table, etc. This is one of the merely psychological distinctions that intrude themselves into Kant's theory of knowledge. Whether any proposition conveys any new information to a person is always a question which cannot be answered irrespective of time, place, etc. In one sense nothing we ever can learn is new, else we could not learn it : it would be quite irrelevant to our already existing knowledge. (This is the truth in the old Sophistic paradox.) In this way all reasoning is reasoning in a circle; but it is a circle so large-as large as the Universe-that we need be under no immediate fear of completing it. To omniscience all propositions must be analytic (identical). That is the ideal of knowledge, and it is the standard by which all statements and all professed inferences are ultimately judged. This amounts to saying, in other words, that the inconceivability of the opposite is the ultimate test of all truth. But it is a test that we cannot safely apply in practice, except where we can be perfectly sure that we have eliminated all risks of ambiguity and have fully realised all the conditions 
under which we are making an assertion. Thus we can only apply it safely in very abstract sciences, such as geometry. We know exactly what we mean and what others will understand by a "straight line" and by "enclosing a space": and therefore we can quite certainly say, "Two straight lines cancannot enclose a space"; because to suppose that they do involves us in contradiction, and would make us assert that the straight line was also not a straight line. But if any one at the beginning of this century had said, "It is inconceivable that a message should be sent from London to New York in a few seconds," his statement would only have been correct if he had inserted the qualification : "the modes of transmitting messages being such as I know of "; for then it would be true that we could not really think of the carrier pigeon, being what we know it to be, traversing space with such velocity.

Logic, then, is concerned not with what actually goes on in the mind of any individual or of the average individual. That is the business of psychology. Logic is concerned with the rules or ideal standards to which the mental processes of every one must conform if they are to attain truth. Parallel with logic there are at least two other "regulative" philosophical sciences (branches of philosophy) concerned respectively with those rules or ideals which must be fulfilled for the attainment of beauty in art, and with those which must be fulfilled for the realisation of goodness in conduct. The presupposition of knowledge was found to be the presence 
of a Self which is eternal and which yet is never completely realised in any one of us, and which thus remains as an Ideal (Sollen) perpetually urging to its realisation. If we approach the study of mankind from the side of Nature, we find everywhere a "groaning and travailing," not, as has been too readily supposed, a universal pursuit of pleasure, but a universal struggle and a seemingly hopeless struggle to escape pain, whether the pain of physical, emotional or intellectual suffering. A dispassionate view of the process of evolution alone seems to leave no escape from a philosophy of despair; for, as the struggle for existence eliminates some physical evils, it intensifies the acuteness of emotional and intellectual desires, and increases the ever-recurring pain that comes from the perpetual incapacity of satisfying wants and cravings which grow with every satisfaction. But, if the necessity of endeavouring to explain how knowledge is possible compels us to recognise an eternal Self ever demanding realisation, may we not, looking back now from the standpoint of the Ideal, regard all the blind struggle of Nature as the lower and unconscious phases of this process of the realisation of the eternal Self ? This identification would be a hypothesis of Speculative Philosophy, and could not have the certainty of the mere recognition of an eternal Self : but it is the theory which seems best to explain all the phenomena, and it does not conflict with any scientific fact, although undoubtedly incapable of scientific verification. From the side of origins the struggle seems vain, 
and yet we can only pronounce it vain, because we have in us an ideal standard by which we judge. We can only know that the crooked is crooked if we have an ideal of the straight; we can only know that the world is evil if we have in us an ideal of absolute good. We know our ignorance, because we have an ideal of perfect knowledge; we know the ugliness and discord of the world, because we have an ideal of perfect beauty and harmony; we know its wickedness, because we have an ideal of a perfected society; we are conscious of $\sin$, because we know that our true self is God, from whom we are severed. How these various ideals grow up in the minds of mankind, and how their content varies at different periods, are matters for the psychologist and the historian. But why there are such ideals at all can only be explained if we start from the side of philosophical analysis-looking at things as a whole.

In saying that we have ideals of knowledge, of beauty, of goodness, I most certainly do not mean to assert that they are the same for all human beings at all times and in all places : that would be a very difficult proposition to maintain, in the light of anthropology and history. The only thing that is common to every reflecting and yet incomplete consciousness is the presence of $a n$ ideal, confronting the actual. The content of the ideal varies with time, place, and person. The form of "ought to be," as distinct from "is," is alone a priori; and it requires something more to explain it than a " natural history" of ideals. The contradiction of 
the actual by thought, which is involved in the very existence of ideals, raises the whole question of the relation of thought to nature-the one question which, in all its various aspects, a speculative philosophy attempts to solve.

Asthetics might, on grounds of etymology, be considered most properly to be concerned with the question, how we (whoever the "we " may be) have come to judge this or that to be beautiful-which is a question of psychology. But we want some name for the philosophical science which attempts to solve the question, why this or that is beautiful; or rather, to put the question in a form that seems better to avoid the assumptions of the old ontological metaphysics which we have discarded, why this or that ought to be considered beautiful. For it will not do to say: "That is beautiful which is generally considered beautiful," since, least of all in matters of artistic taste, is the person of taste ready to accept the opinion of any chance persons. If we say, "That ought to be considered beautiful which is considered beautiful by the person of taste," we have only transferred the ideal to the person, because then we mean that he is the person whose judgment ought to be accepted. He says "I now consider this beautiful, and, if I am right, people will gradually come to acknowledge it," i.e., he gives out his judgment as his own, and yet not as a judgment of a mere subjective liking, but as one that has a claim to have an objective validity - to be valid for all, if they could only come to see as he sees. I am assuming the 
person of taste to be a healthy-minded critic who expects and wishes his judgments to be accepted and does not pride himself on having a peculiar taste, which no one except himself and his own small set will ever share; others may not share it as yet, but unless he expects others to share it, his judgment only claims a subjective validity, i.e., it means only "This pleases me," not "This is beautiful." Neither in explaining the work of the artist nor in explaining the judgment of the lover of art can we leave out the conception of an ideal-an ought to be. All the attempts to reduce this to a statement of "what is" bring in the conception in some concealed form.

Similarly in Ethics. If the moral law be expressed as "that which the good man does" (as by Mr. Leslie Stephen), then in "good man" we have brought in the conception of ought which has been eliminated from "law." How we (the race or the individual) have come to think this or that right is a matter for sociology and psychology-it would be the history of moral ideas and the psychology of the moral sentiments; but these do not explain why there should be any thinking right or wrong at all. The old Intuitional Ethics assumes certain absolute principles of right and wrong, and thus comes into direct conflict with scientific investigations into the origin of moral ideas. The theory of Idealism for which I am contending only maintains that all accounts of the evolution of morality are inadequate to supply a complete theory of Ethics, unless the 
presence of an ideal to all human effort be recognised as involved in the presence of the eternal Self which any account of knowledge or conduct presupposes. What the ideal at any time may be, i.e., the content of the ideal, is a matter for historical investigation. And it is on the evolution of this content that the theory of natural selection has thrown so much light. ${ }^{1}$ The ideal must vary, else progress would be impossible. But there must be an ideal, a judgment of "ought," else morality would be impossible.

The same thing becomes clear when we pass to Politics. Intuitions as to natural rights only prove delusive. We cannot settle in that way what the State ought to do and what not. As already said, "natural rights" is a misleading phrase if supposed to refer to some original rights of man; practically it can only mean "What man ought to have." So, too, it is unhistorical and, what is worse, illogical to say that society originated in a contract ; for contract presupposes society. But there may be a very good sense in saying that society ought to be "contractual" (M. Fouillée's phrase ${ }^{2}$ ), i.e., that members of a good state ought to feel that the laws which they obey are not the commands of an alien force but are self-imposed, so that obedience to them becomes the highest realisation of freedom. Theories which treat the state as analogous to a

${ }^{1}$ In the following essay I attempt to deal briefly with the relation between idealism and evolutionist ethics. See p. $62 \mathrm{ff}$.

${ }^{2}$ See below, p. 226. 
natural organism err in an opposite way from those which regard it as resulting from a contract. Theories of contract state a question of value as if it were a question of origin. Theories which apply the conceptions of organism and evolution to society as if they were as adequate in politics as in biology, while they may give a correct account of the origins of society, leave us without a criterion by which to judge of the goodness or badness of any social condition. The only logically available criterion would be the ultimate success of any given society in the struggle for existence. In practical politics we cannot wait for that; we are safer with the Utilitarian method. But why? Just because it brings in a standard of worth, though too narrowly conceived. It estimates goodness by the end to which a society tends, i.e., by reference to an ideal.

We have heard much lately of the historical method in politics-so much that it is time to hear something on the other side. The historical method has done great services to the study of human society in ridding us of the "metaphysical" fictions of a Law of Nature, State of Nature, Original Contract, Natural Rights, etc. ; but those who are strongly possessed by the historical spirit are sometimes disposed to think that, when they have shown how an institution came into being, they have said all that is worth saying on the matter. It is a mistake to suppose that, because an institution now serves certain purposes, it was created for these purposes; but, when we know how an institution 
came into being, we have still, as practical persons, to ask ourselves: "What purposes does it now serve?"-else we do not estimate it rightly. Because the House of Lords was not invented as a check on legislation, it does not follow that the House of Lords is not a check on legislation-for good or for evil. Because the English State never at any moment in history selected a certain religious body and gave it certain endowments and privileges, it does not follow that the phrases "State Church," "Established Church" are altogether meaningless as representing the present relation of the Church to the State. And it is this present relation, and not historical facts about the Church in the time of the Heptarchy or the proceedings of Convocation in the time of Henry VIII., which the practical politician has to take into account. $\mathrm{He}$ is concerned with value, not with origins. Again, when it is asked by what right an individual owns half a county, history may lead us back to the dissolution of the monasteries, the Norman conquest, the Saxon invasion, and so on, till we come to the first blue-painted barbarian who stuck a rude spade into the ground, half cleared from brushwood. But all this, however interesting, is irrelevant to the question, how far the present system of land tenure can be justified or not. Existing rights may be explained by reference to the past, but can only be justified if it is shown that they subserve social well-being now and are likely to do so in the future. Similarly with the whole question of endowments. "What was" must not blind 
us to "what ought to be," though of course the inconvenience of disturbing customs and expectations, where that is unnecessary, has always to be taken into account. The practical reformer will move, as far as possible, in the line of least resistance. But it is a pity when a scientific theory or the spirit of antiquarianism interferes with the removal of abuses. Philosophy performs a useful function in criticising the conceptions which are being used : in default of a sound metaphysics, strong practical instincts and a sense of humour are the best safeguards.

Lastly, I must refer to the application of this distinction between questions of origin and of validity in the domain of Religion. The theory of knowledge obliges us to assume the existence of an eternal Self-consciousness partially revealed in ourselves. This, which is the ideal of knowledge, of beauty, of goodness, is the God of religion. It is not asserted that there is an intuitive knowledge of the existence of one God. Such an assertion is difficult to maintain in the face of what we know of the history of religions. The idea of God, as held by the religious thinkers of the highest types of religion, is of slow and late growth. The identification of a power (or powers) outside us with our highest ideals of knowledge, of beauty, and of goodness is not dreamt of by the primitive savage, just because he has not our ideals. Nor can the idea be completed till these ideals are completed, i.e., the growth of the idea of God, which we may call the revelation of God, is continuous and is com- 
mensurate with human progress. The criticism of science must be allowed full weight as against the belief that religious truth was conveyed by some inexplicable means to certain individuals at a definite time, and then handed down like some treasure of silver or gold. The prejudice against Biblical Criticism and against the scientific study of religions implies that the value of a religious idea is altogether derived from the channel through which it was first conveyed to mankind-a prophet, a sacred book, an infallible church. But the value of a religious idea cannot be dependent upon an external authority of any kind, but solely on its own adequacy to express, in a manner fitted to appeal at once to the intellect and the emotions, the highest possible beliefs of the time. This is implicitly recognised by Christian apologists, when they appeal to the excellence of Christian morality; but what is the value of such an appeal if the morality is itself dependent for its validity upon the authority of miraculous persons or writings? So far as Christianity is a system of spiritual doctrines and beliefs about the relation between the soul of the individual and that Divine Spirit which is ever operating in the universe, it finds a philosophical counterpart and an intellectual interpretation in Idealism; but, so fàr as it is represented as necessarily inciuding certain statements about alleged matters of fact, Idealism can lend no support to the apologist in his controversy with historical critics. 


\section{NOTE ON HEREDITY AS A FACTOR IN KNOWLEDGE. 1}

WE cannot face the question of the degree to which knowledge consists in, or depends upon, inherited elements, till we know what heredity means and what things can, and what cannot be inherited : and therefore the question must be carried back from psychology into biology. This is unfortunate for the psychologist who is hasting to lay the foundations of all philosophy; but, in this matter, he must wait till the biological controversy between Lamarckian and Weismannite is settled. As to the biological question, I think it is important to distinguish between the negative and the positive part of Weismann's theory. If Weismann's theory of the continuity of the germ-plasm be accepted, the hereditary transmission of "acquired characters" is impossible; but apart altogether from this special theory, and without accepting any theory to explain the fact of heredity, it is possible to hold that the hereditary transmission of acquired characters is " not proven." And I shall not attempt to maintain anything more than this negative position. The onus probandi lies with those who maintain the doctrine of "Use-inheritance" (to adopt the convenient abbreviated formula suggested by Mr. W. Platt Ball). Entia non sunt multiplicanda prater necessitatem.

I. In the first place, the consensus humani generis, though it may be an important consideration in matters of conduct, is no argument whatever in regard to a scientific belief. The very fact that the traditional pre-scientific bias is in favour of the Lamarckian theory seems to me a reason why we should be especially strict in our examination of any "facts" alleged in support of it. "The fathers have eaten

1 Originally written as part of a "Symposium" for the Aristotelian Society (London). Printed with some omissions. In the revision of this Note I am indebted to Mr. E. B. Poulton, F.R.S., for some valuable suggestions. 
sour grapes, and the children's teeth are set on edge." Such sayings and the many legends about inherited curses, etc., predispose people to accept the Lamarckian view without sufficient grounds: and the popular versions or travesties of what is supposed to be Darwinism are generally Lamarckian in character.

II. So far as I am able to judge, no undoubted fact has yet been brought forward which can only be explained on the Lamarckian theory. Natural selection, the cessation of natural selection (Weismann's panmixia), the effects of imitation, training, and other influences of the environment within the individual lifetime-seem to be adequate causes to account for facts, which might of course also be explained by the transmitted effects of use and disuse, were such transmission otherwise certainly proved to take place. Thus, if a cat is taught to beg and her kittens spontaneously beg, it is still possible that the kittens may have inherited the combined tendency of their parents to beg, apart from special instruction. Against such cases (supposing them all reported with perfect accuracy) we must put the experience of horse-breeders, that the foals of trained jumpers are not more easily trained to be good hunters than the foals of horses that have never been trained to jump but whose general build is what is desired for a good hunter. My authority for this statement is an article on "Hunter's Dams" in the Saturday Revieze a year or two ago, the writer of which evidently believed that he had started a puzzle for the "Darwinians!" $\mathrm{He}$ was clearly not a scientific student but a hunting man. If acquired characters (bodily or mental) were transmissible, breeders would surely have made use of the fact, whereas (whatever theories any of them may have held) they have depended entirely in practice on the judicious pairing of sires and dams-as on Weismann's theory they must do.

That young birds in some species are at once able to feed themselves on coming out of the shell, is quite ex-

D. $\mathrm{H}$. 
plicable by the working of natural selection alone. Mr. Platt Ball (to whom I have already referred) has made a searching examination of all the cases brought forward by Spencer and Darwin in support of Use-inheritance, and decides that it is " not proven." (The Effects of Use and Disuse in "Nature Series": London, I 890.)

The biological controversy must be fought out in the realm of subhuman organisms. Because $(a)$ with regard to human beings, it is so much more difficult to distinguish what is due to biological inheritance and what to sociological inheritance. A child is not only the child of its parents, but as a rule is brought up with its parents or among those of the same family. (b) The prolongation of infancy and the possibility of transmitting experience independently of race-inheritance would, on the principles of natural selection and panmixia, tend to make heredity relatively less important than in the lower animals, where heredity is the only means of transmitting any favourable variations. (c) It is more possible to study the question in regard to the lower animals without bias.

III. Lastly, the argument sometimes used from prevalent psychological theories to a biological theory seems to me entirely illegitimate. If it be true, as Mr. Spencer thinks, that the past experience of the race has produced innate ideas and feelings, Weismann's denial of Useinheritance would be refuted. Certainly: but it is just possible that Mr. Spencer's theory is not true.

It needs perhaps to be pointed out that there will often, for practical purposes, be sufficient agreement between Lamarckian and "Weismannite." Neither would recommend marriage with the descendant of a long line of lunatics, or drunkards, or criminals, though the Weismannite would insist on discriminating more exactly than the Lamarckian between the inherited taint and the effects of bad education.

Mr. Sully (Outlines of Psychology, 4 edit., p. 6I) says : 
"When we talk of inherited mental tendencies, we mean that the transmitted tendency is a result of ancestral experience." This of course is the Spencerian view. And on p. 482 he argues that the infant's pleasure at the sight of familiar faces and fear at the sight of strange faces are probably due to the experience of its ancestors. But it is much more likely that the child inherits these tendencies from animals whose young were less completely helpless and less cared for by others than the human infant, and whose instinctive fears and confidences have thus been directed into advantageous channels by the working of natural selection.

Now, to limit myself to the special problem of the influence of heredity in knowledge-(I) first of all, we must endeavour to mark off what is due to the experience which takes place in the life-time of the individual, a factor that counts for a good deal even in the case of birds and other animals lower than man (cf. Wallace, Darwinism, p. 442). (2) We must note that in human beings the acquisition of knowledge by the individual is enormously facilitated by what G. H. Lewes calls "the social factor" (see his Study of Psychology, pp. 78-80). We are apt to ignore the "inheritance" of ideas that comes to us e.g. in the language we are taught to speak. Difference in language makes a vast difference in the mental habits of different peoples. Thus we find that a Frenchman thinks differently from a German. We are not entitled at once to say, this is because the one is a "Celt" and the other a "Teuton." Our Frenchman might happen to be mostly of Teutonic race, and our German might happen to be a mixture of Jew and Slav : and yet each "inherits" a type of thinking in the language he is taught to speak and, therefore, in the books and in the persons to whose influence that language exposes his mind. (3) Only the residual phenomena can be ascribed to heredity; and the inherited or "connate" 
element in knowledge can, I think, be adequately explained by "natural selection" without calling in the help of Useinheritance.

Lewes and Spencer consider it the special trimuph of their theory of heredity as a factor in knowledge, that they are able to reconcile the theories of the a priori and $a$ posteriori schools. This opinion seems to me a complete ignoratio elenchi. Kant's "critical" theory is not psychological but logical. The name a priori is of course most unfortunate: it suggests priority in time. What Kant urges is, that the possibility of science, or in fact of anything that we can call "knowledge," implies certain necessary elements. Hume had already shown that sense-experience can never give necessity. Therefore, argues Kant, this necessity comes from the very nature of thought. Let me take the usual illustration-Causality. J. S. Mill says (in effect) : "I seem to be unable to think of any event as altogether isolated, because I happen to have found that A was always followed by B, C by D, etc." Spencer says (in effect): "I am unable to think of any event as isolated, because my great-grandfathers found out that $\mathrm{A}$ was the cause of $\mathrm{B}$, C of D, etc." Now suppose Use-inheritance possible, if all my great-grandfathers and great-grandmothers had spent all their lives in scientific investigation, this might make me better able than the average person to find the real cause of particular events, but it could never explain, why I cannot think events as isolated. Even the lowest savage does not and cannot. That is the very reason for his grotesque mythologies. They are his attempts to satisfy the demands of his thinking, which requires him to believe that whatever happens is necessarily linked to other things. Now this incapacity of really thinking of anything without thinking of it as connected with other things, must already exist in germ among the higher animals below man, though of course we only recognise it distinctly in the highest human thought. It forms part of what thinking implies. 
And, if we are considering the appearance of thinking (reflection) as an event in time, there seems no reason why it may not be sufficiently accounted for by natural selection. The Kantian criticism deals not with our beliefs, ideas, etc., as events, but with their character and value. The distinction between a priori and a posteriori would be better expressed as the distinction between the necessary or universal element and the particular element which varies with time, place and person. Understood in this way, the Kantian theory of knowledge contains nothing which the theory of heredity can either explain or destroy. 
II.

\section{DARWIN AND HEGEL. ${ }^{1}$}

In every age philosophy has been affected by the sciences, ${ }^{2}$ i.e., the methods and conceptions which are used in the attempt to make some particular province or aspect of the Universe intelligible have exercised a fascination over those who are seeking to understand the universe as a whole. And this is only natural: for the philosopher, who is really the philosopher of his own age and not the survival from an earlier epoch, is the product of the same intellectual movement which has led to the adoption of new methods and new conceptions among those who are pursuing special branches of knowledge. The difference between the genuine philosopher and the average seeker for "completely unified knowledge" is that the former has a fuller and clearer consciousness of the methods and conceptions he is

1 Read before the Aristotelian Society (London), and published in their Proceedings, Vol. I., No. 4, Part II. (I89r).

2 I do not mean that the sciences alone have determined the character and object of philosophy, which are affected by everything that concerns man's spiritual life-religion, art, politics; but only that the method and leading conceptions of philosophy are specially affected by the sciences. 
using, and is less likely to apply them uncritically and in disregard of the subject-matter to which he is applying them.

Mathematics was the only science that had outgrown the merest infancy among the Greeks. And in the Pythagoreans we have an example of philosophers who were completely carried away by the fascination of the conceptions of number and figure. In defining justice as "a square number," the Pythagoreans were for the first time attempting to make ethics "scientific," i.e., to lift reflection on human conduct out of the region of proverbial moralising by applying to it the most scientific categories of which they knew. Plato has puzzled many generations of commentators by those mystic numbers which he introduces into his philosophy; in all likelihood he only half believed in them (if so much as that), and he seems to be playing an elaborate and rather cruel joke on literal-minded persons, hinting all the while at the inadequacy of the Pythagorean symbols. Aristotle introduced mathematical formulæ into ethics, but only with carefully expressed modifications. His conception of scientific method comes, indeed, too exclusively from mathematics; but he is in advance of many modern moralists in seeing that human conduct at least is too complex to be studied by mathematical methods.

It might be objected, that in mediæval philosophy the principle I have laid down did not hold, but that the reverse was the case, that philosophy was not affected by the sciences, but that the sciences were 
"corrupted by metaphysics." The study of nature, however, was by no means that on which the mediæval intellect exercised itself. There were in truth only two "sciences" in which the mediæval mind took a living interest, viz., moral theology and law - that is to say, the application of a supposed divine code to the particular cases of human conduct, and the application in the same way of a human code assumed to be of supreme excellence. Physics was only a tradition (of course I am speaking roughly of what is true "on the whole"). The words of Aristotle or of Galen were accepted on authority. In these sciences, however, where authority is a matter of necessity, the utmost ingenuity of mind could be exercised in bringing general principles to bear on particular cases. Thus the abstract, deductive, and argumentative method actually employed in the sciences of legal and moral casuistry reacted on the interpretation given to Aristotelian logic and on the general theory of method adopted. Aristotelian logic was itself based on the method of geometry. Add to this the mediæval habit of bowing to the authority of the written word in every department of thought and life, and we can easily see the source of the mediæval conception of system in philosophy.

In the seventeenth century the effect of geometrical method on Hobbes and on Spinoza is sufficiently conspicuous. ${ }^{1}$ The conceptions of mechanical

1 With regard to Hobbes, compare Aubrey's story, quoted by Professor G. Croom Robertson, Hobbes, p. $3^{\mathrm{I}}$ : " He was forty years old before he looked on geometry, which happened acciden- 
physics assert themselves throughout this, and still more in the following century, even where the philosopher, in the interests of literary form, is careful to eschew the appearance of science. John Stuart Mill's phrase, "mental chemistry" (Examination of Hamilton, p. 357, ed. 5), suggests a new set of categories which raise the "association" psychologists above the level of their predecessors who used the categories of mechanics. In the present age the most conspicuously advancing science is biology; and the categories of organism and evolution are freely transferred to philosophy with the great advantage of lifting it out of the more abstract conceptions of mathematics or mechanics, but too often with insufficient consciousness of what is being done, so that striking metaphors are mistaken for inclisputable facts or laws.

Now, there were "evolutionists" before Darwin, and even before Mr. Herbert Spencer, who seems to wish to take out a patent for the invention of the theory, and conspicuously calls the attention of a careless public to the fact that his essay on Progress: its Law and Cause, appeared in April, I 857, whereas the Origin of Species did not see the light till October, I 859 (see preface to 4 th edition of First

tally : being in a gentleman's library in - Euclid's Elements lay open, and it was the 47 th Prop., Lib. I. So he reads the proposition. 'By G-,' says he, 'this is impossible!' So he reads the demonstration, which referred him back to another, which he also read, et sic deinceps, that at last he was demonstratively convinced of that truth. This made him in love with geometry." 
Principles). Evolution is in every one's mouth now, and the writings of Mr. Spencer have done a great deal (along with the discoveries of Darwin) to make the conception familiar. But nothing grows up quite suddenly. During the latter half of last century many isolated thinkers had, in this or that department of science, come to apply the idea of development. Though in Kant as a philosopher the idea of evolution, and indeed the whole conception of historical growth, is conspicuously absent, ${ }^{1}$ yet the same Kant, as a man of science, was the author of the nebular hypothesis. Vico and Montesquieu had, still earlier, suggested a way of looking at human institutions, which was not fully understood till several generations had passed. Above all, in biology, Erasmus Darwin (Zoonomia, I794) foreshadowed the work of his grandson. Buffon, Geoffrey St. Hilaire, Lamarck, had all attacked the orthodox dogma of immutable species; and perhaps Lord Monboddo should not be forgotten, for his speculations on the origin of man became widely

1 Of course such a statement is only relatively true-i.e., if we compare Kant with Hegel and other philosophers of this century. Kant does maintain the idea of progress in human society, and explains it as due to the "unsocial sociability of men "-by which he clearly means "repulsion" and "attraction" (concepts borrowed from physics). He is quite aware that the "original contract " never took place as a matter of fact in history, but he prefers to think out problems of politics with the help of these unhistorical fictions. Here, as everywhere, the abstract line which Kant draws between what is a priori and what is a posterioribetween the form of thought and the matter of experience-prevents him from seeing a thought process in the time-process. 
familiar, since the very shallowest wits could raise a laugh about them. Goethe, who, as an old man of eighty-one, was more excited by the news of the dispute between Cuvier and St. Hilaire than by the news of the July Revolution, had forty years before ( I790) published his Metamorphoses of Plants. Thus Hegel grew up in an intellectual atmosphere in which the conception of evolution, and especially of biological evolution, was no inconsiderable element. For Goethe's general view of nature he had the greatest sympathy-so much so indeed that he was led to defend Goethe's theory of colour against the Newtonian theory, a defence which has brought Hegel into much discredit with the modern scientific mind. What attracted Hegel in Goethe's view of nature (as Mr. S. Alexander has well pointed out in Mind, xi. p. 5I I), was that sense of unity or totality in nature which the poet's feeling grasps, but which is apt to escape the analysis of the scientific understanding (cf. Naturphilosophie, pp. 3 I 7, 318, 483): and it was perhaps worth while to remind the world that to regard light as composed of different colours is only a way of making the concrete facts of nature intelligible to ourselves. In the same spirit Hegel complains (p. 489) that the botanists of his time did not appreciate Goethe's Metamorphoses of Plants, and "did not know what to make of it, just because what was represented therein was a totality (eben weil ein Ganzes darin dargestellt wurde)." Goethe gets behind the difference which to the ordinary eye and mind splits up a plant into a combination of un- 
like parts (root, stem, branch, leaves, blossoms, fruit) and sees all these as the differentiations of an identical nature (Grundwesen).

In his Zur Morphologie (written in I795, published in 1807 ) Goethe formulates the law that " the more imperfect a being is the more do its individual parts resemble each other, and the more do these parts resemble the whole. The more perfect the being is, the more dissimilar are its parts. In the former case the parts are more or less a repetition of the whole; in the latter case they are totally unlike the whole. The more the parts resemble each other, the less subordination is there of one to the other. Subordination of parts indicates high grade of organisation" (Lewes, Life of Goethe, p. 358). We are familiar with this in another form: "the change from an indefinite incoherent homogeneity to a definite coherent heterogeneity." Goethe has anticipated Von Baer's law, enunciated in respect of embryology (1828), which forms the essential part of the formula that Mr. Spencer as a philosopher has applied to the whole universe.

Evolution was thus familiar to Hegel, both the theory and the word. Everywhere in Hegel we read about Entruickelung; but of Evolution he does not speak in so friendly a manner. "The two forms in which the series of stages in nature have been apprehended are Evolution and Emanation " (Naturphil., p. 34). By the first, he explains, is meant the process from the less perfect to the more perfect; by the second the process from the more perfect to 
the less perfect. Of the two he prefers the conception of Emanation, because it explains the lower from the point of view of the higher, whereas Evolution carries one back "into the darkness of the past," and only gives us a series of stages following one another in time. "The time-difference has no interest whatever for thought" (p. 33). This is undoubtedly a hard saying. The man who can prefer the Oriental conception of Emanation to the modern scientific conception of Evolution might seem to be more fit to be expounded by the Theosophical Society than to be seriously considered by the contemporaries of Mr. Herbert Spencer. "We must interpret the more developed by the less developed," says Mr. Spencer (Data of Ethics, p. 7); and at least ninety-nine out of every hundred scientific students would cry "Amen." But is this what they are themselves doing? They tell us about the less developed organisms or societies (or whatever may be the subject of investigation), and then they go on to tell us about the more developed. But are they really interpreting the higher by the lower? Let us listen to another philosopher who approached philosophy from the side of biology. In his Study of Psychology, G. H. Lewes writes as follows :- "Once recognising the necessity of observing the sentient activities of men and of animals, and of interpreting these by reference to their organic conditions, what more natural suggestion than that our study should begin with animals? The comparative simplicity of their organisms and their manifestations would seem 
to mark them as furnishing the safest prolegomena to Human Psychology. I have already stated (in the preface to Problems of Life and Mind) that in I 860 I was led to collect materials with this view, but that fuller consideration showed it to be impracticable. To show why it was impracticable will be an answer to my Russian critic, M. Wyrouboff, who objects to my 'sin against scientific method' in not proceeding from phenomena that are general and simple to those that are special and complex; I ought, he thinks, to have made the exposition of the simpler cerebral phenomena in animals precede that of the more complex phenomena in man. This was my own opinion till experience proved its mistake. I found myself constantly thwarted by the fallacies of anthropomorphic interpretation. It was impossible, even approximately, to eliminate these before a clear outline of the specially human elements was secured," etc. (pp. I I 8, I I9). Farther on he says : "It is clear that we should never rightly understand vital phenomena were we to begin our study of Life by contemplating its simplest manifestations in the animal series; we can only understand the Amœba and the Polype by a light reflected from the study of Man" (p. I22). What makes it seem possible for the scientific investigator "to begin at the beginning" is the fact that he is not doing so. The student of the Amœba happens to be, not an Amœba, but a specimen of a highly developed vertebrate, and knows at least something about the differentiated organs and functions of his own body. Professor 
Freeman "explains" the English Constitution by quoting Tacitus about the Germans, and by describing the Landesgemeinden of Uri and Appenzell, etc., etc. : but then we all know something about our present constitution.

Now this I take to be the element of truth in Hegel's preference for Emanation over Evolution. We only understand a part of anything when we can look at it as the part of a whole, and we only understand the elementary stages when we know them as the elementary stages of something more highly developed. This is true in each special branch of knowledge, and it is true in the attempt to think the universe as a whole.

Hegel's "development" (Entrickelung) is not a time-process, but a thought-process; yet Hegel's method of exposition is such that the thoughtprocess is apt to be read as if it were meant to be a time-process. To avoid misunderstanding him we must, as has been said, "read Hegel backwards." "He presents everything synthetically," says Professor Seth (Hegelianism and Personality, p. 90), ${ }^{1}$ " though it must first have been got analytically by an ordinary process of reflection upon the facts which are the common property of every thinker." There has been much innocent laughter over Hegel's absurdity in saying that Being is the same thing as Nothing, and that Being and Nothing between them produced Becoming. But, if we take the conception of "Becoming" and analyse it, we find that it

1 p. 96 , in edit. 2. 
does imply both Being and Not-being. That which becomes is that which was not but now is. The Eleatics were puzzled by the conception of Motion, just because they were trying to think the whole of reality under the category of Being, and did not see that Not-being was involved as well. So, on the other hand, the Heracleiteans seemed to make everything slip away in a flux, because they took the category of Becoming as ultimate and did not recognise that it implied the category of Being. The beginning of Hegel's Logic is, among other things, a memorandum of Plato's solution of these old controversies. $^{1}$

So again, if we are told that Identity passes over into Difference, and that the two produce Likeness and Unlikeness (I am not attempting to follow the minutiæ of Hegel's statement here), we shall see the point of this better by taking the concept of

1 In his learned and admirable work on Early Greek Philosophy, Professor J. Burnet has argued forcibly for the view that the Eleatics and Heracleitus were materialists, as much as the early Ionians. But even if his contention be fully admitted, there is a great difference between "materialism" before there was any philosophy that was not materialistic, and the conscious and explicit materialism of those who are in revolt against idealism of any kind. In other words, though we admit that the early philosophers were conscious only of discussing cosmological questions, yet they were incidentally discussing logical and ontological questions also (just as many religious and some political controversialists have discussed metaphysics without knowing it): and it was the logical and ontological aspects of their philosophies which had most interest for Plato and for Aristotle-and for Hegel. 
Likeness and asking what it implies-a question that is by no means superfluous, for English philosophy has tended to take the category of similarity as if it were ultimate. Thus J. S. Mill says, "Likeness and Unlikeness cannot be resolved into anything else" (Logic, i. p. 75). Hume in his Treatise of Human Nature, resolves "identity" into "resemblance." "This propension," he says, " to bestow an identity on our resembling perceptions produces the fiction of a continued existence" (p. 209, edit. Selby-Bigge). In treating of the Laws of Association, Mr. Spencer aims at reducing contiguity to similarity (Principles of Psychology, $\S 1$ 20, vol. i., p. 267). Mr. Bosanquet has pointed out that "Mr. Spencer is more of an atomist than any one else has ever been, for he says that the syllogism must have four terms, i.e., the middle term is not identical in its two relations, but only similar" (Essays and Addresses, p. 167). Mr. Bosanquet is working out the subject from the other side, attacking the delusion of English philosophers that identity necessarily excludes difference. It is because of their abstract conception of identity that some of them have been led on to attempt to get rid of identity altogether in psychology and logic.

If, then, we read Hegel backwards, we find that his logic and the whole of his philosophy consist in this perpetual "criticism of categories," i.e., in an analysis of the terms and concepts which ordinary thinking and the various special sciences use as current coin without testing their real value. But the

D. $\mathrm{H}$. 
results of this "criticism of categories" Hegel arranges so as to present the appearance of a completed system - the self-development of thought from the simplest to the most complex stages, the less adequate conceptions showing their imperfections, and so by criticising themselves, as it were, leading us on to the more adequate, fuller, and "truer," ways of thinking. This is Hegel's manner of satisfying the demand for "completely unified knowledge." But because of this method of exposition he is peculiarly liable to be misunderstood and misrepresented. The tendency to mistake a thoughtprocess for a time-process arises from our desire to substitute the easier form of picture-thinking for the more difficult effort of grasping the separate elements in their totality. And it is a tendency which may mislead even philosophers themselves and still more their followers. Thus Aristotle carefully defines the logical term as that "into which the proposition is

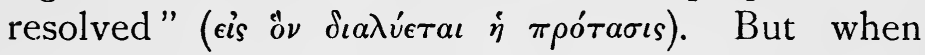
"terms" come to be treated of as the first part of logic, then the temptation is to explain the proposition as arising out of a combination of terms. So again, when the process of inference has been analysed into premises and conclusion, the premises come to be regarded as if they existed first in time and as if the conclusion was afterwards tacked on to them-a piece of picture-thinking which has exposed to unmerited attack the Aristotelian analysis of reasoning. So, too, because we can think of society as recognising certain rights in its members, the in- 
dividuals with their rights come to be pictured as existing prior to the formation of society, in an imaginary state of nature. To take an example from another region-Space is analysed into its three dimensions; then the geometrician, for method's sake, treats of two dimensions first and afterwards goes on to treat of three dimensions. And so some people fancy that you can go on to spaces of four, five, or any number of dimensions; whereas there is, as a matter of fact, no "going on" at allSpace of one or of two dimensions with which we are supposed to start is an abstraction from the only real space.

Why, it may be asked, did Hegel adopt this treacherous mode of exposition? Two, reasons may be given. In the first place, he was influenced, as we have seen, by the Neoplatonic idea of Emanation; but there is this all-important difference between Hegel and the Neoplatonists, that he gets beyond the idea of differentiation as mere loss or evil, and sees in it a necessary step in the movement to a higher unity. Thus the idea of Emanation in his hands passes over into the idea of development from the abstract to the concrete. But, in the second place, this development or thought-process does show itself as a time-process. Hegel's remark in the Naturphilosophie (p. 33) must not be taken to mean anything more than that a mere after-one-another in time is of no philosophical or scientific interest; thus, e.g., the scientific historian will not write mere annals. Annals are the 
materials for history, and are not yet history. Above all in the history of philosophy does the connection between the thought-process and the time-process come to the surface. The history of philosophy gave Hegel his clue to the logical development of the categories. The simpler and more abstract categories come first in time in the process by which the human consciousness becomes gradually aware of the conceptions underlying ordinary thought and language. In the history of philosophy we have a development from the simpler to the more complex, like that which Evolutionists see in the physical universe. Professor Wallace has well compared Hegel's discovery of the self-development of thought by means of the clue given him in the history of philosophy to Darwin's discovery of the process of evolution in the organic world by the help of the clue given him by " artificial selection." " Philosophy," says Professor Wallace, "is to the general growth of intelligence what artificial breeding is to the variation of species under natural conditions" (The Logic of Hegel, Prolegomena, p. cx.).

I should quite agree with Prof. Seth (Hegelianism and Personality, p. I 70$)^{1}$ that Hegel's greatest strength lies just in his interpretation of historyi.e., of the process of human evolution in all its departments. But Prof. Seth blames Hegel for transferring to the development in time the thoughtprocess described in the Logic, without any justifica-

1 p. 179 in edit. 2. 
tion except the ambiguity in the word "development" (p. I 59). ${ }^{1}$ I have just tried to show that the history of philosophy itself is Hegel's justification for the transference; and I think that if he is to be blamed at all, it should rather be for stating the thought-process in the Logic, so that it looks like a time-process.

I suppose the belief still prevails about Hegel that he is an a priori metaphysician who spins theories out of his head regardless of facts. And this reproach is held to apply with special force to his Philosophy of Nature. What Hegel himself says is something very different. "Not only must philosophy be in harmony with experience, but empirical natural science is the presupposition and condition of the rise and formation of the philosophical science of nature." 2 The synthetic thinking of the philosopher must follow after and depend upon the results of the analytic process of scientific research. This being so, it must be remembered in respect of Hegel's Philosophy of Nature, that much of the natural science which supplied him with his material and his problems is now out of date; so that his Philosophy of Nature cannot have the same interest and value for us as his \#sthetic, or his Philosophy of Religion, or his Philosophy of History, though even in these departments we occasionally feel that the philosopher is working with somewhat antiquated materials, and not always dealing with what have

1 p. 168 in edit. 2.

2 Naturphilosophie, p. I I. 
come to be our chief problems. Secondly, Hegel's warmest admirers must admit that Hegel has his prejudices-patriotic prejudices in the main. His sympathy with Goethe's conception of nature was, on the whole, a beneficial influence; but it helped to make him unappreciative of Newton. And, thirdly, Hegel has less interest in nature than in the works of the human mind. He is undergoing the reaction against the deification of Nature, as something higher and better than man. "Vanini says that a straw is enough to reveal the being of God"; but adds Hegel, "any idea of the mind, the poorest of its fancies, the play of its most accidental moods, every word is a more excellent reason for recognising the being of God than any single natural object whatever" (Naturphilosophie, p, 29). Again, "Even an arbitrary volition-nay, even a bad volition-is infinitely higher than the regular movements of the stars or than the innocence of the plants; for a wrong human volition is the error of a thinking spiritual being" (ib., p. I 3.$)^{1}$

Grant all this, it may be said, and what then is the use of bringing Hegel's name into connection with

1 Cf. the passage near the beginning of the "Introduction" to the Asthetic: "If we look at it formally -i.e., only considering in what way it exists, not what there is in it-even a silly fancy such as may pass through a man's head is higher than any product of Nature ; for such a fancy must at least he characterised by intellectual being and by freedom." (Bosanquet's Translation, p. 3.) 
Darwin's? There might be some reason for considering his attitude to evolution, as he saw it represented in the Biologie (1802-5) of Treviranus and in the Philosophie Zoologique (1809) of Lamarck, and some reason, perhaps, for blaming him for his want of appreciation of the first beginnings of the great scientific revolution of this century. I think, however, it is worth while to see whether we can get any help, not from details in Hegel, but from his general method and spirit of philosophising, in making the attempt to think nature and human society as they present themselves to us now, in the light of Darwin's theory of natural selection. Of evolution Hegel had heard-somewhat impatiently, perhaps-but not of natural selection. But neither had Treviranus nor Lamarck; neither had Mr. Herbert Spencer when he elaborated the groundwork of his system. Even in the fifth edition (1884) of First Principles, "natural selection" is only allowed to appear in a footnote, which footnote is intended to minimise the importance of Darwin's discovery (p. 447). Now it is "natural selection" which seems to me the really epoch-making scientific theory: it is this that has produced that "change of categories" which, as Hegel says (Naturphil., p. I9), is the essential thing in all revolutions, whether in the sciences or in human history. Evolution in the form in which Mr. Spencer, for instance, formulates it, is only a further carrying out of an idea which may be traced back to the Ionian hylicists; "natural selection" introduces a quite new method of looking 
at nature, and it has the further advantage of being, not a metaphysical speculation, but an undeniable fact.

What, then, is the effect of the theory of natural selection on Hegel's philosophy? Hegel's method of philosophising Nature could adjust itself quite easily to the new scientific theory. The factors which Darwin assumes for his theory are-Variation, Heredity, Struggle for Existence. Now are not Heredity and Variation just particular forms of the categories of Identity and Difference, whose union and interaction produce the actually existing kinds of living beings, i.e., those determinate similarities and dissimilarities which constitute "species"? But this result-definite, clearly marked kindscomes about through struggle, i.e., through nega tion, the constant elimination of the less fit. Survival of the fittest, on Darwin's theory, comes about only through the negative process of destruction. In the stage of mere Nature this negativity is mechanical and external. In the higher stage of consciousness (spirit) this negativity is self-determined, free-as I shall try to show later on.

This attempt at Hegelianising natural selection may seem fanciful. We know that Hegel's formulæ have been read into Shakespeare's plays and into various inconsistent types of religious creed: and people become suspicious of formulæ so very elastic. I think, however, my interpretation is valid so far as it goes, though it would not count for much except for reasons I now go on to consider. 
There is one matter on which I think that most admirers of Hegel, unless they be of the very straitest orthodoxy, would allow that his view of Nature needs some correction. I mean his conception of "the Contingent" (das Zufällige). That infinite variety which is sometimes praised as "the freedom of Nature," or even as "the divinity of Nature," Hegel regards as, not the glory, but the defect and impotency of Nature. (Naturphil., p. 37 ; cf. the small Logic; Werke, vi. pp. 288, 290; Wallace's Translation, pp. 227, 228.) Thought has in nature gone out of itself into its "other"-its extreme opposite-irrationality. And that is why nature is like a wild Bacchantic god (Naturphil., p. 24).

This conception of the "contingency" and "weakness" of nature is a survival in Hegel of the Platonic and Aristotelian conception of matter. In Plato's view the world in space and time must, just because it is in space and time, fall short of what its Artificer wished. So with Aristotle, "Chance" is an objective cause working in rerum natura, not a name for our ignorance. Professor Seth seems to hold that nature is illogical or nonrational, but that Hegel falls into a "most transparent fallacy" in saying that contingency is itself a category-a form of the Idea which " has no less than other forms of the Idea its due office in the world of objects." "To say that a thing is contingent or accidental," argues Professor Seth, " is to say in so many words that we can give no 
rational account of why it is as it is, and not otherwise." (Hegelianism and Personality, p. I $37 .{ }^{1}$ )

In this criticism I think that Professor Seth has approved of the more defective part of Hegel's statement, and has condemned the part in which Hegel shows most insight. Darwin's theory of natural selection seems to me, while helping, as all modern science does, to correct the despair of giving a rational account of what appears to us merely accidental, at the same time completely to justify Hegel in regarding this seeming non-rationality of nature as itself a form of the rational. The theory of natural selection presupposes (it is sometimes even made an objection to it that it does so presuppose) a tendency to variation in nature. There must be this for natural selection to work upon. Thus the non-rationality (indefinite variability) has its reason-in a sense in which that was never recognised before. Of course this tendency to variation is of itself a fact to be explained; and biologists feel themselves obliged now to face problems that might have been put aside as insoluble in the days before this new conception of natural selection revolutionised their science.

Professor Seth asks: "What logical connection is there between the different qualities of things-between the smell of a rose, for example, and its shape; or between the taste of an orange and its colour?" 2

1 p. 146 , in edit. 2.

2 P. 133 in edit. I ; p. 142 in edit. 2. Prof. Seth would, I believe, defend his question by laying stress on the term "logical"; 
This seems to me rather an unlucky question. We feel sure now that there must be some. The scent of flowers, the taste of fruits, their colours, shapes, etc., are not regarded now as "accidental" results of a fortuitous concourse of atoms or as the mere fancywork of a capricious maker, but as connected in some way with the means through which the plant is reproduced, and the species aided in its competition with others by the insects which carry its pollen and the birds which carry its seeds. Thus, in some plants, successive adoption of self-fertilisation and insect-fertilisation can be read off from the complicated shape of the corolla. ${ }^{1}$ I do not know whether the particular problems, suggested by Professor Seth, about the rose and the orange have been solved. But quite analogous problems have been, such as-Why do white flowers often give out their scent only by night ? ${ }^{2}$ Cats and red clover might seem to have no more logical connection than

we cannot infer the smell (e.g.) from the shape of a flower. If we cannot, it is only because of our ignorance in respect of the particular problem. From the parallel veins in the leaf of a flowering plant I can infer that its petals will be arranged in three's or in multiples of three, in the same sort of way, if not with quite the same certainty, with which I infer that, if one angle of a rectilineal triangle is a right angle, the sum of the other angles must be a right angle. To assume that logical connection is something absolutely different in kind from the connection between things (real connection) seems to me to make scientific knowledge impossible. See Note at the end of next essay.

1 Cf. A. R. Wallace, Darwinism, p. 33 I.

2 Ibid., p. 316. "White flowers are often fertilised by moths, and very frequently give out their scent only by night." 
Tenterden Steeple and Goodwin Sands; but Mr. Darwin has shown how the flourishing of red clover depends on the flourishing of cats, who eat the field-mice, who eat the humble-bees, who fertilise the red clover. ${ }^{1}$

What distinguishes Darwin's theory from other theories of evolution is the kind of explanation it gives. Hegel complains, and I think justly, that merely to go back "into the darkness of the past," or merely to say, "first there was the simple and then the complex was evolved out of it," and so on, is not to explain nature ; it is only to give a chronological table of events-real or imaginary. We want to know "Why?" To refer us back to the homogeneous and undifferentiated is to give "the material cause" ( $\tau \grave{o} \dot{e} \xi \xi o \hat{v})$ of what has happened : it is not to explain why what has happened has happened. But the theory of natural selection does explain "Why." Such a form or characteristic has been of advantage, of utility to the species, and therefore has favoured its continuance. Darwin restores "final causes" to their proper place in science-final causes in the Aristotelian, not in the Stoic or "Bridgewater Treatise," sense. ${ }^{2}$

"The Good" as a means of explanation thus regains the importance which Plato claimed for it. He makes Socrates complain that Anaxagoras, after asserting that Reason was the cause or principle of

1 Darwin, Origin of Species, pp. 57, 58.

2 Cf. Hegel's small Logic, Werke, vi. pp. 378, 379; Wallace's Transl., p. 299. 
all things, went on to assign only " material" causes of things, whereas if we are to give a rational explanation we must do so by showing how the good was realised in the world (Phado, 97, 98). Plato was too hastily trying to see everything in the light of the one supreme good-the end of the universe as a whole. And Aristotle's caution was not unnecessary- "the good for man is not the same as the good for fishes" (Eth. Nic., vi. 7, §4). This conception of Final Causes, which the theory of Natural Selection restores, is not the cruder form of teleology which attempts to explain everything in the universe by showing that it serves the good of man. Each species has come to be what it is by pursuing (if we may speak metaphorically) its own good. Each individual is preserved by its own good. In the conflict between individuals and between kinds that which is better equipped for the particular struggle is selected. From many points of view, e.g., from ours-ours either as the species of human beings, or ours, as members of this or that society, or ours, as individuals - what happens may be very far from what we consider our good, yet it must be the better adapted for success which succeeds. This is a truism when stated thus: but from this it follows that the explanation of structures, habits, etc., must be found in the end or purpose that they serve. This substitution of Final Cause for Efficient or Material Cause as the more important category is as significant for us now as it seemed to be to Aristotle. And of all modern philosophers Hegel 
has recognised most fully this significance of the conception of End. On this head his critic, Professor Seth, allows that he represents "what is profoundest and best in modern philosophy" (Hegelianism and Personality, p. 83). ${ }^{1}$

Let me trace some consequences of the theory of natural selection in Ethics-where the applications of it are perhaps the most interesting to us. In Ethics the theory of natural selection has vindicated all that has proved most permanently valuable in Utilitarianism, while correcting those parts of the theory which made the negative work of the Intuitionalist critic very easy. Right and wrong appear now as what help or hinder the good of the society -whatever the society may be. The happiness of the individual, as Professor Clifford pointed out (Lectures and Essays, ii. p. I 73), is of no use to the community, except in so far as it makes him a more efficient citizen. Thus ethics is again, as to Aristotle and to Hegel, closely bound up with politics. The ethical end for the individual must be a social enda common good (whatever the community may be).

Natural selection (as I have tried to show more fully elsewhere $)^{2}$ is a perfectly adequate cause to account for the rise of morality-in that same sense of "cause" in which we use the term in scientific

1 p. 89 in edit. 2.

2 Art. on "Natural Selection and the Spiritual World," in Westminster Reviewe, May, 1890, reprinted in 2nd edit. of Darzvinism and Politics (1891). See esp. pp. 96-106. 
explanations of natural phenomena. Regarded as events in time, the appearance of consciousness and the capacity for language with the consequent possibility of storing up the results of experience, may be accounted for by natural selection, i.e., they favoured in the struggle for existence those species which happened to possess them. The facts of consciousness, of reflection, of self-consciousness, however, make an enormous difference in the character of this struggle. Natural selection in its lower stagesthose with which the naturalist is familiar-works solely by the destruction of the less favourably circumstanced organisms and species. Natural selection among " articulate-speaking," thinking mortals, who can "look before and after," works in other ways as well. Morality, to begin with, means those feelings and acts and habits which are advantageous to the welfare of the community. Morality comes to mean the conscious and deliberate adoption of those feelings and acts and habits which are advantageous to the welfare of the community; and reflection makes it possible to alter the conception of what the community is, whose welfare is to be considered.

In human history, except where there has been retrogression, we find an advance in the ideals of life, i.e., man has been coming to a fuller and fuller consciousness of the end or good at which from the first, merely as a social animal, he has been blindly striving. It is worth while referring to retrogressions, because such cases show us to what 
an extent morality and all other differences between man and the animals, between the highest and the lowest races of human beings, are due to the influence of social institutions and not to any original, innate, or inherited instincts. Long centuries of civilisation do not prevent mankind from reverting to a condition not far from that of the lowest races, where circumstances, such as a terrible pestilence, long-continued warfare, a barbarian invasion or life among savages, have removed the ordinary restraints of civilisation. Still these are exceptional conditions. What may appear to be a general breakdown and return to barbarism may be the transition to a new and, in some respects, higher type of social organisation. For in human evolution we are forcibly reminded that progress does not go on in a straight line; but, just because thought enters into the process, at each step there is an attempt to correct the one-sidedness of the preceding stage.

In the history of philosophy this "dialectic movement" comes clearly to the surface. The philosopher who is not a mere echo of what has become a dogmatic system is driven, by reflection on the prevalent manner of thinking, to lay stress on the aspects of truth which have been neglected. But the criticism he applies to his predecessors must in due time be applied to him. The great constructive philosophers seem indeed to gather up into their thought all the elements that existed scattered in preceding systems; but the time comes when a 
new criticism and then a new reconstruction are needed, if philosophy is to remain living and not to be fossilised in a traditional dogma. "Let us follow whithersoever the argument leads us"; and, if we do not let ourselves become "misologists," we must hold fast this Athenian faith in the value of the perpetual conflict of ideas, which is the highest form of the struggle for existence.

But what comes out clearly, and with some consciousness on the part of those concerned, in the history of philosophy is also going on in all other parts of human evolution. If natural selection operated among human beings exactly as in the lower organic world, there would be no advance except by the destruction of all the individuals composing an unsuccessful form of social organism. In the lower stages of human history that must have happened often enough. In the higher stages the organism may change without the members of it being destroyed; the race (the merely natural element) is not inseparably linked to the fate of all its institutions, its language, religion, form of government, etc. A vigorous race may live through many political and social institutions; on the other hand, successful institutions may become the possession of many races. Now in the history of civilisation generally we can see, though not in every respect so clearly as in the history of philosophy, this criticism of customs and ideas going on. Revolutions, peaceable or otherwise, are the transitions from one stage to another, provoking generally D. $\mathrm{H}$. 
a counter-revolution, but in progressive societies, helping the forward movement through whatever apparently zigzag courses. Mr. Herbert Spencer thinks that the movement of human progress is all in one direction-from status to contract. Any attempts to get rid of some of the anarchy of individualism he can only interpret as a return to militancy. A follower of Hegel would agree with the average man that it is no such thing. We are not returning to the Middle Ages, but advancing to a new stage which shall reconcile both elements. Of course this new stage will not be final-though we are always apt to look on the stage just ahead of us as if it were final, because it is what to us seems most needed. Defects, one-sidedness in it, will show themselves and need correction, perhaps at first by opposite exaggerations. The correction may take place more and more through peaceful debate, instead of through fighting. A still higher stage would be reached when people themselves made the correction instead of leaving it to a rival party to do so: the dialectic movement may go on within the soul.

This seems to me a type of interpretation of human evolution which is in entire accordance with Darwin's theory of natural selection, and which yet admits of what is most valuable in Hegel's dialectic method. The analysis of the conception of punishment in $\mathrm{Mr}$. Alexander's Moral Order and Progress (pp. 327-333) seems to me a most admirable example of such a reconciliation of Darwinian and Hegelian evolution. 
"Punishment in man," says Mr. Alexander, "corresponds to the struggle of the dominant variety with other varieties. . . . We punish in order to extirpate ideals which offend the dominant or general ideal. But in nature, conflict means the extinction of individual animals ; in punishment it is sufficient that the false ideal is extinguished, and it is not necessary always that the person himself should be destroyed." Punishment, as Mr. Alexander puts it in summing up, has three characters: "It is retributive in so far as it falls under the general law that resistance to the dominant type recoils upon the resistant or guilty creature: it is preventive in so far as, being a statutory enactment, it aims at securing the maintenance of the law irrespective of the individual's character. But this latter characteristic is secondary, and the former is comprehended under the third idea, that of reformation, which is the superior form under which retribution appears when the type is a mental ideal and is affected by conscious persons." This account of Punishment is Darwinian in its application of the concept of natural selection. It is Hegelian in its recognition of the diverse elements that enter into the idea of punishment, unlike the rival one-sided theories on the subject; and it is Hegelian, above all, in its recognition that what seem the extreme opposite theories of retribution and reformation are, after all, different stages of the same concept.

Hegel's treatment of ethical questions agrees with that of the evolutionists in two main respects-both 
of which have been made grounds of objection to his philosophy. (I) The complete separation which Kantian ethics and the ethics of the Intuitionalist school make between "ought" and "is" tends to disappear. Hegel protests vigorously against the philosophical weakness of Fichte's perpetual Sollen, and seems to take up an almost "Philistine " attitude towards the enthusiasm of the romantic dreamer or of the reformer indignant with the abuses of society. Similarly we know that a very general consequence of the evolutionary and historical view of society has been to aid the reaction against the revolutionary appeal to " natural rights," and to support a political and social conservatism of the type so brilliantly illustrated in this country by Burke. And in ethics the evolutionary moralists tend to do away with the distinction between moral laws and laws of nature, to treat moral action as not distinct in kind from action in general. (2) Hegel's ethics are a part of his "Philosophy of Law"; the familiar separations between politics and ethics, between society and the individual, appear only as aspects of what cannot properly be thought of apart from each other. So, too, ethics to the evolutionist is a branch of sociology. And to both Hegel and the evolutionist the reproach is sometimes made that they ignore the significance of personality.

Now, first, as to Hegel's too passive acquiescence in fact, let me admit, once for all, that that is the great flaw in his practical philosophy. All wisdom seemed to culminate in Hegel's Encyclopadia, all 
history in the Prussian bureaucracy of 1820 ; and Hegel's orthodox disciples were ready to weep that there remained no more realms for the world-spirit to conquer. But this "finality" is an inconsistency in Hegel's application of his philosophy. The same dialectic movement, which had brought the human spirit to the stage at which Hegel found it and interpreted it, must urge man onwards. Yet Hegel's error is only the exaggeration of his perfectly sound feeling that the philosopher as such has mainly to do with what has already come into existence-the same sound feeling which, as I have already shown, makes him insist that the philosophy of nature must follow and cannot anticipate the course of the physical sciences. Hegel's famous dictum, "The Real is the Rational," has been a stumbling-block to many, in spite of what he himself says in explanation of it (in the Introduction to the Encyclopadia). Mere existence is a very different thing from reality. Professor Seth (Hegelianism and Personality, p. 203) ${ }^{1}$ treats this distinction as a "quibble" on Hegel's part. Surely it is a perfectly legitimate use of that fatally ambiguous word "real." The use of "real" in antithesis to "sham" is common enough; and, as a matter of fact, it is more of a quibble, when those who boast themselves "Realists" in philosophy take advantage of this popular moral connotation of the term " real" to claim support for themselves in their polemic against Idealism, when e.g. they tell us that an atom is something more real than a thought.

1 p. 213 in edit. 2. 
This is true in the sense that the atom must be thought of as being in space; but the ordinary mind takes it as if it meant that the atom is more important. That "the real is the rational" is a doctrine which is implied in, and may be well illustrated by, the theory of natural selection. All sorts of variations occur, i.e., they exist ; but only those that prove to be of some value persist. Whatever maintains itself must do so because of some rationality that it has or had. When the rationality ceases, we have an appearance and not a reality, a sham that is doomed to perish. This, as we know, is the one lesson that Carlyle read in history.

Hegel's temperament and his circumstances led him to lay less stress on the converse of his proposition: "The Rational is the Real." It does not matter how few hold an opinion now, if their opinion is what makes for the greater well-being of society, they have got "the root of the matter" in them, and their opinion will ultimately prevail. The Idea, as Hegel himself would say, cannot remain a mere "ought to be," it must make itself real. It may take a long time; but time is indifferent to it. Similarly, the evolutionist is apt to decry all attempts to better the world. He knows that all institutions, practices, etc., that have established themselves must have done so because of some value they had (some rationality); but, occupied as he is in studying past and existing forms, he is apt not to see the promise in new variations. Certainly of these new variations (i.e., new ideals, new pro- 
jects, etc.) a great many will fail. Even a man of inventive genius may make a lot of "unreal" inventions. It needs a sort of prophetic intuition to see what makes for welfare in the future. But, on the principle of natural selection, whatever institution or type of conduct ceases to serve the wellbeing of society is doomed to perish by the working of those same forces of struggle which at one time gave it reality and predominance. Whether it perishes, dragging with it the happiness and the lives of human beings or not, will depend on whether it perishes by the mere natural struggle, or is peaceably set aside by the conscious act of the reformer, anticipating on behalf of his society and obviating the cruel process of mere natural selection.

Hegel's philosophic endeavour to see the rationality of all established institutions has sometimes been condemned as an unreasoning optimism. But we have seen that he does not mean that, "Whatever is, is right." And his optimism is no more than that faith in the ultimate rationality of the universe, which is the presupposition (however unexpressed or unrecognised) of all scientific interpretation and of all practical effort. Hegel takes this presupposition quite seriously, and states it explicitly, by constructing his Encyclopadia; he has the true ideal of a philosophic system as the attempt to state the whole truth about the universe. He errs in so far as he seems to claim to have himself completed " an absolute system." It is philosophical to hold 
that the universe is rational; for all the sciences presuppose it, and all serious human conduct presupposes it : it is rash to be too confident about any particular interpretation of the rationality of the small portions of the universe that the sciences (including history) have as yet explored, or to be too confident of the adequacy of any particular institutions to the demands of the reason, which partly reveals itself to us and in us, in the development of human society. ${ }^{1}$ Hegel, as I have said, gives up too rashly the rationality of nature; he also interprets too rashly the rationality of human society. Yet our very dissatisfaction with existing institutions, if it leads to serious attempts to better them, implies a belief (however little formulated) that human life is based on reason and not on chaos or deception.

To come to the second great objection made to Hegel-Professor Seth complains (and with widespread sympathy) that in Hegel's system there "is room only for one Self-consciousness: finite selves are wiped out, and nature, deprived of any life of its own, becomes, as it were, the still mirror in which the one Self-consciousness contemplates itself" (Hegelianism and Personality, p. 162). ${ }^{2} \quad$ The

1 Prof. Seth says (in his 2nd edit. p. 213 , note): "An absolute system cannot afford to leave any nook or cranny of existence unexplored." I only defend Hegel's ideal of a philosophical system; and that ideal may surely be right, though we have to admit the inadequacy of any particular performance-even if it be that of Hegel himself.

8 p. 17 in edit. 2. 
individual is supposed to be a fatal objection to Hegel's system; he will get in the way of it and throw it off the rails. But, perhaps, we may recall George Stephenson's answer to the objection about the cow getting in the way of the steam-engine: "It would be very awkward for the coo." And this conception of the abstract individual-the favourite idolon of popular philosophy-is destroyed by the logic of Idealism, whether in the region of Metaphysics or of Ethics. Of course each of us, if we had been making the universe, might have made his own individual self the centre of it; but logic teaches us that we cannot think the universe rightly from our individual point of view, and life teaches us that we must not live it from our individual point of view. If we try to do so to any very great extent, our neighbours may be obliged to shut us up in an asylum or to hang us, in the interest of something that is greater than the individual self. And so we find that the real individual is not the individual in isolation from and in distinction from all other individuals, but is a synthesis of the universal and particular self.

The scientific study of nature shows us that not only is nature "careless of the single life," but that even the type or species is transitory, that the infinite diversity of kinds and individuals does not exclude the essential unity of nature. And thus the modern man of science, if he takes to philosophy, is generally able to appreciate Spinoza. Hegel, however, has risen above the category of substance. 
Self-consciousness is to him the highest category, and, as Professor Seth admits (p. $89^{1}$ ), is "our best key to the ultimate nature of existence as a whole." But what is this "Self-consciousness"? Is it God or is it the individual self, or is it a mere abstract universal? Is the critic, who asks these questions, quite sure what he means by "God," and by the individual "self," and that what he means by these terms represents an intelligible reality, and not merely the picture-thinking of ordinary beliefs ? Is it not, at least, a hypothesis worth taking account of, that in our consciousness of self we have the clearest manifestation of the unity which science presupposes in the universe? Hegel admits-in perfect accord with the most materialistic science-that spirit comes from nature; nature is the potentiality of spirit. But, if we take this conception of potentiality quite seriously, will it not be nearer the whole truth to say, with Hegel, that spirit, being out of itself, estranged from itself in nature, comes to itself in human consciousness? The separateness and isolation of one self-conscious being from another is only a necessary consequence of the manifestation of spirit in space and time. It is the negativity which makes the manifestation possible. But the "truth" of our separate selfhoods is only to be found in our ultimate unity, which religion calls "God," which ethics calls "goodness"- - a unity which is not the abstract "One" of the Neoplatonist, but an organic unity realised in a society which is not a mere aggregate 
of individuals, but a spiritual body animated by that love which is the highest religious conception of Deity.

Let me recall what I said before about the concept of "Final Cause," or " the Good." Might not a philosophical theology substitute this concept for that of "First Cause"? I shall not enquire how far the consequences might be favourable to orthodoxy (of any particular species) or not; but at least such a theology would be more in accordance with a truly ethical religion.

Hegel's critics are puzzled by what seems the union of mystical theology with " the crudest materialism." Regard his system in its general outlines (I am not thinking of details or applications) as a great speculative hypothesis-is it not a strong argument in favour of this hypothesis that it can at the same time accept without reserve the results of scientific discovery, however materialistic they may seem, and can yet explain, and to some extent justify, the speculations of those great religious thinkers who have attempted sincerely, but perhaps too boldly, to grasp in their thought of God the whole secret of the universe? If we may judge by past experience, all attempts on the part of "Intuitionists" to meet Evolutionists on questions of "origins" are doomed to failure: one untenable position has to be surrendered after another. The Idealist makes no such attempt. He only insists that, after we have had as complete a history as can be given of how things have come to be what they 
are, we are justified in looking back from our vantage ground and seeing in the past evolution the gradual "unrolling" of the meaning that we only fully understand at the end of the process. The process is not completed; and therefore this attempt has to be renewed for each generation. But at every stage it is in the highest that we know that we must seek the key to the philosophical interpretation of nature and of man. 


\section{III.}

\section{WHAT IS REALITY ? ${ }^{1}$}

THE critics of Idealism, so numerous at the present time, seem to me more ready to uphold against the claims of thought the superior dignity of the Real, than to explain what they mean by that very ambiguous term. Our "Realists" nowadays are too cautious, or too polite, to speak about "the Vulgar"; I am compelled to think, however, that like their predecessors of last century, the Scottish Common-Sense School, they are playing off the vulgar against the philosophers. Nevertheless, I believe that the vulgar are being deceived by words, and that not "Realism " but "Idealism" corresponds to what the plain man really holds, if he can only be induced to go behind the deceptive forms of ordinary speech and think the matter thoroughly out. This may seem a very rash statement, and I must endeavour to prove it. What, then, does "real" mean?

I. There is, first of all, a sense in which every sensation or feeling or idea may be described as "real," if it actually occurs as a psychical event in

1 Reprinted from the Philosophical Review, May, 1892. 
the experience of any one. In this sense-it is a sense rather in favour with some Realist philosophers than with the plain man-the real is whatever is truly in any one's experience and is not falsely alleged to be so. If a person really, i.e. truly, sees " blue devils," they are real to him at the time he sees them, although they become unreal to him when he recovers health, and although throughout they are unreal to other persons. So, too, one's dreams, however absurd they may be, are real to one at the time-more or less. But how do we distinguish dreams from reality? Is it not by the test of coherence or persistence in our experience? If one's dream-experience in any one dream were to be perfectly coherent with itself, and if the events of one dream were always to follow in an intelligible sequence on the events of the preceding dream, undoubtedly our dream-life would be as real as our waking life. But these are two pretty big "ifs," and, consequently, all sane and normal persons are able to distinguish between the merely temporary and subjective reality of dream-events and the $o b$ jective reality of what are commonly called real events. It must be noted that subjective reality is equally predicable of all feelings and thoughts which we actually have, whether or not the content or objective reference of these feelings and thoughts turn out to be valid or not. A distinction, however, must be made : (a) I may form a mental image of a dragon, while fully aware that no such creature exists and that it is a mythical animal; but (b) people 
who believed in the actual existence of dragons would, in forming the mental picture of a dragon, add the idea of its reality. Its essence would for them involve existence: to us it involves fabulous existence. Now subjective reality would, I fancy, be generally limited to $(b)$, the actual occurrence of a thought with the added suggestion of its objective reference. When we know that we are dreaming, we are near waking. When we know that our hallucinations are hallucinations, we are on the way to get rid of them. It is said, correctly I believe, that if a person sees a ghost sitting in a chair, but can be induced to sit down boldly as if the ghost were not there, the ghost will take offence and go away. I am not personally acquainted with the habits of ghosts: so I speak under correction. With regard to feelings, I do not think we can make the same distinctions as with regard to mental images or general conceptions which imply some sort of image or picture to help them out. I cannot have a feeling of pain, unless that feeling is subjectively real to me. I may have a memory or an image of myself as having pain; but that cannot be described as a feeling of pain. In ordinary language more is meant by the reality of a pain, than the fact that a person has a feeling of pain : it is implied that the feeling has causes or grounds such as other persons would regard as sufficient to produce the feeling of pain in them. Thus, when any one is induced to admit that "imaginary pains are, after all, real pains," or that "sentimental grievances are, after 
all, real grievances," the admission is made with the consciousness that the phrase is an oxymoron.

II. Of objective reality we have a further test than coherence in our own experience : and that is the experience of other persons. If $A$ seems to himself to see a mouse run across the floor, but if B, C, D, E, and F, being all present, having good eyesight, and looking in the same direction, maintain truly that they saw nothing, A may well doubt the reality of that mouse, though no one need doubt, if $\mathrm{A}$ be a trustworthy person, that he really had the perception of a mouse, i.e., some affection of the nerves of sight plus a judgment. To settle the question it might be convenient to obtain the opinion of a sane and fairly hungry cat, whose sense of smell would confirm or contradict the visual perception of A. Macbeth sees Banquo's ghost ; but nobody else does. Banquo's ghost, therefore, has no objective reality.

The objectively real is not that which stands outside everybody's mind (if that phrase could have any meaning), but that which has a validity or possible validity for the minds of several persons who can agree as to the content of their mental experience. The agreement between the inferences drawn from the experience of our different senses, the agreement between the judgments of different persons, and the harmony of present experience with the results of our and their previous experience, constitute between them the test of reality. In all practical affairs of life we consider ourselves justified 
in regarding any alleged reality with suspicion, if it cannot be shown to harmonise with the experience of sane, healthy, and normal persons. What does not so harmonise can claim, at the most, only subjective reality, i.e., reality for the persons having such abnormal experiences.

The opposition between the "real" and the "imaginary" is very often supposed to correspond to the opposition between "sensation" and mere "thinking." Mere thinking may of course mean imagining, and then the opposition is to some extent the same; but only to some extent even then. Because there may be sensations (in the psychological sense) or feelings which we may come to discover to be unreal in exactly the same sense as thoughts may be unreal; i.e. they may not fit in with the rest of our experience and with the experience of sane and healthy persons. The antithesis between sensations (in the psychological sense) and thoughts cannot be an absolute one. If by sensation be meant, not simply the excitation of a nerve (which may not be felt and so is not psychologically a sensation), but a sensation as felt, and, moreover, felt as this or that sensation, i.e., discriminated, here we already have an act of judgment (Aristotle defines

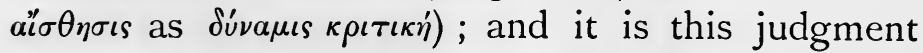
which we pronounce to be true or false according as it corresponds or not to reality (i.e., the rest of our experience and the experience of other people). A person hypnotised may be made to feel a sensation of heat, when there is no cause external to his organ-

D. $\mathrm{H}$. 
ism to produce the sensation, and not to feel the prick of a pin where there is an external cause. In such cases the sensation, or absence of sensation, not being such as persons in a normal condition would experience, is not considered to correspond to reality.

I fancy that to some persons a sensation might seem to have more reality than a thought, because the organism is affected in an obvious way in the case of sensation, either by some external or internal stimulus, whereas a thought does not so obviously depend on any organic process, and was in oldfashioned psychological theories supposed to occur independently of anything happening in the brain. But all scientific psychologists would, I imagine, admit now that thoughts must have their physiological equivalents just as much as sensations, although in the former case what happens in the brain is much more complex, obscure and difficult to discover.

Pleasure and pain seem to have reality in a special degree : pain in particular forces itself on our consciousness in a way which may make mere thoughts or ideas seem unreal in comparison. But pleasure and pain are purely subjective feelings. As psychical events they have no more reality than thoughts as psychical events. When people try to argue one out of a feeling of pleasure or of pain, they do so by saying that it is not real ; i.e., it is unimportant, it is not connected with what is permanent and persistent in our experience, it is not such as the sane or 
healthy man would feel. ${ }^{1}$ That is to say, so far as the meaning of reality is concerned, pleasures and pains are real or unreal just as thoughts are-subjectively real if they are actually experienced by any one, objectively real if they fit in with the rest of experience, i.e. if they belong to a coherent and intelligible system of thought-relations. Thinking is, therefore, the test of objective reality.

Such a sentence seems far from the plain man's mode of expression, and I fancy the objection would be made here that I am ignoring an important distinction: that which is in space is real in a sense in which that which does not occupy space is not. Real things, it will be said, are different from ideas.

First of all, let us observe that this statement about reality is quite inconsistent with that just noticed about the superior reality of feelings. Feelings are not in space : and yet, as we have just seen, feelings are very real. It is true that sensations and feelings imply a physiological process that must take place in space and a body that must be in space. But in exactly the same sense thoughts imply a brain which is extended, and they also imply a society of human beings living and moving in space. Thus the distinction between sensations and thoughts is not parallel to the distinction between what is in space and what is not in space.

Clearly, however, this notion of filling space is a notion very commonly attached to the real. Let us

1 The fifth meaning of Reality, the ethical meaning, comes in also, however, in reference to pleasure and pain. 
see what it implies. The sensation of resistance to muscular movement gives us probably our earliest notion of reality-notion, I mean, as distinct from mere feeling, Resistance is offered by one part of our body to another, and yet both feel: so our body as both resisting and feeling is specially real to us. What does not resist, or resists only in a way not easily recognised, is not thought to be real. Thus air seems to be emptiness-empty space. "Airy" is a synonym for " unreal," "imaginary." Yet to the scientific mind, air is real and space-filling, besides being not unimportant to human life. To the scientific mind the space between our earth's atmosphere and the stars is not empty, but filled by what is called the luminiferous xther. To the unscientific mind this does not seem to be real quite in the same way as stone or clay is real. The more resisting seems the more real. "Solidity" and reality are used as convertible terms.

III. Our attention is thus called conspicuously to the fact that the real world of ordinary belief and the real world of scientific belief are very different. Colours, sounds, etc., are translated into their physiological and then into their physical "causes"; i.e., they are represented as movements in space. The primary qualities of matter thus seem, from the scientific point of view, to have greater reality than the secondary. Not that which is felt, but that which can be thought in terms of mathematical conceptions, has the greater reality to the scientific mind. A thing really is (to the scientific mind) - that 
way of thinking about it which fits it into its place in an intelligible system of the universe.

This difference between ordinary and scientific reality is not the antithesis between the "phenomenal" and the "real." The real with which science has to do is what would be the phenomenal, if we had keener vision; e.g., what appears at rest to the naked eye is seen to be in motion if we look through a microscope. If by reality were meant things-inthemselves, and not phenomena or possible phenomena, then reality would be identical with the unknowable. Ultimate reality may be the unknowable to us, as well as the unknown, but it must be that which would appear to a being possessing complete knowledge. Complete knowledge is to us a mere ideal : but the most real world we can know must be what the world means when we come to think it out. Thus when science comes to put aside any theory, such as, e.g., the corpuscular theory of light, this means that the light-corpuscles are considered unreal, because their existence conflicts with the less rapid transmission of light in water than in a vacuum, etc. The logical tests of the value of any scientific theory always imply that that alone can be real which is coherent, which forms part of an intelligible system. To say that thinking is the test of reality may seem to open up the way to the most mischievous and unscientific delusions of metaphysics: metaphysicians being supposed to be persons who evolve the world out of their inner consciousness, instead of making their minds the 
passive mirrors of reality (whatever that may mean). But we are familiar with this test of reality in its negative form - the inconceivability of the opposite. This test has sometimes been discredited for two reasons :-

( I) Conceiving has been taken to mean representing in a mental image or picture, whereas it is only in the sense in which conceiving means thinking that inconceivability can be the test of truth. We are very apt to suppose we can or cannot think something, simply because we have not taken all the conditions into account. Thus, (I) when the infinity of time or space is discussed, our incapacity to form a mental picture of infinite time or space has been taken as if it were a consideration that weighed against our incapacity to think a limit in time or in space without contradiction. (2) People used to think the Antipodes inconceivable, because they thought of gravity as a force acting in the direction of an absolute down : that human beings, constituted in any such way that we could consider them human beings, should be able to walk on the lower side of the world meant, to the disbelievers in the Antipodes, the same sort of thing as if it were said that we here could walk like flies on the inside of the roof with our heads down. Change the meaning of gravitation, change the meaning of up and down, and it becomes inconceivable that a man walking in New Zealand should fall off into the air, since falling off would mean falling up, which is a contradiction. The obvious difficulty of applying the test safely comes simply 
from the difficulty of being sure that we have exhausted all the relevant conditions. And that is why we can only apply the test easily in very abstract matters, where we have purposely eliminated all except the very simplest conditions, e.g., in the mathematical sciences. In the case of more complex subjects the inconceivability of the opposite remains rather the ideal to which our knowledge approximates. The more thoroughly we understand anything, the more we see that it must be so and not otherwise. To the savage or the child anything may happen, anything may account for anything : to the scientific mind the world appears more and more as a necessary system of thought-relations, "a materialised logical process," as Professor Huxley has described the course of nature. ${ }^{1}$

But, I may be reminded, "a materialised logical process" implies a difference between thought and existence. "What things are," it will be said, "is one thing; what we may think about them is another, and so is what we may say about them. No one, at least no careful person, would confuse what we say about things with the real existence of them. Why should you confuse what we think about them with their real existence ?"

Now what zve, i.e., any particular "we," may happen to think about them is certainly not their reality. Their reality is what we ought to think about them and would think about them if we knew them completely. That is a big "if" ; for to know"

1 See Note at the end of this essay on "Logical Necessity." 
any one thing, the "flower in the crannied wall," or even a mere atom completely, would be to know everything. And, if we think out the conception of omniscience, we shall find that it is identical with omnipotence. In theological language, the will of God cannot be separated from the intellect of God without making God cease to be God and become a finite, imperfect being with things to be learned and ends to be attained outside his own nature. The thoughts of God are the ultimate nature of things, as Kepler recognised when he said he was "thinking the thoughts of God after him." The identity of thought and being does not imply the identity of any particular thought with any particular thing (e.g., that my idea of one hundred dollars is one hundred dollars) but that the ultimate reality of things is only to be found in thought. Even the reality of the hundred dollars consists not in their being merely space-occupying things, but in their meaning, their significance for the thought of more than one human being ; i.e., their reality is their ideality.

I think I hardly need recur to the suggestion that reality must be what is in space; for that would make our feelings unreal. Nevertheless reality, to beings constituted as we are, must appear spread out in space and in time. Yet the very fact that we know space as space and time as time, i.e., that we recognise the outside-one-another of things and the after-one-another of events, proves that in some sense or other (whether we can explain it or not) we are not in space and time. Space and time exist 
for thought as forms in which we must perceive things. But if we ascribe to them an absolute existence, independent of any one's thought, we are speaking about what we cannot possibly know. Because if we did know them as absolutely existing, they would no longer exist absolutely. Thought cannot grasp anything outside itself, "outside thought " being simply a metaphorical way of saying "not thought about at all." My thought is, of course, incomplete; coming to know more of reality means that our thought comes to be more coherent, that it comes to itself.

Ordinary language does indeed always suggest a dualism of thought and things. Knowing is distinguished from the known. And the distinction is necessary for our ordinary thinking, which is picturethinking, and takes different aspects as if they were separable in fact. ${ }^{1}$ But any philosophical theory of dualism raises more difficulties than it solves. If thought and reality are ultimately separated, then we have to face the question how they can be combined. How can we ever know anything, if thought and reality are ultimately distinct from one another? Scepticism is the logical outcome of dualism, as the history of philosophy has sufficiently proved.

Is it necessary nowadays to discuss the idea of

1 The acceptance of the antithesis between thought and being, as a permanent antithesis for philosophy (however convenient and necessary in psychology and in ordinary language) seems to me just one of those "abstract accounts" or "reductions to simpler categories" against which Prof. Seth so strongly protests (Hegelianism and Personality, p. 93, in edit. 2). 
material substance as something existing apart from and independently of thinking? Matter either means (I) sensations and mental images referred in thought to past or future sensations-and this is what matter means to the ordinary person-or (2) it means the metaphysical hypothesis of an unknown and unknowable matter-in-itself. But if matter means sensations, present, past, and future, it can have no real existence except for a thinking being which can relate these sensations and images to one another. As already said, if sensation means anything more than a psychical event, it implies judgment; i.e., an act of thought. On the other hand, to attempt to think an unknown and unknowable material substance is to try to get outside thought, which is as impossible as to get outside one's skin and yet remain alive.

It might be said, however, that the element of matter in things is the as yet unknown element. This, I suppose, is the Aristotelian view. But can we then say that matter is the real? If we did, we should be left with this difficulty, that as knowledge grows, reality diminishes - a position which the plain man would hardly be inclined to take up. If the reality of things be not their intelligibility, but just that element in them which cannot be known and cannot be expressed, should we not go on, in the fashion of Gorgias, to argue that nothing exists, that reality is that which is not?

The sciences ultimately refuse to recognise dualism. The world is only intelligible by science on the 
assumption that it forms one coherent system. A philosophy based on the special sciences cannot recognise anything outside the material universe. But then an examination of the nature of science (a criticism of the conditions of knowledge) shows us that the material universe can mean nothing except for thought. ${ }^{1}$ Science leads us to Monism; and Monism, to be philosophic, must be idealistic.

When all this is said, the feeling somehow comes up that there must be some confusion between things and thoughts, between fact and theory. This feeling I believe to be entirely due to fallacies of language, to the habit of picture-thinking and to the influence of old philosophical theories. What are facts (to put the question about reality in a different form)? Facts are theories. Is sunrise a fact? It is a theory, now discarded, to explain some of our sensations. The reality, we know, is not sunrise but the rotation of the earth: and yet we are in the habit of speaking as if sunrise were the reality and the rotation of the earth the theory. But if we think the matter out, we see that the reality, by which we explain, to which we refer, our sensations, is an object of thought and not of sensation at all. And I have already shown that objectivity means coherence of my thinking with that of others.

IV. One sense of the term real need not detain us

1 The two views are not parallels standing on the same plane; because materialism logically presupposes idealism. The distinction between thought and matter falls within thought, as will be pointed out later. 
long-the sense in which we speak of " a real circle," meaning a perfect circle. In this sense "the real" is confessedly " the ideal." We call a figure of wood or stone or iron a circle only in so far as we can think it under the form of a perfect circle; we admit that the material figure existing in actual space is not the real circle.

V. Connected with this use of reality, is that in which real is used in a moral sense, the sense in which it is held that "The Real is the Rational." People have scoffed at this utterance of Hegel's ; but it expresses a truth constantly recognised in practical life-a truth which people ignore at their hazard. The real is distinguished from the sham. We go behind the phenomenal existence of institutions to examine their ethical content, and we pronounce them real or unreal. Now this sense fits in with the main sense of reality as the coherent and intelligible, except that we bring in a moral standard of value, so that what is real, in the sense of not being imaginary, may yet be unreal, in the sense of being absurd or mischievous. The precise relationship between reality in this sense of rationality, and reality in the general sense of intelligibility, is the initial question of the science of ethics : what is the relation between being and well-being? Does well-being differ from being except in having respect to more permanence and to a more complex system of relations? These are questions I need not discuss at length now. Enough, if it is clear that the real in the sense in which it is said to be the rational, is at least a further 
carrying out the principle that the real is the intelligible.

The real as the rational differs from the merely existent (the objectively real-the second sense noted) just as definite species in plants or animals differ from "sports" and from "survivals." If a variation proves advantageous, it gives rise to a new species : when a survival comes to be distinctly disadvantageous, the individuals in which it exists tend to disappear. The distinction between simple objective reality and reality as rationality thus corresponds to the distinction between simple causality and teleology. In the purely physical sense the real is what can be thought of and must be thought of in the causally connected system which we call the nature of things. In the moral sense the real is what can be and must be thought of as serving an end, as having a value.

This moral sense of reality is extremely common in ordinary language. "Real jam" (to quote a vulgar expression) is the genuine article with no humbug about it. Now when the Realist Philosopher insists that an atom is more real than a thought, the vulgar are deceived; for they fancy that this means that an atom is more important than a thought, whereas all that it means is that an atom occupies space, while a thought does not. A thought, even a foolish thought, belongs to a higher type of existence than an atom.

Yes, it will be said, but does not such a phrase admit that existence is wider than thought, if thought 
is only some particular kind of existence? This merely quantitative way of stating the problem might well be objected to. But passing that over, let us admit that, from the point of view of the physicist, if . the ultimate physical reality of material things were to be found in atoms, then it would be true that there could be no thought without atoms; so that thought would be resolved into atoms as the ultimate reality. That would be true, from the point of view of the physicist ; but philosophy is the endeavour to speak not merely the truth, but the whole truth. And so we have to go further and ask what an atom would be except for thought? Will any Realist undertake to tell us what an atom is, unless it is either a way of thinking which we find convenient in trying to think out the nature of things, or an unknown and unknowable which he can neither think nor express? ${ }^{1}$

That within reality we can make a distinction between greater and less reality may be used as an argument to prove that the universe contains an element which cannot be rational: in other words that Thought finds itself confronted by an irrational

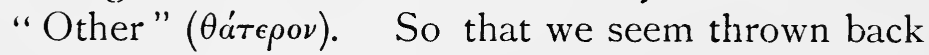

1 Cf. Prof. K. Pearson's Grammar of Science, pp. 210, 21 5 , where it is said that an atom is a conception, a mode by the aid of which the scientist resumes the world of sense. Prof. Pearson's plentiful abuse of metaphysicians may commend his (unacknowledged) Neo-Kantianism to scientific readers : I call it Neo-Kantianism, because it is a sort of Kantianism minus "things-in-themselves." By "Grammar of Science" Prof. Pearson evidently means a criticism of scientific categories. 
on the Platonic dualism. And, if this argument be combined with the feeling which lurks even in the mind of the convinced idealist - that thought and things are not ultimately identical-does not this dualism seem to have good grounds?

It must be admitted that, unless thought had an other over against it, we never could call anything in our experience imperfect or evil-nay more, we could have no knowledge of the kind we now have. The problem of knowledge seems to leave us with this dilemma:--If thought has ultimately an alien something to confront it, there can be knowledge; but if thought merely thinks itself, there can be no knowledge. Of this dilemma I can see only one solution-and it is one which I know many persons will consider nonsensical-the metaphysical hypothesis that thought makes its own other, i.e., that the distinction falls within the identity. I have called this a metaphysical hypothesis, but I believe it to be much more, and to be the ultimate fact to which every avenue in philosophy leads. In Logic, abstract identity brings us to a deadlock : so would abstract difference. Identity cannot exclude difference nor difference identity. In the evolution of the physical universe, the rationality of the process can only be manifested in the chaotic multiplicity and variability of nature. We cannot know anything except by thought getting its material from sensation and feeling. Good has no meaning to us save in reference to imperfection and evil. But all these distinctions fall within thought-in its widest sense. In theo- 
logical language, God is both transcendent and immanent : nothing in the world is outside God and yet God is not simply the sum of particular existences. This idea of Thought realising itself in nature, its own "other," in order to return into itself, seems the only way out of the difficulties of the philosophical problems. If it is asked "Why should the Absolute be this self-differentiating unity?" 1 I cannot answer that question, because to explain the whole universe would mean that one could get outside the whole universe, which is impossible and absurd.

I come now to what may be thought the most formidable objection of all, though an answer to it seems to me to be contained in what has just been said. As all thought has to work with universals, thought, it is urged, never can be adequate to the fulness of Reality. "The individual alone is the real." ${ }^{2}$

Very good; but what is the individual? In what sense are we to take this old Nominalist objection?

(I) Is everything to be called an individual that can be thought of, or spoken of, as "one?" I have heard of a preacher who wished to prove that all nature testified to Unity-a very good thesis-but he tried to get at his conclusion by a short cut.

1 I do not say "Why should the Absolute differentiate itself ?" because that might imply that the Absolute could be a unity without difference.

2 Cp. Prof. Seth, Hegelianism and Personality, p. I 28 [in ed. 2, p. 135$]$. 
"There is one sun, there is one moon, there is one great multitude of stars." The one great multitude of stars, nay, even our one solar system, is only one in the same sense that humanity is one, or a nation is one (though a nation or a solar system is one in a much fuller sense than a mere multitude is). If the individual is identical with the real, it must follow either that the great multitude of stars is an individual or that it is not real. I suppose it would be answered "The individual star is real ; the collective unity is merely a creation of our thought."

(2) Well, then, is the individual whatever can be expressed by a single term? Popular belief, would, I fancy, consider a noun substantive to express greater reality than an adjective, because the real is thought of as substance rather than as attribute. But, if the real is the individual, we are limited to singular terms-not the horse, but this horse. But if this horse be allowed to be an individual, what is to be said of this lump of clay? Is that more an individual than this great multitude of stars? Are we not falling a prey to the popular habit of speaking of every thing as if it were an ultimate reality incapable of analysis? What is any individual thing except a meeting point of universal attributes? Qualities are all universals : are we then to say that they are not real? This would be in strange conflict with what the plain man believes. If the redness and the heaviness and the stickiness of the lump of clay are put aside as being only universals, what remains except that metaphysical phantom of

D. $\mathrm{H}$. 
the thing-in-itself? Even if we deal with the organic, the individual organism for science and for ordinary belief is an individual only from some points of view ; it is a collection of units from other points of view. This horse is an individual ; but so is this hair out of this horse's tail. So is every cell of which its body is composed. If we take " individual" strictly we must get back to atoms. But the qualities of the atoms, if they have any, must be universals. If they have no qualities, not even impenetrability nor indivisibility, are they even atoms? Are they not fictions of our minds-convenient or otherwise?

(3) It might be answered that qualities are real, but only as individual sensations. I have already shown that the individual sensation is not at all what the plain man understands by reality. The individual sensation is an abstraction, a metaphysical phantom, except as my sensation or your sensation, and except as discriminated from other sensations, i.e. except as interpreted by thought. The feeling of the moment is real only in that sense of the term which is least familiar to the unsophisticated mind.

(4) Well, then, is the individual the conscious self which has sensations? Are the ultimate "reals" monads or spiritual atoms? This is a possible metaphysical speculation, and by the help of it a very pretty picture of the universe may be made, a sort of glorified or " animated" atomism. ${ }^{1}$ But is

${ }^{1}$ For an excellent example of such a speculation see Riddles of 
it not a speculation which results simply from taking literally the popular Vorstellung of independent individual persons, while discarding the popular Vorstellung of independent individual things? Berkeley applied analysis to material substances and resolved them into "ideas" (i.e., sensations plus images of sensations); and yet he left a world of individual spiritual substances existing alongside of one another. Hume applied to mind the same analysis which Berkeley had applied to matter, and resolved mind into its component parts also. If by the "self" we mean the person who is born, grows up, dies-the concrete phenomenal ego-what the ordinary man would call the "real person"-is this strictly individual? In the waste and restoration of the bodily tissues there is a constant transition between the organism and the environment: and the same holds with respect to the mind or spirit. So much is inherited, i.e., represents a mere part of a continuous stream; so much is constantly being acquired from the physical and social environment. Self-identity is not an immediate datum of consciousness : it is a matter of inference. I think of myself as the permanent substance of which particular actions, feelings, etc., are predicable. But the real self is not a bare unity: the real human individual

the Sphinx, by "A Troglodyte." (Published by Sonnenschein, London, I89r.) To this work, as well as to that of Prof. Seth, just quoted, I may refer the reader who cares to know what objections to Idealism I had specially before my mind in writing this paper. 
is his ancestry and his age epitomised. What we call "originality" is a new combination of elements already there. If there is any difference between a person and a thing in respect of individuality, it is a difference in degree only and not in kind. Spiritual substance, like material substance, is either simply a meeting point of universal qualities or a metaphysical phantom ${ }^{1}$-like the geometrical ab-

1 Prof. Seth in a note in the 2 nd edition of his Hegelianism and Personality, p. I 36 , objects to this statement that it would imply that my own existence, for myself, "is no more than a cluster of abstractions." By no means: my existence "for myself" is not that of a spiritual substance but of a conscious subject (as recognised throughout this paper.) The real self, the self which feels and knows, in distinction from the self we talk about as an object, cannot correctly be represented as a substance or thing. Prof. Seth, in another note added to his 2 nd edition (p. 23I), clearly disclaims the metaphysical theory of "isolated self-existent reals." "Each finite individual," he says, " has its place within the one real universe, or the one real Being, with all the parts of which it is inseparably connected. But the universe is itself an individual or real whole, containing all its parts within itself and not a universal of the logical order containing its exemplifications under it." Now this is practically identical with what I say in the next paragraph about the ultimate real individual which=the universe. I am glad to see that, after all, I am on the same side with Prof. Seth as against "the realist." If p. 64 of Prof. Seth's ist edition be compared with the corresponding p. 69 of the 2 nd, a very considerable modification in expression will be observed. Instead of speaking of separate individuals as being "absolutely and for ever exclusive," he now writes "whatever may be the mode of their comprehension within the all-containing bounds of the Divine life, it is certain that, as selves, it is of their very essence to be relatively independent and mutually exclusive centres of existence." With the revised version of this passage I am delighted to find myself in agreement. 
straction of a point treated as if it were a real thing. "But," it will be said, "there is the difference of consciousness." Well, if by reality be meant consciousness, an idealist is not likely to quarrel with the statement. But then, I suspect, the realist means by consciousness simply an attribute of a substance : he has got his Vorstellung of spiritual substance in the background.

(5) If, however, the self be taken to mean, not an object existing among other objects, but the subject logically implied in all knowledge, the "Transcendental Ego" which we never can know as an object, and which therefore we never can "get behind," that may be allowed to be the ultimate reality. But that is individual only in the sense in which the unity of the cosmos is individual : and that, I fancy, is hardly what the realist means to mean. "Nothing in the world is single"except the whole world itself : and that is not "in" the world.

We often hear it argued "thought implies a thinker." True, but a thinker is not necessarily a thinking substance : a thinker is a thinking subject. All that is immediately given in consciousness is the mere $E_{g o}$, the mere self-ness, a unique and individual appearance in the moment of feeling or thinking or willing. ${ }^{1} \quad$ As already said, a feeling is only real, in the lowest sense of reality, as $m y$

1 In the act of judgment, involved in all perception, I compare and put together the experiences of different times, but only as present noze to my consciousness. 
feeling, a thought as my thought. This absolute subjectivity is the ultimate reality: we never can get behind it. That other persons are, each of them, subjects in the same way we know only by inference. That the "I" is the same in different moments of our own experience we know only by inference. It is an inference also, that the transcendental Ego is identical in any way with the phenomenal Ego (what we call our " real self," though it is not the self that knowes, but the self as object). The mode of that identity is a matter of speculative hypothesis, as is also the question whether or in what way it is the same or different in different persons. "I" is experienced directly; or rather it is "I" alone that experiences. "You" is a matter of inference. The relation of "I " to "you," "they," etc., is a matter of hypothesis.

An analysis of the nature of the logical judgment gives the same result. The subject of every logical judgment is ultimately "I." "I am such that $A$ is $B$." " I experience (I feel or I think) $A B$." Recent writers on logic generally lay down that "Reality" is the ultimate subject. "Reality is that which . . . ," or "Reality is such that . . ." This comes to the same thing. The only fault I can find with the latter formula for the ultimate logical judgment, is that reality is a notion capable of farther analysis, whereas the mere "I" is not. Whether we say that judgment always contains a reference to and implies "Reality" or "the unity of the cosmos" or "I" is a matter of indifference to the science of 
logic. The last term seems to me preferable philosophically, simply because then the judgment is expressed in a way that corresponds most exactly to our actual experience. Thus, if we examine judgment in its simplest form, where it is just becoming differentiated from mere inarticulate cries, we find a predicate such as " hot," " hungry," " happy," "sore," "[it] hurts." Now the subject of these predicates, the $x$ which may be expressed in our language by the impersonal pronoun, but which in many languages is not expressed at all, may be described as being either "the nature of things" or "I," but "I" seems to me nearer the exact truth of experience.

We may picture the universe as a multitude of centres of circles, recognising that every one is the centre of his own universe-just as each of us sees a different rainbow ; but such a picture is the result of inference and hypothesis. In strict truth (and that is what Philosophy is concerned with) we never get outside one circle, nor away from one centre. I may admit the truth of judgments about other persons and other things, when stated without any reference to my consciousness ; but strictly speaking they are only true to me (and that is what I mean by truth) when this reference is introduced.

The distinction, noticed at the beginning of this essay, between subjective and objective reality is a distinction which falls within what one may call the absolute subjectivity (or the essential relativitythey mean the same thing) of all reality. When we 
distinguish the particular self, the self with a history in time, from the not-self generally and from other selves, then we distinguish between the subjective and the objective. But this particular self is, as I have shown, not an individual incapable of further analysis, but like other things it is a unity of the manifold, an identity with differences in it. The ultimate subject of knowing, the ultimate reality, is incapable of further analysis, in the sense that we cannot get behind or round it: we cannot know it as an object like other objects. But on the other hand it only becomes properly "real," knowledge only passes from mere possibility into actuality, by the recognition of differences, of a manifold, within consciousness.

When the "I" is treated psychologically, it is made into an object. We are not any longer dealing with the strict truth or genuine reality of it ; we are dealwith an abstracted material as in all the other special sciences. Philosophy must take account of the fact that everything we can know is within the "I." The knowledge of reality is thus the "I " coming to know itself, i.e., its content. "God" must be thought of as the "I" completely actualised, the absolute "subject-object." We are aware that we never can know anything fully. The "I" is always striving for a more complete realisation, seeking to become "real," in the moral sense, i.e., to be more adequate to what it professes to be.

Except as to this ultimate question we need have no quarrel with the realist, and are quite as ready to 
talk of "thought conforming to reality" as we are to talk of sunrise and sunset, although in both cases we have accepted the "Copernican" theory. We might even get at the same ultimate result, although we accepted provisionally the point of view of ordinary language and of the special sciences. If we abstract from the mode in which alone we can know the world, we may talk of phenomena as having behind them a thing-in-itself, and we may call that the ultimate reality. The tendency of modern science is to regard all the various phenomena of nature as different manifestations of one " Energy." Consciousness or thought is then simply the highest form of energy which we know. (Will itself is not the highest form: for rational volition implies thought.) If we call energy (or material substance or anything else) the potentiality of which thought is the realisation, and if we take these notions of potentiality and realisation quite seriously, we are arriving from a starting point of " dogmatic materialism" at the same result as if we started with a philosophical theory of knowledge: the ultimate reality is thought. But unfortunately the uncritical metaphysics of the ordinary and of the scientific understanding does not generally take the notion of potentiality quite seriously. Hence it is necessary to follow the longer route of philosophical criticism. ${ }^{1}$

1 Criticisms on this paper by Mr. F. C. S. Schiller, a reply by myself and a rejoinder by Mr. Schiller will be found in the Philosophical Reviere, Vol. I., No. 5, and Vol. II., No. 2. Save for two slight explanatory phrases, which I have inserted to meet some 


\section{NOTE ON LOGICAL NECESSITY.}

When John Stuart Mill maintains that there is no necessity except the necessity of logical inference, ${ }^{1}$ he seems to me to maintain what is perfectly true, although he does not recognise the full implication of what he has said, and although he has himself, in his theory of inference, eliminated the very element of necessity which he here seems to assert.

(I) Physical necessity, or the necessity of the causal nexus (If $A$ happens, $B$ must happen) is simply equivalent to a necessity of inference from $A$ to $B$. The supposition of a force or power in $A$ to move $B$-the view of causality against which Hume and Mill rightly protest-is a survival of primitive animism, We fill up the content or connotation of cause ex analogia hominis. We think of one billiard ball giving the other a shove, etc. In scientific thought and speech, we only assert that $A$ and $B$ are so related within the system of nature that from $A$ we can certainly infer $B$. There is no absolute gap between "reasons" in geometry and causes in physics [cf. p. I 53, note].

(2) What then of axioms? Their necessity is not any mere psychological readiness to believe them (the theory which Mill supposes to be the a priori theory he has to overthrow); their necessity consists in their being logically involved in the possibility of any science whatever. They are proved per impossible (Kant's "transcendental" proof

objections of my critics, I leave the paper (apart from purely verbal corrections) as originally printed, as I do not yet feel driven to desert the position adopted in it. I could not attempt to deal with all objections, without making it unduly lengthy.

${ }^{1}$ Cf. Logic, Book II. ch. v. $\S$ i. Edit. 8, Vol. I. p. 262 : "The only sense in which necessity can be ascribed to the conclusion of any scientific investigation, is that of legitimately following from some assumption, which, by the conditions of the inquiry, is not to be questioned." 
-a most unhappy adjective). Logical necessity is the necessity of consistency, of coherence in thought. Consistency is, as I have said, our negative test of reality. Complete consistency (to us a mere ideal) would be a positive test. To say that through natural selection our minds have become such that they require to believe in the uniformity of nature, is to give what seems the most probable historical account of the development of human thought; but it is no logical solution of the question about the ultimate relation of thought to reality, it only restates the fact that Nature, in the only sense which it can have for the scientific man, is a rational system, whose "laws" are the logical necessities of our thought. If we ask why this should be so, there is first of all, an answer with which some persons profess to be satisfied: The necessity, it is held, is merely subjective ; what "nature" really is, we do not know. Observe, it is generally assumed, that we know somchow (but how ?) that there is a reality "behind" the phenomena-a survival from old metaphysics in the minds of those who boast that they are not metaphysicians. It seems to me an odd use of the word "real" to make it mean what stands in no relation to our lives. Secondly, dissatisfied with this "positivism" or subjective idealism, with or without a hypothetical "realism" in the background, we may be content to fall back upon the dualism of popular language, and assume a "parallelism" between our thought and the nature of things. But the demands of philosophical criticism will hardly allow us to rest satisfied with this metaphor of parallelism, which easily leads us back into the other metaphors of mirrors, waxen tablets, etc. Knowledge is not possible, if thought and things confront each other as alien substances. Is it not the better hypothesis (not to call it anything more) that our thought is in some way identical with the reason in things? Logical necessity is the necessity, not merely of this or that individual mind, nor of a sum of individual minds, but of thought as such, and therefore of the universe. 
(3) In regard to human actions, Mill shows quite well (Logic, Book VI. ch. ii.) that the necessity presupposed by any science such as psychology or sociology, is, as with physical phenomena, simply necessity of inference. On the other hand, moral necessity (if the phrase be used for a moral precept, "You must, i.e., ought to, do so and so") is a totally different thing. A political or moral law is the statement of an ideal ; it puts forward one motive for conduct among other motives. It is through association with this sense of "must" (implying a command with threats of penalties) that our understanding of physical necessity is apt to be vitiated (see below, pp. I74-177). 


\section{IV. \\ ON PLATO'S PHAEDO. ${ }^{1}$}

I.

BEFORE we can answer the questions: "What are Plato's arguments about the soul's nature and destiny?" "What is their relation to one another?" "What is their value?" we are obliged to consider how far the expressions used by him are to be understood literally.

Plato's visions of another world have fixed themselves indelibly in the common consciousness of Western civilisation. We hardly know, without the most careful examination, how many of those beliefs that are often spoken of as if they were peculiar to Christianity, are due directly or indirectly to Platonic influence. Thus, even if it should be the case that the mythical element in Plato is (as $\mathrm{Hegel}^{2}$ holds) quite unessential in his philosophy, or (as Teichmüller ${ }^{3}$ holds) not believed in at all by Plato him-

1 Read before the Aristotelian Society (London) on Nov. 30, I885, and published in Mind, Vol. XI., No. 43.

2 Geschichte der Phil., ii. 207 ff.

3 Studien zur Gesch. der Begriffe and Ueber die Unsterblichkeit der Seele. Some criticisms of the late Prof. Teichmüller's on this paper of mine will be found in his Religionsphilosophie (Breslau, 
self, this mythical element would still deserve the attention of all students of human thought, both as taking up previous Pythagorean, Orphic, probably Egyptian and perhaps Indian ideas, and as influencing all the Hellenic and Roman world, i.e., what we commonly call the whole world. And, in any case, the mythical form of expression must throw some light on Plato's habitual manner of thinking; for we cannot abstractly separate form and content, expression and thought.

Let us take the three characteristic Platonic " doctrines" of Recollection, Pre-existence and Transmigration, and endeavour to discover in what sense they are to be understood.

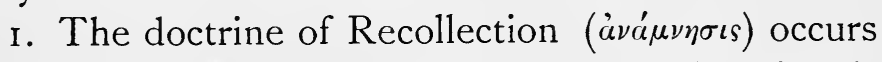
both in the Meno and the Phado. "Knowing is remembering." This theory seemed to obviate the Sophistic puzzle about the impossibility of learning : -We either learn what we already know or what we don't know : in the first case we don't learn; in the second case, we can't (cf. Meno, 8o E). This is just one of those instances where the Aristotelian distinction of potentiality and actuality comes at

I886), p. 502. Prof. Vera in his monograph entitled Platone e ''immortalità dell anima (Naples, I88I), to which Dr. J. Hutchison Stirling kindly directed my attention, maintains a theory very much like Teichmüller's, except that he would treat Plato's "myths" as approximations, "serious jests"-the world itself being such. "Il giuoco è l'involucro, la parvenza dell' idea, cioè la poesia." But, as he says philosophy is essentially "esoteric," his general attitude to Plato comes to be the same as that of Teichmüller. 
once to our help, We learn what we are capable of knowing: we cannot learn what is quite alien to us. But the knowledge, which in some form is there already, is there only virtually, and requires the effort of what we call learning to become actual, to be realised, to become what we can properly call knowledge. Plato in the Theatetus (which in many respects may be called the most "modern" of all his dialogues, for in it he discusses, not the usual ancient question of Being, but the modern question of Knowing) does arrive at this Aristotelian distinction in his recognition of the difference between "possessing" and "having or holding," illustrating it by the birds in a cage (Theat., I 97) ; but it remained for Aristotle to grasp the full significance of this distinction, which has become so much a commonplace of our language and our thought that it requires an effort to see its importance and to understand how the problems of knowledge presented themselves before the time of Aristotle. Now, this is just the philosophic truth of Plato's theory of Recollection: in learning the mind is not filled with something alien to it,- - as popular language, now as then, is inclined to assume, and as even some philosophers have been apt to suppose, e.g., when they ask how Mind can know Matter, after defining Matter in such a way that it is of its very essence, as the exact antithesis of Mind, that it cannot be known. According to Plato, in learning the soul recovers its own. This is more than a theory of knowledge merely. In the Phadrus it becomes a theory of art and morality as well. The 
ideal of beauty, the ideal of goodness, is figured as something we have once known and have to regain. And are we not all ready to speak and think in this way? What is the meaning of the phrase "Natural Rights," which popular politicians have not yet given up, and which even Mr. Herbert Spencer defends against Bentham and Mr. Matthew Arnold? We have come to form an ideal of society, and we speak as if that were a state from which we had fallen away. We transfer the "ought to be" to "once upon a time"- -a golden age, "a past that never was a present," The same tendency of imagination may be found in the treatment of the term "a priori." A priori conceptions, in Kant's use of the term, are those which are necessarily implied or presupposed in knowledge. How often is the Kantian theory of knowledge criticised as if Kant had meant that the infant comes into the world with a ready-made logic? We become explicitly conscious of the necessary conditions of our thinking very late, if at all ; but the conditions are there implicitly all the same. In the word "presupposed" there again slips in the suggestion of priority in time.

The doctrine of Recollection has been made most familiar to us by Wordsworth's Ode. But this, we may well say with J. S. Mill (though I know not whether in his sense), is "falsely called Platonic." Wordsworth makes life a gradual decline: Plato makes it a progress. To Wordsworth it is a forgetting : to Plato a remembering. In Wordsworth the child is nearer heaven than the full-grown man : 
in Plato the full-grown man, if he has used his time well, has regained much of what he lost by birth. ${ }^{1}$ Wordsworth's beautiful fancy owes more to the sentimentalism of Rousseau than to Plato's idealism.

How far was Plato conscious that his doctrine of Recollection was only a Vorstellung representing a Begriff, an expression in terms of a history in time of what is really a logical development? The theory of Education in the Republic seems to supply an answer. It is sometimes said that in the Republic Plato applies the theory of ideas at which he was arriving in the Meno, but that he has given up the doctrine of Recollection at least as an essential part of his theory of knowledge (though it is alluded to in the "myth" at the end, 62 I A). Now I shall assume as a canon of interpretation in the case of Plato, as of any other philosopher, that we must start with the supposition that his thinking is coherent, and that we must begin by looking for agreement rather than for disagreement. On the other hand, we cannot put the canon in the form in which Prof. Teichmüller and Mr. Archer-Hind put it-" That any interpretation of Plato which attributes inconsistency to him stands self-condemned." ${ }^{2}$ Consistency is a very poor virtue to ascribe to Plato:

1 This has been pointed out by Mr. Archer-Hind in his edition of the Phado, p. 85 .

2 Edition of the Phado, p. 24. Mr. Archer-Hind cannot mean this to be taken too literally, because he certainly admits a development in Platonic doctrine.

D. $\mathrm{H}$. 
it would imply that his system sprang ready-made from his head and that it admitted of no growth-a view seriously maintained by Schleiermacher, who regards the order (i.e., the order which he conjecturally prefers) of the dialogues as representing an order adopted for purposes of exposition and not an order of development in the writer's mind. When, therefore, in the Republic, we find Education described as "the turning round of the eye of the soul to behold the truth," ${ }^{1}$ it seems reasonable to identify this with the theory of Recollection divested of its mythical setting: but we are not therefore justified in arguing that this mythical setting never had any real significance for Plato himself.

2. If the doctrine of Recollection be merely a figurative way of expressing the logical nature of knowledge, what becomes of the Pre-existence of the Soul about which so much is said, not only in the Meno, Phado and Phadrus, but in the end of the Republic itself? The pre-existence of the soul is "proved" in the Phado sooner and more easily than

1 Rep., vii. 5 I 8 B, C. "Certain professors of education must be mistaken in saying that they can put a knowledge into the soul which was not there before, like sight into blind eyes. . . .

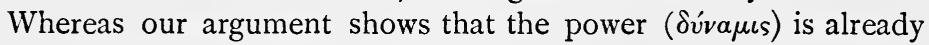
in the soul; and that as the eye may be imagined unable to turn from darkness to light without the whole body, so too, when the eye of the soul is turned round, the whole soul must be turned round from the world of becoming into that of being, and learn by degrees to endure the sight of being and of the brightest and best of being, or, in other words, of the Good." (Jowett's Translation, according to which most of the other quotations in this paper are given.) 
its existence after death; and all the arguments in the Phado, as well as the argument in the Phce$d r u s$, prove existence after death only in such a way that existence before birth is necessarily implied also. This is not the case with the argument in the Republic, although the "Vision of Er" introduces pre-existence as much as do the Apocalypses of the Phado and Phadrus. Mr. Archer-Hind goes so far as to say: "It is in fact impossible to bring forward any sound arguments for the future existence of the soul which do not also involve its previous existence, its everlasting duration. The creational theory is matter of dogmatic assertion, not of philosophical discussion " (p. 19). The idea of pre-existence was rejected by most Christian theologians, because it seemed inconsistent with the creation of the human soul by God. (It was accepted by Origen; but then Origen was not accepted by the Church.) Quite consistently, the idea of a necessary immortality of the soul was rejected by most of the early Christian theologians. It is only later theology that has fallen back on the metaphysical doctrine of immortality.

As we have obviously, in the ordinary sense of the term, no recollection of having existed before our birth, it might be argued that, since Plato puts the existence of the soul after death on the same level with its existence before birth, either (I) he did not seriously hold the immortality of the soul at all, or (2) the immortality in which he believed was not what people ordinarily mean, or think they mean, by 
immortality, since it does not imply consciousness and memory ; Plato, it might be said, maintains an individual but not a personal immortality, i.e., the individual soul remains permanently self-identical, but consciousness and memory pass away at death. ${ }^{1}$ It is somewhat strange that Plato should have made no reference to this very obvious objection, that if after death we are as little conscious of an identity with our present selves as we are now of any identity with a self before our birth, the immortality of the soul cannot matter to us. As Hume says : "The soul if immortal existed before birth: and if the former existence noways concerned us, neither will the latter" (Essay "On the Immortality of the Soul"). Yet the objection evidently was made in ancient times, ${ }^{2}$ because there is an attempted answer in a fragment of Aristotle's lost dialogue Eudemus, preserved to us by Proclus: "Aristotle," says Proclus, "tells us the reason why the soul coming hither from the other world forgets what she there has seen, but going hence remembers her experience here. Some who journey from health to sickness forget even their letters, but this happens to no one who passes

1 In this sense of the terms Teichmüller (Unsterblichkeit der Seele, pp. 147-149) maintains that individual immortality can be apodeictically proved, but that personal immortality cannot be apodeictically proved or disproved. He holds, however, as we shall see, that Plato's idealism prevents him maintaining even individual immortality.

${ }^{2}$ It is to be found in Athenæus, Deipnosophistae, xi. II 7 (507 e, f). Cf. Lucretius, III. 830-869. But the fragment of Aristotle, if genuine, is the earliest evidence of this objection. 
from sickness to health. Now the life without the body, being the natural life of the soul, is like health, the life in the body like disease. Whence it is that they who come from the other world forget what is there, but they who go thither remember what they experiencd here" (Arist., I 480 b. 5, Fr. 35, Edit. Berol.). We cannot say how far Aristotle, when he wrote the Eudemus, may have seriously or halfseriously meant what he said. We cannot certainly decide whether in his opinions about the soul he passed through an early "Platonic" stage (as Zeller thinks, Arist., p. 602), or whether he was writing a Platonic dialogue more or less as a literary exercise, or whether the dialogues, being (as Bernays thinks) merely "exoteric discourses," must not be taken as evidence of Aristotle's genuine philosophical views. We know of course from the De Anima that Aristotle held no doctrine of either individual or personal immortality. But the passage quoted by Proclus may be taken as representing the answers which would have been made in a Platonic dialogue to an objector. It certainly agrees perfectly with the position of the Phado, according to which this life is a temporary imprisonment of the soul.

3. The idea of Metempsychosis or Transmigration has been more widely held than any other view about the destiny of the soul, and has even in modern times been regarded as that most capable of philosophical defence. Thus Hume says, in the Essay I have already quoted: "The Metempsychosis is the only system of this kind that Philosophy can hearken to." 
Hume may be writing ironically, maintaining the doctrine least acceptable to his enemies, the theologians, to be the most plausible. But no such suspicion attaches to the famous passage in which Lessing at the close of his Erziehung des Menschengeschlechtes (\$\$93-100) says: "Why may not each individual man have been more than once present in this world? Is this hypothesis so ridiculous because it is the oldest? . . . It is well that I forget that I have already been here. The recollection of my previous condition would only let me make a bad use of my present. And what I must forget for the present, have I forgotten for ever? - . . Is not all eternity mine?"

Plato's accounts in his different dialogues are certainly not easy to reconcile with each other even in important points. Thus $(a)$ we may doubt how far, according to Plato, any human soul can ever exist without a body of some sort: perhaps the completely free existence is only an ideal, never quite attained, although approximated to by the philosopher. In the myth in the Phadrus (246 D) even the gods have a body. So in the Timceus the created gods are compounded of body and soul. In the Laws however (x. 899 A) the incorporeal existence of the soul (he is speaking especially of the soul of the gods) is put forward as an alternative. Again $(b)$ in the Timaus (4 I D, ff.) it is said that the soul is necessarily implanted in bodily forms: whereas in the Phadrus (248) the descent into a body is spoken of as resulting from forgetfulness 
and vice, i.e., as being a punishment for sin. This difficulty may be put aside: it is only one form of the contradiction between the conception of Necessity and Freedom which appears in all human thought, in all philosophies and in all theologies. Man falls by free-will, and yet the fall is regarded as necessary. (c) Zeller (Plato, Engl. Transl., p. $4 \mathrm{IO}, \mathrm{n} .55)$ has raised a difficulty about the migration of a human soul into lower animals. "How can man," he asks, "to whose nature the capability of forming concepts, according to Phadrus, 249 B, essentially belongs, become a beast?" To this it might quite well be answered, within the limits of the Transmigration-doctrine, that Plato means that because man knows by universals, his soul must once, i.e., when "in heaven," have seen them: a soul which to begin with was a beast's, and so only a beast's, could not rise to be a man's. A soul may sink from among the gods to man, and then to beast, and rise again to be with the gods, only because at first it was with the gods. The rest of Zeller's objections may be met in a similar way. Thus, when he asks how can the life of the beast serve to purify the soul, the answer would be found in the conception of expiation by suffering. When the soul came to choose again, it would have been taught the evil of the merely animal life. And even among beasts, as the Buddhists recognise, there are degrees of moral quality. Again Zeller asks: "Are the souls of the beasts (acc. to Tim., 90 E., ff.) all descended from former human souls and so all intelligent and im- 
mortal according to their original being, or (Phadr., 249 B) only some of them?" Plato might answer that all souls, which are now souls of beasts, may quite well once have been human. The passage in the Phadrus only implies that, if there were any soul of a beast that had never been human, it could never become human. Thus, though it may represent a different view from that of the Timaus, it is not necessarily inconsistent with it. But the want of formal consistency in the mythology may be taken as indicating, what Plato himself suggests at the beginning of the Timaus $(29 \mathrm{C})$, that it is not to be taken too literally. We have here only "probability," not truth.

The key to the interpretation of Plato's myths seems to be given us in the Republic ( $382 \mathrm{C}, \mathrm{D})$, where, after condemning altogether "the lie in the soul," i.e., ignorance, he allows that "the lie in words" may be used in two cases : (I) as a medicine (фа́рмакор) against enemies and to deceive men for their own good, as we do with sick persons and madmen; (2) as an approximation to the truth: where it is impossible to express the truth exactly, we may give something which, though false, resembles the truth as far as possible. Teichmuiller ${ }^{1}$ holds that the myths about the soul belong to the first class, like the myth of the earth-born men (Rep., 4I4 C ff.) which justifies the caste-system. The story of the earth-born men is obviously a dogma to be imposed authoritatively by the legis-

1 Studien zur Geschichte der Begriffe, p, I63. 
lator on the ignorant classes; but the accounts of the origin and destiny of the soul seem to me to be 'permissible lies' of the second kind, as is suggested by the passage just referred to in the Timceus and in the end of the Phado itself (I I4 D): "A man of sense ought not to say, nor will I be too confident, that the description which I have given of the soul and her mansions is exactly true. But I do say that, inasmuch as the soul is shown to be immortal, he may venture to think, not improperly or unworthily, that something of the kind is true. The venture is a glorious one, and he ought to comfort himself with words like these, which is the reason why I leigthen out the tale." There is certainly a passage in the Laws (959 A), to which Teichmüller refers, that seems to favour his view. With regard to the burial of the dead it is there written: "Now we must believe the legislator when he tells us that the soul is in all respects superior to the body, and that even in life that which makes each one of us to be what we are is only the soul; and that the body follows us about in the likeness of each of us, and, therefore, when we are dead, the bodies of the dead are rightly said to be our shades or images; for that the true and immortal being of each one of us, which is called the soul, goes on her way to other Gods, that before them she may give an account-an inspiring hope to the good, but very terrible to the bad, as the laws of our fathers tell us, which also say that not much can be done in the way of helping a man after he is dead. But the living-he should 
be helped by all his kindred, that while in life he may be the holiest and justest of men, and after death may have no great sins to be punished in the world below." This passage does seem to rest the doctrine about the soul merely on the authority of the legislator. But while Plato holds that for the mass of mankind, who have only "opinion" or "belief" on all matters, such authority is sufficient, surely he does not mean us to think that the Socrates of the Phado, who is dying as a condemned heretic, holds the doctrine of immortality only as something imposed by old tradition. If so, all the lengthy arguments would be very much out of place. Though, in the Laws, Plato puts the views about the future life as "a medicinal myth" for the multitude, they may still be "a myth of approximation" for the philosopher: a traditional belief may be the stammering expression of a true and vital idea. And in any case, the Laws cannot be taken as certain evidence of what Plato held when he wrote the Phado.

Let me assume, then, that what is said about the life before and after the present life is intended as an approximation to the truth. The difficulty remains to decide where myth ends and where logic begins. Critics have been too apt to suppose that Plato himself could always have drawn the line exactly. Our language and our thinking are conditioned by our ordinary experiences; and when we have to speak of that which belongs to the insensible, we find ourselves compelled, however much we try to avoid it, to use phraseology belonging properly only 
to the sensible. We have to talk of the mind, which we know not to be in space, as if it were in space and had parts and divisions ; and we have to apply to what our logic compels us to recognise as independent of time conceptions and images which have strictly no meaning except as applied to what Plato calls "the moving image of Eternity." In illustration one need only refer again to such phrases as " a priori," "presupposed," to see how we ourselves are obliged to use "the verbal lie." Philosophy cannot dispense with metaphor. But we should try to use our metaphors with as full a consciousness as possible. It is metaphors which escape notice that are dangerous. Besides being subject to this common necessity of human thought, Plato is essentially a poet ; and thus to him the language of myth is natural. His notions clothe themselves readily in sensuous imagery. And we cannot make a sharp distinction between Plato the poet and Plato the philosopher (as Teichmüller tries to do, Studien, p. 158). As already said, we cannot completely separate the form and the content of his thinking.

We can no longer hold, as used often to be held, that there is a fundamental antithesis between Plato and Aristotle. The agreement between them is far more fundamental than the difference. The severe and often captious criticisms of Aristotle must not blind us to the fact that almost every Aristotelian doctrine is to be found implicitly in Plato. As Sir A. Grant admirably said, "Aristotle codified Plato." In that phrase there is an expression at once of the 
essential agreement in thought and of the obtrusive difference in manner. There is of course a Platonic system of philosophy, in the sense in which every great philosopher, every thinker who is more than a mere brilliant penseur, has a system; but Plato's manner of working, not merely his manner of writing, is artistic rather than scientific. The difference between Plato and Aristotle is not that Plato is an idealist and Aristotle a realist-Aristotle is as much an idealist as Plato-but that Plato is a religious poet and Aristotle a scientifically trained physician.

Let us recognise, then, as fully as possible, that the philosophic truth of Plato is to be found in Aristotle. But it does not therefore follow that Plato himself would have accepted Aristotle's doctrines as his own. The student of Kant feels that Kant himself did not fully recognise the philosophic significance of many of his own positions. He retained much of the phraseology, and along with it not a little of the way of thinking, of the LeibnitioWolffian School, and would not have admitted the interpretation given to his doctrines by Fichte and Hegel. So too in Plato there is retained much Pythagorean phraseology belonging to a stage of thought beyond which he had really advanced, and he would certainly not have recognised the Aristotelian developments as his own. I am quite aware that this is a way of treating the history of philosophy which does not commend itself to a great many, especially among English, students of philosophy; but it seems to me the only way in which the 
history of philosophy-nay, in which any history becomes intelligible at all. Rousseau might not have recognised his own work in the French revolution; and yet none the less it was, in certain of its aspects, only an attempt to translate his ideas into facts. Luther might have been horrified at the modern theology and philosophy of Germany; and yet they are the direct product of his revolt from ecclesiastical authority. No man, not even the greatest and wisest, can fully understand the significance of what he is doing.

Thus, while admitting and insisting that Aristotelianism is "the truth," or, in other words, gives the philosophical interpretation of Platonism, we must not suppose that Plato himself would have admitted it. We must distinguish between the Platonism of Aristotle and Platonism as it existed for the mind of Plato himself. Hence, however much we feel, with Hegel, that the mythical element, the picture-thinking, is not of the essence of Platonism, we must not go on to say, with Teichmüller, that Plato himself did not hold any of it at all. To say this is to imply that Plato had an exoteric and an esoteric philosophy, ${ }^{1}$ and that when he argued for the immortality of the soul he was deliberately deceiving his readers by "a noble lie," such as he allows his rulers to use towards the lower classes in the state. But surely such a "deception" is quite foreign to Plato's spirit. No philosopher does his thinking more openly before

${ }^{1}$ This Prof. Vera expressly says. See his Platone e l'immortalitiz dell' anima, pp. 33 seq. 
the public-that public, at least, to which he appeals. Because, as we have shown, the truth of the doctrine of Recollection is to be found in that theory of knowledge which presupposes an identity of Thought and Being, it does not follow that Plato himself did not in his own mind figure the soul as having existed previously to birth and as recovering again in this life some part of the knowledge it had possessed before. However conscious Plato was that such language, in terms of time, was inadequate to express the exact truth, the frequent use of such language must be taken as showing a habit of thinking and not merely an artificial mode of expression.

II.

Let us now consider separately the arguments for immortality in the Phado. It has been much debated how many they are. ${ }^{1}$ They may be con-

1 It may be convenient to state briefly the distribution of the arguments according to Sir W. Geddes and Mr. Archer-Hind respectively, their editions being those most likely to be in the hands of the English reader.

Geddes.

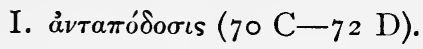

II. ảvá $\mu \nu \eta \sigma \iota s(72 \mathrm{E}-76 \mathrm{D})$.

Archer-Hind.

III. The soul is simple, not composite, in nature II. $(78 \mathrm{~B}-80 \mathrm{E})$.

IV. Objection of Simmias, that the soul is a Harmony, refuted $(85,86,9 \mathrm{I}-95)$.

Objection of Cebes, that the soul may outlast the body but not be immortal, refuted (86-88).

V. The soul partakes in the idea of life, and therefore III. cannot perish (100 B-107 B). 
veniently treated as three in number, though all really form steps in one great argument.

I. There is an old tradition that souls come back from Hades and live again (cf. Meno, 8I). This Plato explains and vindicates by the doctrine that

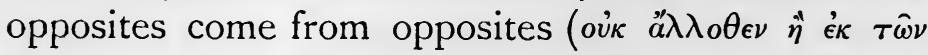

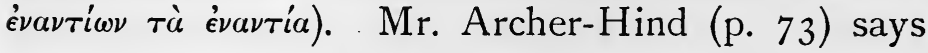
that Plato appeals to the uniformity of nature and has seized on the principle of the conservation of energy, and "has applied to spirit the axiom which previous philosophers laid down for matter." Is not this misleading language? Plato knows nothing of "laws of nature" in the modern scientific sense: it is not a formula with which he works. He does not get the conservation of energy as a "natural law" and read it into "the spiritual world." The conservation of energy, if we can use the phrase at all to express a conception of Plato's, is to him a necessity of thought, a logical law, not primarily a law of nature. Omnia mutantur, nil interit and Ex nihilo nihil fit were axioms arrived at from the logical impossibility of thinking either an absolute beginning or an absolute ending, not established like what we call laws of nature by a combination of hypothesis and experiment. And these axioms appear in Plato in the form: "If generation were in a straight line only, and there were no compensation ( $\epsilon i \mu \dot{\eta} a \dot{a} \epsilon \stackrel{\alpha}{\alpha} \nu \tau \alpha \pi o \delta \iota \delta o i n$, etc.) or circle in nature, no turn or return of elements into one another, then all things at last would have the same form and pass into the same state, and there would be 
no more generation of them" (72 A, B). We can easily see that this principle. by itself does not prove the immortality of the soul in the sense in which the term is generally understood. It would be accepted by the Democritean atomist and would be more than satisfied by Aristotle's conception of nature attaining immortality in the species, though not in the individual (De Anima, ii. 4). Yet, of course, if from other sources we can get any arguments for the indestructibility of the individual soul, this principle of the movement from life to death and death to life will fit in with them. This argument may perhaps be compared with Fechner's idea-not that the idea is peculiar to Fechner-that as the life (of the embryo) before birth is to the life in the body as it now is, so is this present life to that after death. ${ }^{1}$ Yet there is a most noteworthy and characteristic difference. Plato thinks of birth as an "eclipsing

${ }^{1}$ G. T. Fechner, On the life after death (Engl. Transl. by Wernekke), ch. i. Cf. the passage in the Autobiography of Lord Herbert of Cherbury: "And, certainly, since in my mother's womb this plastica, or formatrix, which formed my eyes, ears, and other senses, did not intend them for that dark and noisome place, but, as being conscious of a better life, made them as fitting organs to apprehend and perceive those things which should occur in this world; so I believe, since my coming into this world my soul hath formed or produced certain faculties which are almost as useless for this life as the above-named senses were for the mother's womb ; and these faculties are hope, faith, love, and joy, since they never rest or fix upon any transitory or perishing object in this world, as extending themselves to something further than can be here given, and indeed acquiesce only in the perfect, eternal and infinite." (Edition in "Camelot Series," p. 2r.) 
curse ": he thinks of the soul as passing through cycles of existence. Fechner is thinking of a continuous development. The idea of a cycle conditions all the thinking of Plato, and of Aristotle too, both in regard to the individual and in regard to society. We may indeed say that the conception of continuous progress is absent alike from their Ethics and their Politics.

This argument from the alternation of opposites is, however, not allowed to stand alone. It is at once supplemented by the doctrine of Recollection. Mr. Archer-Hind insists that these must be considered as making up together only one argument, $\dot{\alpha} \nu \tau \alpha \pi o ́ \delta o \sigma \iota s$ proving the existence of the soul, a $\nu \alpha \alpha_{\mu \nu \eta \sigma \iota s}$ its possession of intelligence (consciousness) apart from the present bodily life. We may note that Plato himself

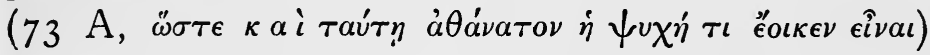
seems to treat them as distinct arguments. But the question is not of much importance. In truth all the arguments lead up finally to the argument from the theory of ideas, and this reference to the doctrine of Recollection already brings in that theory. We have previously considered this doctrine of Recollection and seen that it necessarily implies only the presupposition in knowledge of an eternal element, i.e., an element not dependent on temporal conditions: it implies the eternal character of thought, not the continued duration of the individual human person, although Plato himself, at least at some part of his life, may quite well have interpreted it in connection with an actual belief in continued personal, or at least individual, existence.

D. $\mathrm{H}$. 
2. The next argument is, that the soul being simple and not composite, is indissoluble : it cannot perish by being decomposed. It may be supposed that this is the same argument which has been largely used since Plato's time and which is criticised by Kant ${ }^{1}$-viz., that the soul is permanent because it is a simple substance. But the conception of the soul as "substance" is an addition to Plato's view which we do not find in Plato himself. ${ }^{2}$ If we are to compare this position of Plato's with any modern position, we might rather compare it with a view such as results from Kant's criticism, viz., that the soul is the unity of self-consciousness. But in truth the conception of self-conscious subject is equally absent from Plato's psychology with the conception of thinking substance. Rather we should regard Plato as having taken the Pythagorean mathematical conception of Unity to explain the soul, using the Pythagorean conception as suggestion and startingpoint for his theory of ideas. The soul which is invisible, he argues, is akin to $\left(\sigma v \gamma \gamma \epsilon v \eta^{\prime} s\right)$ the unchanging and incomposite, the invisible world of ideas, not the changing and manifold world of sense.

1 Crit. of Pure Reason, "Transcend. Dial.," book ii., chap. i., "Refutation of the Argument of Mendelssohn for the Substantiality or Permanence of the Soul."

2 It might indeed seem to receive countenance from the words

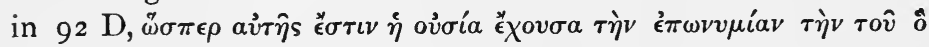
दै $\sigma \tau \iota v$, which appear to make absolute existence the substance of the soul. But if the words mean this, they stand in contradiction to all that is said elsewhere in Plato. And Schanz is probably justified in altering a $a \hat{\tau} \hat{\eta} s$, of the MSS., into av่tí. 
Thus the soul is likely to be at least more permanent than the body and nearly or altogether indissoluble.

There may be good ground for holding that the view of the soul as a substance conjoined with the body is very much due to the language of Plato's Phado, as ordinarily understood and popularised through the medium of Stoicism, which tended more and more to assimilate or adopt Platonic phraseology. It is a view which gained currency especially among materialistic Christians like Tertullian, who regarded soul and body as two substances or things, both material, though the soul might be of finer matter, which could be joined together and separated, externally and as it were mechanically ${ }^{1}$ - a view which has naturally led to the question, Where is the soul? But Plato must not be made responsible for the crude dogmatism of unphilosophical writers who have been influenced directly or indirectly by his words. As we have seen, the soul's permanence of existence is not by him made absolute (as in the metaphysicalsubstance theory which Kant attacked) but is dependent on its affinity to the ideas, to the divine. This being so, as already suggested, it would be less erroneous to say that he thinks of the soul's existence as a necessary condition of knowledge, though he rather puts it in the reverse way. Indeed he sometimes speaks as if the philosopher, the man who

1 Aristotle, De An. i., 3 fin., objects to the Pythagorean " tales" of transmigration, that they make any soul fit any body. But the "tales" as Plato gives them always insist at least on some connection in character between the soul and body. 
knows, who reflects and lives in the true world of ideas, had a better chance of life apart from the body than the ordinary man whose soul is sunk amid the sensible and changing (Phado, 8o E-8I E). The true life of knowledge is not dependent upon material things, and the soul which lives this true life can therefore exist independently of the body,

Teichmüller (in his book Ueber die Unsterblichkeit der Seele) applies to every theory about the soul what in appearance is a very simple question: "Is the soul according to this view a substance or is it not? If it is not a substance, it is illogical to hold any doctrine of immortality. The Materialist makes soul a mere function of body; the Idealist regards it only as the subject of knowledge, and holds the eternity of thought but cannot hold the immortality of the soul." Let us ask, what is meant by calling the soul a substance. Substance in its simplest meaning is nothing more than that which has qualities, the permanent subject of which we can predicate attributes. But probably most persons who use the word substance about the soul, only mean by it reality. Primitive man did not regard soul as substance. Rather the body was thought of as the real self or person, the soul, spirit or ghost, being only a sort of shadow or emanation given off by him. Because the dead and absent appeared in dreams, the appearance was supposed to be some emanation from the person. The ghost had a less real existence than the man while living; and there were ghosts or souls of other animals and even of things. We have good 
examples of this primitive "Animism" in the Homeric poems. The slain warriors themselves are a prey to dogs and birds, while their spirits are sent to Hades. ${ }^{1}$ With Plato this is completely changed. Socrates is asked how they shall bury him. "You cannot bury me. Only my body will remain. I shall go away" (Phado, I I 5). The spirits whom Odysseus visits have a very feeble and shadowy existence, not, as Plato puts it, a more real and true existence than men living on earth, so that the life of the wise man becomes " a practising of death" (Phado, 64 A). This Animism of course still survives in the co-existence of a belief that the ghosts of the dead flit about near graves and their old haunts (cf. Phxdo, 8I C, D ; Lawes, 865 D), along with the idea that their souls are in another world. The differentiation of the words " soul " and "ghost"

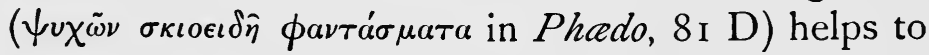
keep two distinct views alongside of one another. The distinction in Christian psychology between "spirit" $(\pi \nu \in \hat{v} \mu a)$ and "soul" ( $\psi v \chi \eta \dot{\eta})$ was, in the hands of the more philosophical writers, parallel to the Greek distinction between "reason" (vous)

1 Il. i. 3,4 :

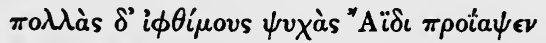

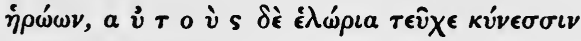

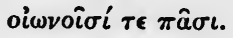

xvi. 855 , xxii. $3^{62}$ :

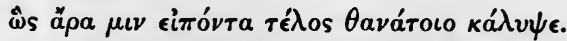

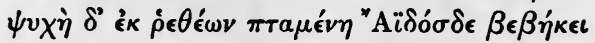

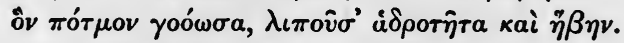

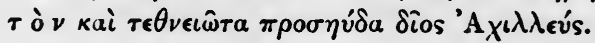


and "soul"; the adoption of "spirit" rather than "reason" for the highest element in the soul indicating the abandonment of Greek intellectualism and the preference for the ethical and emotional over the intellectual. But the Christian psychology allowed the old Animism to spring up again, and our word "spirit" hovers between the meanings of the German "Geist" and the English "ghost."

Plato, then, does think of the soul as being that which is most real and permanent in a man, but he does not express this by making the soul a "substance." The category of substance, being applicable properly only to what we perceive in time and space, is an inadequate conception for soul, as Kant showed in fact, though he writes as if it were in a way a misfortune that we could not prove the soul to be a substance in relation to its experiences in the same sense in which in a physical body we distinguish the substance from the properties. ${ }^{1}$ Self-conscious subject is a higher and better conception for soul ; and if the soul is called a substance, it can only be this that is meant. Lotze applies the term "substance" to the soul, but explains himself as only meaning by substance "everything which possesses the power of

1 Kant argued that identity of self-consciousness need not imply identity of substance. Thus the same movement is transmitted through a series of elastic balls ; the substances change, the movement is the same. And so, conceivably, the self-same consciousness might be transmitted through a series of substances. (Note on "Third Paralogism of Transcendental Psychology" in first edition.) 
producing and experiencing effects, in so far as it possesses that power." Again he says : "The fact of the unity of consciousness is eo ipso at once the fact of the existence of a substance" (Metaphysic, pp. 426, 427, Engl. Transl.). Thus Lotze does not maintain that the soul is a substance, in the sense in which Kant denies that we can know it to be a substance, and according to which alone Teichmüller seems to think the soul's immortality can be logically held, but only in a sense with which there is nothing in Plato to conflict. Plato, as we have already said, has not this conception of self-consciousness to work with; but he considers the essential element in the soul to be its knowing rather than its merely existing. And so (if we are to yield to the inevitable temptation of interpreting him in terms of modern controversies), if he is not yet Kantian, he is at least free from the metaphysical assumption against whose validity Kant argued.

The argument which Socrates directs against the objection of Simmias that the soul is the Harmony of the body, and as such cannot outlast the destruction of the body, has been sometimes treated as a separate argument for the immortality of the soul (e.g., by Ueberweg and Sir W. Geddes). ${ }^{1}$ This Mr. Archer-Hind denies; rightly, if we consider only the formal nature of the argument. But it contains the assertion of the priority and independence

1 Cf. Teichmüller (Studien zur Geschichte der Begriffe, p. 1 18), who puts the argument in the form : The ideal principle is prior to the becoming and not a product of it. 
of the soul, and thus does really advance the general argument of the dialogue. (I) The doctrine of harmony is shown to be inconsistent with the already accepted doctrine of Recollection (91 C-92 D). A harmony can only come into existence after that which produced it. (2) A harmony is dependent upon the materials that produce it, and is more or less of a harmony according to their condition; whereas the soul as such (i.e., in its ultimate essence, as we might say the mere "I" which is the condition of any knowledge) does not admit of degrees. The virtuous soul is not more a soul than the vicious, though it may be called more of a harmony (92 E-94 B). (3) The soul rules the body, whereas a harmony, as before said, is dependent on its materials (94 B-95 A). The harmony-theory is also criticised by Aristotle (in the De Anima, i. 4), who, like Plato, speaks of it as widely held. It is impossible for us to find out with whom the theory originated. It may, to begin with, have been nothing more than a poetical image popularly accepted. Plato's main argument against it is the first one-that it is inconsistent with the theory which alone explains knowledge. On this position the other two depend.

J. S. Mill (Essays on Religion, p. 197) considers this argument of Simmias to be that which a modern objector would naturally make to Plato's argument, viz., "that thought and consciousness, though mentally distinguishable from the body, may not be a sub stance separable from it, but a result of it, standing in a relation to it like that of a tune to the musical 
instrument on which it is played." 1 We may compare Voltaire's question whether the song of the nightingale can live when the bird has been devoured by an eagle. It should be noticed that $\dot{\alpha} \rho \mu^{\prime} \boldsymbol{v}^{\prime} \alpha$ means properly a succession of notes, and so is equivalent to our word " tune " or "air," rather than to "harmony." This being so, does not the illustration of the lyre tell the other way? A tune certainly cannot exist apart from the notes of which it is composed. They are, in Aristotelian phrase, the matter of which it is the form. But the same tune, i.e., the same combination of notes may be played on many instruments, and so the analogy would not prove the mortality of the soul, unless the soul be, as in Aristotle's view, the form or realisation of the body. If the body be analogous to the notes of the tune, the soul perishes with the body; if the body be analogous to the musical instrument, it need not. It may seem strange that Plato should not have noticed this way of turning aside the objection. Perhaps the whole harmonytheory seemed to him to deny too much the essential unity of the soul.

3. We can now pass to the third great argument, to which all the others lead up, that which makes the question of the soul's immortality expressly and directly depend on the doctrine of Ideas. It is impossible here to go through the complicated and

1 Mr. J. M. Rigg in Mind, vol. xi., p. 89, says : "The modern analogue of the harmonic theory is the attempt made by biologists to identify the soul with a special form of that correspondence between organism and environment in which life is held to consist." 
difficult details of the argument. The difficulties are partly matters of interpretation of language and must be left to the philologer ; partly they depend on the whole problem raised by the different forms in which the theory of ideas appears in Plato. We are at a loss to know how far we may take as a guide the presentation of the theory in other dialogues. ${ }^{1}$ The main argument in its briefest form is this. The soul partaking in, or manifesting in itself, the idea of life cannot partake in the opposite idea, that of death, just as fire which partakes in the idea of heat cannot admit the idea of cold, and as the abstract number three, which is odd, cannot admit the idea of even. Cold fire, even three, dead soul would imply cold heat, even odd, dead life, and so involve a contradiction in terms.

What, according to Plato, is the relation of the soul to the ideas? Teichmüller argues that, because the soul is not an idea, and because in Plato's system only the ideas really exist, therefore the soul does not exist. That the particular soul does not exist in the same way as the ideas we may agree. But (I) it may be doubted whether Plato and his critic are using "existence" (being) in the same sense. As Lotze has very well pointed out (Logic, Eng. Tr., p.

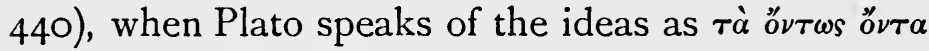
he really means that they are alone valid, not that they are existent things; but the Greek language does not admit of a distinction between validity and

1 The questions of interpretation will be found most carefully discussed in Mr. Archer-Hind's edition. 
being. ${ }^{1}$ Plato's ideas are not to be thought of as equivalent to Leibniz's monads, though Leibniz himself strangely thought so (Epist. ad Hanschium, I 707, Ed. Erdmann, p. 445). Rather they are the equivalent in Plato to what we call laws of nature. The idea of the Good is, in Plato's system, "God"; and Leibniz makes God the monad of monads. But is not this just the final difficulty of Leibniz's system? If we are to explain a universe of monads, God must be the totality and unity of the relations between the monads; but, if so, Leibniz would be nearer Spinoza than he thought. (2) The soul has not indeed the same absolute significance or value that the ideas have, but it has a significance or value which the composite man or animal has not. It is, as has already been argued, " nearer to" or "more akin to" the ideas, because it is what knows, and so is ultimately of the same nature with what is known, i.e., the ideas. The identity of the knowing and the known is thus the logical truth at the bottom of the ideal theory, as we have already seen in the special case of the doctrine of Recollection.

The soul not being an idea, may we say that there is an idea of the soul ? We talk of souls as we talk of other classes or kinds of existences ; so that, according to the view of the ideal theory which we have in the Republic, there ought to be an idea of the

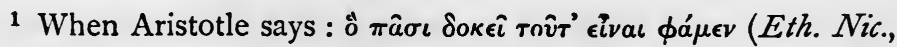
x. $2, \S 4$ ) he means that universal opinion has worth or validity, that there is in it (an element of) rationality, as in the parallel pas-

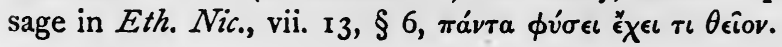


soul. Plato certainly never uses the phrase. But Mr. Archer-Hind thinks it necessary in the argument in the Phado to assume this "metaphysical monstrosity," as he calls it. "We have," he says, "the following terms; (I) the idea of life, (2) the idea of soul, which carries the idea of life to particular souls, (3) the particular soul, which vivifies the body, (4) the body in which is displayed this vivifying power." In the argument soul is treated of as parallel to the triad (the abstract three), and Plato does use the phrase $\dot{\eta} \tau \hat{\omega} \nu \tau \rho \iota \hat{\omega} \nu i \delta^{\prime} \dot{a} a$ (IO4 D) ; so that there would seem no escape from this conclusion. But surely, if we are to argue from the view of the theory of ideas in the Republic, Plato does not place the abstract conceptions of mathematics on the same level with the ideas, but in an intermediate region between the particular things of sense and the ideal world. The Pythagorean doctrine of numbers served Plato as suggestion and starting-point for his theory of ideas ; and the relation of abstract numbers to concrete numbered things serves as an illustration of the relation of ideas to things (cf. Arist., Met., i. 6). Might I suggest, therefore, that "the idea of three" is here not to be taken too literally? In any case the number "three" is not an idea in the same sense or of the same dignity as the quality "odd" : and similarly soul belongs to a region intermediate between the idea (of life-the living) and the concrete living animal. We might then compare the position assigned to the world-soul in the Timaus as "the mediatising principle between the Idea and the 
Phenomenon, the first form of the existence of the idea in multiplicity" (Zeller). Nothing is said about the world-soul in the Phoedo, but we are justified in expecting that Plato, even if the Timaus represents a different stage of his thinking, should treat it analogously to the human soul.

The chief difficulty which meets us in Plato's theory of ideas is the relation of the ideas to one another. We feel that they ought to be all organically connected with one another and with the idea of the Good. But the science of dialectic which should do this exists for him only as a possible science, as an ideal. We are puzzled by his recognising ideas of qualities, of concrete things in nature, of works of art, all separately, just as occasion requires ; and we do not know exactly how the idea of "the just," for instance, stands related to the idea of "man" or the idea of "table" (I am referring only to the forms in which the theory appears within the limits of the Republic). Some of these, we feel, are more properly "ideas" than others. This difficulty is partly due, doubtless, to the tentative and "sceptical " character of Plato's philosophy; partly perhaps to the influence of the undogmatic and vague character of popular Greek polytheism. The relation of the various gods to one another and to the supreme god is left undetermined. Plato and Aristotle themselves

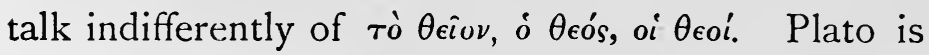
anxious to prove that God is good, and the author of good only (Rep., ii.): it seems to be a matter of indifference to him whether God is one or many. 
The Timaus does indeed suggest a hierarchy of divine beings; but then the Timaus stands by itself in its Pythagorean dogmatism. The result of the whole discussion in the Phado then amounts to this: that the particular concrete man (composed of body and soul) passes, as we saw, from life to death and death to life (cf. $70 \mathrm{C}, 103 \mathrm{~A}-\mathrm{C}$ ); the soul which makes him live is always living. It cannot admit death, and is therefore indestructible. This result may indeed appear to be a purely verbal statement : "Anima est animans"; but its significance comes from the connection established between the soul and the ideas.

Neither in the Phadrus nor in the Republic do the arguments used for immortality turn on the theory of ideas. The argument in the Phadrus, which is put forward as the prominent argument by Cicero (in his Tusc. Disp., i. 23.- also translated by him in De Rep., vi. 25), may however be connected with the concluding argument of the Phado. "The soul is immortal because it is self-moving" (Phadr., 245 C) ${ }^{1}$ may be considered as only one form of stating the argument from the idea of life. If we look for a modern parallel, we may perhaps find it in the argument from freedom (criticised by Lotze, Met., Engl. Transl., p. 420) - an argument which of itself will not prove a personal or even an individual immortality. Only "Thought" is free, and even Thought in its use by us is conditioned by material phenomena.

${ }^{1}$ Cf. Lares, X. 896 A, XII. 966 E. 
The argument in Republic $\mathrm{x}^{1}$ is that nothing can be destroyed except by its own proper evil. The body is destroyed by its proper evil, disease. The evil of the soul is wickedness; but men do not die simply by being wicked, else wickedness would be a less terrible thing than it is, and there would be no need of the executioner. Thus the soul, not being destroyed by its own evil, cannot be destroyed at all. The argument is so far the converse of the argument in the Phado. There it is argued that the soul, because not admitting death, is indestructible : here that the soul, because not in fact destroyed, does not admit of death. By itself it seems a very feeble argument. It would only prove that in this life the soul is not destroyed; and though it might suggest a future life, it would not prove immortality, because the destruction of the soul by wickedness might go on after death. Indeed from the position in Rep. i., that evil is a principle of weakness and dissolution, it might be argued that evil must in course of time destroy the soul. It has been ingeniously suggested to me by a friend that it might be retorted to Plato that if sin does not destroy the soul, sin cannot be the evil of the soul but must be proper and natural to it. On the other hand, we find a German writer, Julius Müller (quoted by Sir W. Geddes, p. xxvi.), using a parallel argument to Plato's: "So indestructible is

1 Teichmüller (pp. 121, 127) considers Rep. 6I I C and 6 I 2 an argument: "The ideal principle is divine"; also Rep., 6r I A-C : "The becoming remains always identical in quantity." Surely these are not "Beweise" ? 
the Personal Individual, that it is able to place itself through that which is wicked in the most enduring contradiction with itself, without at the same time compromising its existence. That the human creature can surrender itself to that which is wicked with full determination, without annihilating itself, is in fact one of the most powerful and tremendous witnesses for the Indestructibility of Personal Existence." But here we see that a conception of the self-conscious Person is assumed before the argument from wickedness is applied ; and so it might be said for Plato that, as he assumes the necessary connection between the soul and the eternal ideas, the fact that its own evil does not destroy the soul is a confirmation of its immortality. Yet it is striking, and characteristic of his way of working, that the arguments in the Phadrus, Phado and Republic, which we may fairly suppose all to belong to the same general stage of his philosophy, are stated in complete independence of one another.

The special interest of the Republic in connexion with our question is that here Plato comes most distinctly face to face with the ethical significance of the conception of immortality ; and it is, therefore, perhaps fitting that the argument should be rather ethical than metaphysical. Plato does not use at all the ethical argument as we have it in Kant, an argument which is, so far, the converse of Plato's argument from Recollection. Plato's argument might become : We have ideals by which we judge the imperfections of our present life ; therefore we must have known 
them in a previous state. Kant's argument may be put in the form: We have ideals which we cannot realise in this present life; therefore we must exist in a future state. And it is to be observed that Plato's argument turns on the character of knowledge even in moral matters, Kant's on the nature of conduct.

In the early part of the Republic Plato is compelled to protest against the demoralising effect of popular and of Orphic ideas about a future life, and appears therefore to reject altogether the ordinary beliefs about rewards and punishments in another world. But having shown that justice in itself, irrespective of consequences in this world or the next, is better than injustice, he now feels able to restore the element of truth, which he recognises in these old traditions, in a way which, so far from being demoralising, shall be morally educative. It would be misunderstanding him, however, to suppose that, either here or in the Phado, he considers the moral value of the doctrine an argument for its truth. Plato is perfectly true to the Greek faith in Reason : having established the truth of the doctrine, as he thinks, independently, on intellectual grounds, he is ready to accept its moral value. Thus the visions of a future life at the end of the Republic and of the Phado lead to the practical lesson of the immense importance of knowledge and conduct in this. Life is thus regarded, not as a time of probation to determine once for all the eternal destiny of man, but as a time of education to prepare him for the life or

D. $\mathrm{H}$. 
lives to come-a view which has nowhere been so forcibly expressed in modern times as in some of Browning's poems (e.g. "Apparent Failure," "Evelyn Hope," "Christina" : not so distinctly in the argumentative "La Saisiaz," where the idea of probation is made use of, though not in the ordinary dogmatic way).

\section{III.}

In what sense does Plato hold immortality? What part of the soul is immortal? To these questions it is not easy to find a consistent or uniform answer in Plato's dialogues. In the Phadrus the soul is imaged as a charioteer driving two horses. This image we may fairly interpret in accordance with the psychology of the Republic as representing

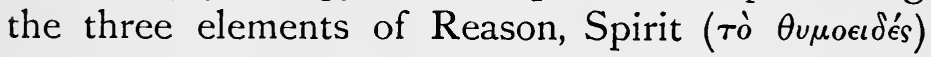
and Desire. All these elements, then, are in the Phadrus spoken of as belonging to the immortal soul and as existing apart from the body.

In the Timaus the different parts of the soul are localised in different parts of the body. In the Republic (ix. 588) we have the soul described as a complex creature-man, lion, hydra, all enclosed in the form of a man. [Can this be taken as a recognition that the Reason, the highest element, is the true

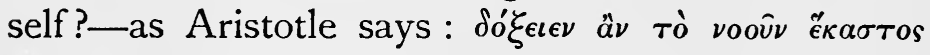
eival (Eth. Nic., ix. 4, \$4)-or does it only mean that every individual, though apparently one, is really complex?] In Rep., 6i I C, D, the true and immortal soul is said to be ordinarily crusted over and 
concealed by impurities. And so in the Phado the soul of the philosopher is spoken of as free from passion and desire. Again, Plato seems to waver between the view of the Phadrus and Republic, that the soul of the good man is that in which the lower elements are under control, and the more ascetic view of the Phado, that the good man is free from passions and desires altogether. Of course it is obvious that all turns on what is meant by desire. Plato often tends to regard desire as an altogether irrational element, though he sometimes sees that Reason, in order to act, necessarily implies desire (or

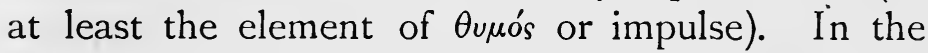
Phado the desires are, indeed, distinctly ascribed to the body, whereas in the Philebus $(35 \mathrm{C})$ they are ascribed to the soul. These apparent inconsistencies arise very much from our tending to understand Plato too literally, when he speaks of parts of the soul. Indeed it should be noted that he more often says $\epsilon^{\prime \prime} \delta \eta$ or $\gamma^{\prime} \dot{\nu} \eta$ ("forms " or " kinds," " aspects" as we might say) than $\mu$ ép $\eta$. We may reconcile all these passages, more or less, as follows :-The soul in its essence is Reason (vous). By admixture with the body it shows itself in the forms of passion and desire, which we may therefore ascribe to the soul or to the body, according as we are thinking of the soul as embodied or as distinct from the body. When the soul in a future life is spoken of as being punished, it must be the soul as having desires. The soul escapes, i.e., does not need, punishment, just in so far as it is free from desire (appetite, 
$\dot{\epsilon} \pi \imath \theta v \mu i a \iota)$. Only the soul of the tyrant which is altogether given over to desire is punished for ever. (This is a characteristically Hellenic touch, and need not be rejected, as by Mr. Archer-Hind. It is not more fanciful than any other part of the myths in the Gorgias and Republic. The tyrant is Plato's ideally bad man, opposed to the ideally good man, the philosopher.)

If then it is asked whether Plato thinks bodily existence necessary for the particular human soul, we can only answer by distinguishing the meanings of the words "body" and "soul." If by body be meant, as is ordinarily meant, our body as it exists now, then Plato does hold that the soul can exist apart from the body. If by soul be meant the soul as we know it with its passions and desires, then evidently some sort of body must be supposed for it, else there would be no passions and desires. If we ask whether Plato believes in a personal immortality, we should need to ask ourselves further what we mean by personality; and we should note that it is not a conception which has become at all prominent in ancient ethics. We might perhaps expect that a consistent Platonist would have held that, just in so far as the soul becomes purified from passion and desire, it loses its materiality, its element of otherness ( $(\dot{a} \tau \epsilon \rho o \nu)$, and thus becomes reunited to its divine source. This is an interpretation which the mythical element in Plato might suggest. Yet Plato himself argues (in Rep., x. 6I I A) that the number of the souls remains always the same; and the greatest 
of the Neo-Platonists, Plotinus, holds explicitly that there exists a real plurality of souls, the highest being the soul of the world, of which the others are not mere parts. Was this position retained out of respect for the authority of the divine Plato, or was it rather from an intuition that the Universal apart from individual manifestation is a logical abstraction?

Personality, however, is something more than mere individual existence. The person in the ethical sense, the subject of rights and duties, must be the member of an organised society. And it might be argued that it is only in so far as any one ceases to be a mere individual, that he becomes in the true sense a person, only in so far as he identifies himself with something wider and higher than self. In his theory of ethics, as expounded in the Republic, Plato sees this fully. It is not because he makes his citizens merge their lives in the life of the community that his ethics is inadequate, but because his conception of the community is too abstract and too much limited by the prepossessions of aristocratic Hellenism. In his visions of another world, so far from his neglecting the value of the individual, it might even be contended that he exaggerates the significance of the mere individual existence so much in his doctrine of metempsychosis, as to neglect the greater ethical significance of the person, which, as just said, depends on membership of a society. $\mathrm{He}$ speaks indeed of the good man in the evil state as being the citizen of a heavenly city; but in his accounts of the life free from the trammels of the 
body, there is no hint of a perfected community. His ideal in the Phado, and even in the Republic, is only an ideal for the philosophic few that escape from among the multitude who are "unworthy of education." May we not say, though it may sound paradoxical, that Plato has no adequate conception of personality just because his conception of the soul is too individualistic?

And yet individualism is not a fair charge to bring against Plato's doctrine of the soul. As we have seen, the soul is not conceived of by him as a selfsubsistent monad or atom. The soul is dependent for its life and its immortality on the eternal ideas, ultimately therefore on the Idea of the Good. So that, as Prof. Jowett has said (Plato, vol. i. $420^{1}$ ), his ultimate argument is equivalent to this: "If God exists, then the soul exists after death." That is, Plato himself like most of the older Christian theologians, ${ }^{2}$ and unlike many who have supposed themselves Platonists, did not hold that the soul was immortal per se, but only because and in so far as it partakes in the divine nature and has the divine nature manifested in it. Immortality to him also was

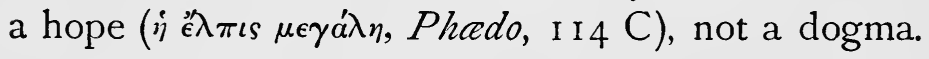

1 Edit. 2 : = vol. ii. 186 in edit. 3.

2 I have advisedly not complicated this statement by any reference to the doctrine of the resurrection, which, from the point of view of philosophy, may be regarded as the assertion of the continued existence of human personality plus the assertion that such personality will be connected with an organism of some sortanalogous to the present body according to popular belief, altogether different from it according to St. Paul (I Cor. xv. 35-50). 


\section{V. \\ WHAT ARE ECONOMIC LAWS ?}

I.

The phrase "Economic Laws" has been used by theoretical students as implying the claim of Political Economy to be a science like the sciences of nature. It has been used, or misused, by practical persons to imply that they possess rules or maxims to guide them in social and political affairs. People have debated as to the amount of respect which economic laws deserve-whether they ought to be relegated to Saturn or fulfilled on this earth. It would have been wiser to ask first, what economic laws mean, or can mean. Whether they can mean anything at all has certainly not been a usual question. But in the January number of the Economic Review (for I 892) ${ }^{2}$ Professor Cunningham has propounded the thesis, "that economics is not a science of 'cause' and effect, but a pure science, like logic or

1 Reprinted, with a few alterations, from the Economic Revieze, July, I892.

2 Art. "A Plea for Pure Theory." In my article, as originally written, I somewhat over-stated Prof. Cunningham's views. In the light of his "Reply" in the October number, I have modified some phrases and omitted others. 
geometry, where this conception of 'cause' is not appropriate "; ${ }^{1}$ and in accordance with this view he wishes to get rid of the phrase "economic laws" altogether. $^{2}$

Professor Cunningham speaks of the gratitude we owe to Ricardo for giving a precise meaning to the term rent, ${ }^{3}$ and says that the economic historian has his work simplified for him by the progress of pure theory. But is there any meaning whatever in Ricardo's definition of rent (let me call it a definition and not a law, reserving discussion of the relation between these terms) apart from the question, What is the cause of rent? The definition, as (according to Aristotle) every good scientific definition should do, states the cause of rent, i.e. explains how economic rent arises. This is the very service which economic theory, even though it may seem to be merely concerned with disputes about the meaning of words, renders to the ordinary practical discussion or to the historical investigation of economic questions. Take a familiar illustration of the way in which an economic theory helps us to get beyond the confusions of ordinary thought and language. A shopkeeper in a fashionable and much-frequented street will say that he charges high prices because he has to pay a high rent ; and if one does not go beyond the facts present to his mind when he says this, he may be said to be speaking correctly, so far as he means that his high prices and his high rent go together. Particular cases might even occur
1 Page 33.
2 Page 4I.
3 Page 29. 
where he had to raise his prices after his rent had been raised; and such cases would certainly confirm the notion that the high rent caused the high prices, though, of course, the owner's motive for raising the rent is his knowledge of what can be paid. Scientific theory must, however, go farther back, and ask why a high rent can be paid-why a shop in a fashionable thoroughfare brings to its owner a higher rental than a shop, which it costs an equal sum to build and keep in repair, in an unfashionable and little-frequented street. The owner of the premises may explain that he has to charge a higher rent to make his investment in house property "pay": he had to pay so much more for the site, or he has to pay so much more ground-rent. The theorist must still ask, Why does the ground-landlord get more in one place than in another ? and the answer must contain something like the essential element in Ricardo's theory of rent, difference in convenience of situation taking the place of difference in fertility of soil. We thus arrive at the conception of economic rent as distinct from interest on capital, etc. Now, is not such an analysis an investigation of "causes," quite as much as in any natural science? In pathology there may be the same initial difficulty in distinguishing causes and effects, as in the case we have been considering. What appear "causes" to the patient may be regarded as only symptoms, i.e. effects, by the scientific physician. ${ }^{1}$

1 One reason which Professor Cunningham gives for denying 
Professor Cunningham's thesis appears to me to make it worth while asking: (I) What is the nature of scientific "laws" generally? (2) What is the position of economics among the sciences? (3) In what sense can we have "laws" in a historical science?

that economics deals with causes seems to me very curious. The conception of cause as invariable antecedent, the conception usual in physics (at least, in the opinion of many English logicians, and in the words of most English scientific men who have got their logic from that quarter), is, according to Professor Cunningham, "not appropriate, because it is inadequate. The economist must endeavour to grasp at one view 'manifold mutual action' [Professor Marshall's phrase]. Such mutual and simultaneous action cannot be satisfactorily treated by looking at it, first from one side and then from another, as a sort of double causation. Kant has taught us that we must apply a different category altogether, and deal with it as a case of reciprocity" (p. 33). The inadequacy of the popular theory of causation does not, however, prove that the conception of cause which was applicable in physics is inapplicable in economics ; still less does it prove that economics must be treated on the analogy, not of physics, but of the more abstract sciences of geometry and "pure" logic. It would be an argument for applying to economics less abstract "categories" (i.e. fundamental conceptions) than are applied in physics, and certainly not for applying more abstract "categories." A sounder logic and metaphysics than those of popular language and popular science might make the physical conception of cause less inadequate to economics, but should hardly lead us to thrust the conception out of economics altogether. Nay, if we come to see that causality is not one isolated relationship among others, but that causality ultimately implies the relationship of every phenomenon to every other in the universe, so far from denying causality in economics, we should have to recognise it in geometry. So that even the analogy of geometry will not put an end to economic "causes" and economic "laws." 
I. We seem to have lost somewhat our sense of the unity of scientific method by the modern use of the terms "law" and "cause." There is, indeed, a great difference between a geometrical formula, applicable irrespective of time, and a theory in geology or biology, which cannot be expressed at all without bringing in a reference to time; but nevertheless there is something common to both. The Aristotelian logic of science, formulated with special regard to geometry as the type of science, is still applicable, though not fully adequate, to science generally. A'ı "cause," was, in Aristotle's view, not inapplicable in geometry. The geometrician asks " the why" of spatial phenomena which the practical craftsman may have discovered. The scientific "definitions" in which a science culminates, as distinct from the mere nominal definitions or explanations of terms with which it begins, are what we should call "laws." Thus the law of gravitation is our definition of gravitation, a definition which gives not merely the fact but the reason, by connecting the fall of an apple here and now with all the matter in the universe ; just as a proposition in geometry connects one fact of space-relations with others, e.g. the properties of the parallelogram with those of the triangle. Darwin's theory of natural selection may be called a definition of "species," superseding the older definition, which is descended from Plato's theory of ideas through the mediæval doctrine of infima species. Suppose we agreed, then, that eco- 
nomics had to do only with definitions, that would not prevent its having to do with "laws" and "causes."

2. Even "pure" logic, which must mean an analysis of the forms of thought, cannot be profitably pursued without some reference to the language in which our judgments are formulated, and therefore cannot quite avoid recognition of the influences of time and place, or does so only at the cost of ceasing to be a genuine analysis of actual human thought. ${ }^{1}$ Much more is this the case with a science that deals with wealth, i.e. with the instruments for the maintenance and enjoyment of human life and human society. Wealth has necessarily varied in character according to the other conditions, natural and social, of human living. Even the exchange of wealth cannot be properly or profitably studied, as it were, in vacuo, apart from the conditions which

1 I cannot here discuss the question, in what sense logic is a "pure" science. I would only point out that the more fruitful developments of modern logic have not been brought about by assimilating logic to a branch of algebra, but by introducing into the analysis of logical forms some of the vivifying conceptions of biology. I may refer to Mr. Bosanquet's Logic, where the forms of judgment are classified on a genetic principle. This may not be "pure" logic. It is, however, more like logic worked at in the spirit of the Analytics than the mechanical treatment of abstract formulæ without any examination of the concrete living judgments which actual human beings think, and which they express in this or that language. Even in logic it seems a pity that so little account has generally been taken of the diversities of language. How much of Aristotle's logic is explicable by reference to Greek idioms, and would have been differently phrased by any one using a different language ! 
make different commodities desirable in different degrees to different persons. The attempt to construct a pure theory of economics equally applicable at all times and in all places, must necessarily result in the economist taking certain phenomena of his own time in isolation from their social context, and formulating principles which can only be made rigidly true and universal by being gradually divested of all reference to any reality, so that they finally become absolutely identical, i.e. purely verbal propositions. The interest of such formulæe can only be restored by replacing them in the historical environment which produced them. Ricardian economics and Austinian jurisprudence, similar in their abstractness and in their endeavour to reach absolute universality, require to be looked at in the light of the particular conditions of English industry and of English legislation in the earlier part of the century. ${ }^{1}$ The attempt to escape history in dealing with human phenomena makes the restoration of the particular historical background of the theorist essential to the understanding of the professedly abstract theory.

Those who have treated the laws of economics as

1 Bagehot, in his brilliant essay on The Postulates of English Political Economy (p. 5 in Prof. Marshall's edition), points out the analogy between "political economy as it was taught by Ricardo," and "jurisprudence as it was taught by Austin and Bentham," and remarks on the similar fate which has befallen both : they have remained "insular." In each case the attempt to work out "pure theory," unadulterated by history, has resulted in the "theory" being unintelligible and inexplicable except in the immediate surroundings of those who have enunciated it. 
analogous to those of physics are not wrong in treating the science as too concrete, but in not treating it as concrete enough. Its place is among the social sciences, and it fully shares the difficulties and complexities which attend the study of human beings when we consider them as more than mere animals, i.e. when we pass from biology to sociology. Economics has certainly an advantage over certain other branches of sociology in dealing with a subject that admits of quantitative measurement. The quantitative measurement of pleasures and pains (the assumption of the older Utilitarians) is an illusion ; but the objects of desire admit of quantitative measurement by whatever medium of exchange is adopted. The possibility of obtaining an object of desire by exchange permits and compels the person desiring it to quantify his demand precisely. A man climbing a mountain under a hot sun may say vaguely that he would give "anything" for a glass of beer; but the presence of a refreshment-hut may prove that his demand does not really amount to one franc. This possibility of expressing economic desires quantitatively, and this alone, gives economics the appearance of being more closely related to the mathematical sciences than, e.g., jurisprudence or politics. Statements about value have an air of mathematical exactness, and consequently of detachment from a historical environment which does not belong to propositions about the relation between crime and punishment, or about the differentiation of the sovereign power in a community. But this facility 
of general statement has in it something illusory. As has just been said, many propositions can be made perfectly and universally true in proportion as they are removed from definite and particular application. We might extend the money measurement into morals, and say that every man has his price; but to make the proposition true we should have to add that there have been some men, the price of whose corruption by certain temptations would be something more than all the kingdoms of this world. The maxim then simply means that every one is induced to act in any given way by the motives which are strong enough to make him act in that way-which is certainly true, but is somewhat pointless, and is not quite what the royal cynic meant.

3. History stands apart from other sciences in being concerned with things that happen once for all : in this aspect it is not, strictly speaking, a "science," science being concerned with universals, with statements not about " this," but about " the." 1 Yet of history we may say that it is always "wishing" or striving to be a science, to see the universal in the particular-whilst giving a true picture of the events which have happened, to give also a true picture (as Thucydides says) "of the like events which may be expected to happen hereafter in the order of human things." 2 The scientific and philo-

1 Cf. Aristotle's well-known saying about poetry being more philosophic than history, because it deals more with the universal, with "what might occur" (Poet., c. 9).

2 Thucydides, i. 22. 
sophic historian of the English or of the French Revolution is dealing with general problems of human nature and human society, as they appear at a particular time, and in a particular country. Besides the mere investigation of particular events, there is a possible "political science" (or, at least, a possible ideal of such a science), which, based upon history, shall attempt to arrive at some general "laws" about the nature and functions of the State; i.e., to give "definitions" of political concepts, which shall be, wherever possible, genetic, assigning causes, and so taking the subject explained out of its isolation and showing its connection with other phenomena of social life. Thus, an analysis of "representative government" should contain a recognition both of its origin and of the purposes which it serves-in Aristotelian language, of its material, efficient, and final causes. (That a good definition gives the "formal cause" goes without saying.) If economic history deals with particular events and series of events, is there not also conceivable an economic science which deals with the "laws" of the production, exchange, distribution and consumption of wealth-in other words, which gives scientific definitions (in the sense already explained) of economic concepts, such as value, rent, interest?

In order to get economic laws, however, we must, it may be urged, abstract from the concrete facts; we must make hypotheses. Our laws are not, therefore, generalisations from observation of 
economic facts, but deductions from the assumption of certain facts of human nature-assumptions made by popular psychology, supplemented (and this must not be forgotten) by certain, usually tacit, assumptions as to stage of civilisation, etc. Granted that economic laws are hypothetical in their character, that makes no difference between them and laws of nature. Laws of nature are commonly supposed to be generalisations from observation of facts. They rest upon certain facts, it is true; but they are general only because they are hypothetical. If they are not mere "empirical laws," i.e. mere generalisations of experience, but true "laws of nature," they contain some fact of causation, they assert a necessary connection, and therefore they would be most correctly formulated as hypothetical propositions. The true universal judgment, i.e. the judgment which asserts necessity of connection, and which is not a mere summation of observed particulars, ${ }^{1}$ is best expressed in the hypothetical form. Thus : " All triangles [not merely " all these triangles," but "all triangles quâ triangles"] have their angles together equal to two right angles," means, "If this, or any figure, is a triangle, it must have its angles together equal to two right angles; it has this property because it is a triangle. The triangularity is the 'cause' of its having this property." And this proposition, this "law," if we care to call it such, would be true, although no actual perfect triangle could ever be "observed."

1 I.e. the judgment which is true ка日ódov and not merely ката̀ mavrós.

D. $\mathbf{H}$. 
The same holds in physics. The first law of motion asserts that, " if a body be in motion, it will move in a straight line and with a uniform velocity, unless acted on by some external force." Where are the "observations" from which this could be said to be a "generalisation"? The "law" is a statement of what is never realised in our experience. Its necessity and its hypothetical character go together. In formulating laws of nature, we are simplifying nature for ourselves; not attempting to follow facts, which are too complex to be grasped in their entirety all at once, but seeking to interpret facts. The laws of economics claim to be laws in the same sense. They are hypothetical propositions stating what, under certain conditions, would happen. (The mischief is, that "the practical man" is apt to run off with the statement of a tendency, and to forget the qualifying conditions.) These "certain conditions" may be more or less far removed from anything that can be observed or realised in our experience. The conditions for observing the law of gravitation in operation are not so difficult to fulfil as the conditions for observing the first law of motion. To observe the first law of motion (at least, the part of it I have here quoted) in operation is strictly impossible. In economics we can find cases where the condition of absolutely free competition is approximately realised; but it is only an approximation at the best. On the other hand, such a condition as the "transferability" of labour (to use Bagehot's expression), i.e. the possibility of 
its being transferred from one occupation to another, cannot be even approximately realised, except within very narrow limits, or unless we take into account a long period of time.

It is customary to oppose the abstract and deductive method to the historical and inductive. Neither of these methods can exist in absolute isolation from the other, though the opinion that they can is apt to prevail, and to cause misunderstanding. If, to simplify some economic problem, we set up a fictitious "economic man," a human being actuated solely by the desire to obtain the greatest possible wealth, we must place him in an environment of similar individuals - and these similar individuals must be thought of as held together in a community, though it be merely a community based on economic interests. We must presuppose a certain minimum amount of mutual trust and confidence, even as the basis of the most purely commercial relation. That is to say, we borrow our notion of the economic man from the business world which is known to us, leaving out of sight the other aspects and relationships of the individuals. The fact that it is possible to construct illustrations of the most abstract economic laws, shows that there is, even in deductive political economy, an element of induction, i.e. of verification in experience, though it may be fictitious experience; for all our fictions must be borrowed from facts, although by a process of abstraction. These tales of the economic textbooks ("Place two men on a desert island," etc.) are 
the very imperfect substitutes for the laboratory experiments of physics and chemistry.

On the other hand, mere inductive generalisation, unmixed with hypothesis, is impossible. Even in collecting statistics, we must have some rough guiding idea to determine us what sort of "facts" to collect. If in collecting information about London pauperism, we find out how many of the paupers are town-born and how many country-born, we do so under guidance of the hypothesis, suggested to us by our ordinary practical knowledge of human nature, that there may be some connection between the two sets of facts, e.g. that the town-born may be of inferior physique and brought up under worse conditions, or that the country-born may have less capacity of adapting themselves to town life. The falsehood of a hypothesis, as logicians have often pointed out, does not prevent it from being useful ; the important thing is that a hypothesis should be capable of at least approximate proof or disproof.

It is obvious that the historian in searching for the causes of social phenomena must have hypotheses in his mind, just as much as the physician in making a diagnosis of a case. Here comes in the value of the trained imagination. The historian of the French revolution would not make a study of the literature of the eighteenth century, or of the opinions then prevalent about the English constitution, or of the American revolution, except under the idea that these subjects had some connection with the main subject of his research. 
The difference between the method of pure theory and the historical method can only be one of degree. The ideal of an absolutely pure theory unmixed with any empirical element is as impossible as the ideal of an absolutely pure logic unmixed with any reference to the actual judgments and actual inferences made by human beings. And such an ideal seems the more out of place in a science which professes to deal with social phenomena. Mere history, on the other hand,-if we may apply the term "history" to a mere empirical collection of facts unmixed with any element of hypothesis, any attempt to find causal connections,-is impossible: except, perhaps, to some kinds of lunatics. Any approach to it seems ludicrous, as in the irrelevancies of Juliet's nurse, or in that sentence of Burnet's, ridiculed by Swift: "Upon the King's death, the Scots proclaimed his son king, and sent over Sir George Wincan, that married my great aunt, to treat with him while he was in the Isle of Jersey." Swift asks, in the margin of his copy, "Was that the reason why he was sent?" The reader expects a causal connection, and finds a statement that has a mere private interest to the writer.

\section{II.}

So far I have considered only the resemblance between economic laws and laws of nature (in the sense in which that term is used in physics, chemistry, biology, etc.). I must now ask whether there is any difference between a physical and a sociological 
law? This question involves the most important of all philosophical questions, what is the relation of man to nature?-a question which is ambiguous with, at least, all the ambiguity of the word " nature." In one sense it may be said to be a presupposition of any scientific study of human phenomena, whether in psychology or in any of the social sciences, that man is a part of nature, i.e. that his actions may be regarded, like other events, as belonging to a coherent and intelligible system of things-in more familiar, though perhaps less accurate words, that they present certain uniformities of co-existence and sequence, capable of being discovered and expressed in generalisations. If we are to have psychology or any social science at all, we must recognise the universality of the causal nexus. But while this is admitted, we must not lose sight of the difference between (I) events in which the agents attain ends without purposing them, and (2) events in which the agents attain ends which they have more or less purposed to attain. A great part of human phenomena belongs, as much as do the non-human phenomena of nature, to the former class ; and even where purpose comes in, it comes in in very different degrees. In all parts of social evolution, many of the most striking results have been those which the agents did not intend. If human phenomena did not, to some extent at least, belong to the nonpurposed class, we should often have to count the persecutors of a religion among its supporters. Even where the result is in the direction of that 
which was designed, it often contains elements which are due to some stronger forces than the volitions of the individual actors, forces of the same kind as those operating among plants and animals. Nevertheless, we are not viewing the facts of human evolution aright, if we fail to recognise the occasional presence of conscious and deliberate purpose among the causes at work. Reflection and effort are causes which may be explained and traced back to their causes like any others, but they make a difference between the regions where they are present and those where they are not.

The first effect of applying scientific methods and conceptions to human phenomena, and so lifting them out of the domain of chance or arbitrariness, has generally been to produce a feeling of the helplessness of individual and even of social effort, in the presence of great natural forces and tendencies. The recognition of order (i.e. of what is order to the scientific understanding, not necessarily to the moral sense) has been apt to mean the abdication of rational endeavour. It is therefore worth calling attention to the differences which gradually show themselves between social and merely natural phenomena.

Some instructive illustrations of the resemblance and difference between human and physical science may be found in the case of language. It has been argued that language has a life and growth of its own with which men cannot interfere. In support of this view, Professor Max Müller has brought 
forward the famous examples of the Emperor Tiberius being unable to give Roman citizenship to a word not recognised by grammarians, and of the Emperor Sigismund being unable to make schisma feminine at the Council of Constance. But can it be inferred from this that the development of language is a purely natural process? In the first place, an absolute ruler can permanently alter very little of anything, unless he has a strong current of public opinion with him. As has been said of the Emperor of China, "Le fils du ciel peut tout-mais à condition de ne vouloir que ce qui est connu et traditionnel." These stories of Tiberius and Sigismund do not prove language a natural growth independent of human volition, any more than any admitted "institutions," such as laws, social usages, fashions of dress, etc. Secondly, while it is obviously true that the will of an individual, however highly placed, can do very little, yet many changes in language are ultimately dependent on the will of individuals. Who gives nicknames? Who invents slang? Generally it is impossible to discover; and yet we know that some one person must have used the new term first of all, just as much as in the case of new technical terms, where the originator can be more easily traced. Introductions of new words or phrases, which we may observe within our own experience, are, however, only specimens of the nature of a process which has always been going on in language. The new "variation" must originate with some individual. If it proves convenient, or in 
any way suits the fancy of others, it takes root and spreads ; if not, it withers and dies out. The rise of literature gives greater fixity to language: the establishment of schools, the recognition of certain usages as "classical," the making of grammars and dictionaries increase the force of the check imposed on "natural," i.e. simply unconscious, phonetic change. But such fixity is produced by more or less deliberate human institutions. The most conspicuous case of what, by contrast, might be called merely natural change, is where a people, adopting a new language (e.g. that of a conquering tribe), modify sounds that are difficult or unfamiliar to them. Here the resultant language might almost be compared to a chemical combination. But there is no limit to the possible changes in language that may be made on conscious individual initiative, except the limit of the capacities of the human voice. No fashion could induce men to speak with the tongues of nightingales or larks.

Political institutions supply other illustrations of the relation between the volitional and the merely natural element in human history. That " constitutions are not made, but grow," is accepted as so much a commonplace that people forget to ask, "How do they grow?" At least, they grow not exactly like weeds, but like cabbages that have to be planted. Besides, the most ingenious political schemes come to nothing, if not adapted to the people and the time; they are unsuccessful "variations." But every change in law or custom must 
originate in some person doing or abstaining from doing some particular thing. So that the "growth" of constitutions does not exclude the "making" of various parts of them. The idea of "natural selection" will apply perfectly to human evolution, if we remember that the variations on which natural selection works in human phenomena arise, not merely (I) "spontaneously" or "accidentally" (the words we use to express our refusal or our incapacity to pursue the question farther), but (2) by imitation -which is at least a half-conscious process-and (3) by deliberate effort, as the result of reflection, with a view to obtain certain ends. Where such reflection has really anticipated what is advantageous, natural selection seems to be superseded in successful artificial or rational selection. ${ }^{1}$ The limits of deliberate constitutional change are sufficiently obvious; they are, chiefly, geographical conditions (though the effect of these may be very much modified by mechanical inventions) and the intellectual and moral capacities of any particular race (though these may be greatly affected by the discipline of education and religion).

Changes in the economic condition of a people are, it is clear, very largely dependent on circumstances over which man's control is limited. The duration and hardiness of human life, climate, the supply of minerals, the fertility of the soil, the

1 On this subject I may refer to what I have said at greater length in Darwinism and Politics, second edition. See especially pp. 24-36, 99-106, 1 26-1 31. 
facilities of communication, are all in different degrees incapable of modification. There are, further, obvious limitations to the possibility of human effort and endurance, though these may be greatly modified by improved methods, by economy of labour, etc. There are also certain necessary limits to the extent to which any given occupation may be adopted by the members of a community. Thus, to take an old and extreme instance, everybody could not subsist by taking in everybody else's washing.

But there are very many economic phenomena which are dependent on individual action and social approval, e.g. the different forms of land-tenure, the degree in which freedom of bequest is permitted, the kind of contracts which are sanctioned by law and custom. All these may be and have been alterednot indeed by the arbitrary will of individuals acting in isolation, but by the will of individuals approved of by the general consent, or submitted to by the general acquiescence of the community.

Such matters as the hours of labour, the standard of comfort, the health conditions of industrial occupations, are partly dependent on natural necessities which can only be affected through mechanical inventions, but partly also on custom, which may be affected by moral and political changes. Thus, while it has been proved that the hours of labour can, in many cases, be diminished to some extent, without a necessary diminution in the product of labour, it is clear that this diminution cannot go on 
indefinitely; else with no work at all, as much would be produced as with a great deal of work. But what amount of commodities are required, and what kind of commodities, are questions which depend, to a large extent, on demands which are not permanently fixed by the nature of things, but are partly dependent on moral causes. Such questions are surely proper subject-matter for scientific inquiry; if they are not the subject-matter of economics- "applied economics" let it be called, if necessary-to what science do they belong? They cannot belong purely to economic history; for history has to do only with what has been, and here we are dealing with questions as to what economic conditions are possible, and what are their usual or probable effects on human well-being.

The recognition of a "moral factor" in economic law need not therefore vitiate the scientific character of the study : it will only make the difference between a less abstract and a more abstract "law." The more conditions our law takes account of, the more likely are we to be able to verify it in experience.

Political history and the history of morals also have gained from the recognition of the economic factor. It is essential to have the connection pointed out between political, moral, and even intellectual revolutions on the one side, and economic changes on the other, to see how economic pressure has often brought about what moral efforts alone could not effect. But it would be quite a perversion of truth to resolve everything solely 
into its economic conditions : and it would be to misunderstand those economic conditions themselves. Economic wants are dependent on the whole social environment in which people live; and therefore moral, religious, intellectual, artistic conditions must be taken account of in order to explain them fully. Man cannot live without bread or some equivalent; but man cannot live, and never has lived, by bread alone.

If "Nature" be taken to include the whole of human phenomena, then it is inconsistent to exclude from nature anything that may be done by conscious and deliberate human effort. If we say "All that is is nature," we must include in our conception of nature the spiritual ideals as well as the material necessities of man. But, if so, it is inconsistent to deny intelligence or a "spiritual principle" in what we call nature, since this intelligence or spiritual principle shows itself in human beings. It is inconsistent science to regard man as entirely within nature, and yet to exclude from nature, in the widest sense, the highest intelligence and the highest goodness that have shown themselves in man. And it is surely an inconsistent " natural theology" which sees God in natural forces and yet refuses to recognise the clearer revelation of wisdom and justice in the history of social institutions and of philosophical and religious ideas-which sees God in the earthquake and the whirlwind, and yet refuses to hear when $\mathrm{He}$ speaks with the human voice of legislator, sage, and prophet. 
III.

To recognise the existence of economic laws analogous to laws of nature does not require us to exclude from them the moral factor. But this recognition of the moral factor does not turn economic laws into moral laws. Moral laws are precepts respecting conduct : the phrase "moral laws" implies that morality is regarded on the analogy of a legal code. The term "laws" is used in the same sense as that in which it is used by lawyers-as an expression for what is expected to be done, not for what necessarily, under certain conditions, must happen. If the word "must" is used in expressing " moral laws," it means "ought to," and not, as in laws of nature, "cannot but." In both senses, indeed, "law" implies uniformity. Law, in the juridical sense, though it may nowadays be thought of as a command issued by a sovereign, was, in primitive times, simply the custom of the tribe, which every one was expected to follow, and which almost all persons did, as a matter of fact, follow. And. in the ethical sense, though moral laws may, among the higher religions, be regarded as enjoined by a divine legislator, primitive ideas of right mean the observance of the customs of our fathers. But, in spite of this resemblance, laws in the moral and juridical sense cannot be completely assimilated to laws of nature, not even if we introduce the sanction of them. "If you commit murder, you will be hanged," is not like a law of nature; because a murderer may escape hanging. "Murderers, if caught and convicted, are 
generally hanged," would, indeed, be a sociological law, analogous to a law of nature, expressing the prevailing custom. But in any formula which expresses a moral or juridical law there must be an expression, not of simple fact, but of something which is expected as right, although it may be that which is not always done. Even if ethics be looked at entirely from the point of view of the natural sciences and "metaphysics" rigidly excluded from it, it is still necessary to recognise the distinction between moral laws and sociological laws. "If society is to hold together and prosper, its members must keep faith with one another." This may be called a sociological law; it may be reached by deduction from some obvious psychological facts, supplemented by inductions from our ordinary experience and from history. It expresses the fact that human beings have to recognise the "moral law" which enjoins fidelity to one another. The liar, the fraudulent person, and the various violators of this moral law do not, and cannot, violate the sociological law: they illustrate it. A healthy society wars against them; because if they become abundant, any society will go to pieces. "In primitive conditions of society rigid observance of custom is essential to cohesion "- this is a sociological law, on which Bagehot has written luminously in his Physics and Politics. The "moral law" belonging to this stage of society would be, "Thou shalt not be eccentric"-a law which, in the form, "Thou shalt strictly follow the fashion," still holds among 
various groups of civilised persons who, for many purposes, are in the mental condition of barbarians. This sociological law is a law of the same kind as the biological law, that animals in a state of nature (i.e. not domesticated by man) do not exhibit unsymmetrical markings, because those with unsymmetrical markings are crushed out by natural selection. The moral law corresponding to this would be the precept, "Thou shalt not have unsymmetrical markings" - which sounds meaningless, because the tiger or the leopard cannot at will change his stripes or his spots.

Laws of nature, then, including sociological laws, cannot be violated. If a law of nature seems to be violated, either it has been incorrectly formulated, or else we are speaking, incorrectly, of violating a law of nature when we really mean violating some precept of prudence based-or supposed to be basedon a knowledge of the law. The man who dies from wilfully eating poison has violated the precepts of health : he illustrates the laws of physiology. Economic laws, being sociological laws, are not precepts ; in the strict sense they cannot be violated. Those who boast that they "believe in economic laws" can only mean that they believe in a certain form of society as desirable; and it would be less misleading if they said so openly. Economic laws are true or false. They are to be believed or disbelieved; they are not an ideal which can be believed in. It is necessary to protest strongly, and even at the risk of repeating truisms, against this common confusion 
of language about economic laws. The protest is necessary both in the interests of science and in the interests of practical politics. The student of economic science, as such, does not provide social precepts ; it is his business to study the phenomena in the same spirit as that in which the physiologist and pathologist study the phenomena of health and disease. The practical physician is dependent on their discoveries ; and the relation of the practical politician or social reformer to the economic theorist ought to be of the same kind, and of the same kind only. The physician is concerned with the lifehistory of microbes, with a view to the safe-guarding of human health; and similarly the politician is concerned with the operation of economic forces, not in order that he may necessarily always give them a free field to operate in, but in order that he may further them, check them, or direct them into new channels, so far as it is possible for him to do so, in the interests of social health. It is not meant, of course, that the functions of the scientific economist and of the social reformer cannot be combined in the same person, but simply that the functions are distinct from one another, and that the most careful student of facts is the least likely to confuse sociological "laws" with moral ideals or precepts of political practice.

D. H. 
VI.

\section{LOCKE'S THEORY OF PROPERTY.'}

“THE great and chief end of men's uniting into commonwealths and putting themselves under government is the preservation of their property." " This opinion of Locke may to some readers appear to express, with an air of unintended satire, the principles of the Whig statesmen who carried out that glorious and peaceable Revolution of I688, of which the "Treatise of Civil Government" is the theoretical defence. We should, however, be misinterpreting Locke and those whose ideas he represents, did we not attend to his own explanation of the term "Property." A man's property means, according to him, "his life, liberty, and estate" (II. $\$ \$ 87$, I 23). " "By property," he says elsewhere ( I 73), "I must be understood to mean that property which men have in their persons as well as goods." Property, in the sense of "estate" or possessions, is not to Locke, as indeed it could hardly be to any philosopher or thoughtful person, an ultimate category, a conception standing in need

1 Reprinted from the Economic Revieze, January, I89I.

2 Treatise of Civil Government, II. § I 24. 
of no further justification. It is derived from the conception of human personality.

"Though the earth and all inferior creatures be common to all men, yet every man has a property in his own person. This nobody has any right to but himself. The labour of his body and the work of his hands we may say are properly his. Whatsoever, then, he removes out of the state that Nature hath provided and left it in, he hath mixed his labour with, and joined to it something that is his own, and thereby makes it his property. It being by him removed from the common state Nature hath placed it in, it hath by this labour something annexed to it that excludes the common right of other men. For this labour being the unquestionable property of the labourer, no man but he can have a right to what that is once joined to, at least where there is enough and as good left in common for others" (II. $\S 27$ ).

Thus, in this apology for the most conservative of revolutions, we seem to come upon' the theoretic basis of modern Socialism-that to the labourer rightfully belongs the product of his toil. But we need not go far in Locke to find inconsistencies, or at least difficulties, in the working out of his theory. At the end of the very next section $(\$ 28)$ he says :

"The grass my horse has bit, the turfs my servant has cut, and the ore I have digged in any place where I have a right to them in common with others, become my property without the assignation or consent of anybody."

$M y$ horse and my servant are thus equally with my labour the means by which I acquire property; so that the capitalist employer of labour would, according to this clause, be fully entitled to the entire product created by his servants, if he can manage to get it. 
The qualifying clause at the end of $\$ 27$, "At least where there is enough and as good left in common for others," suggests an endless series of difficulties. We can, indeed, easily think of occasions on which " the state of Nature" allows this qualification a real practical value. Thus, men on a desert island or travelling through unoccupied territory need impose no limit on their use of the fruits and game they can obtain, save a consideration for each other's needs. But does such a principle afford us help as a criterion for estimating the value of positive laws or the conduct of established governments? Thus, when Locke says ( $\$ 32)$, “As much land as a man tills, plants, improves, cultivates, and can use the product of, so much is his property," this may be considered an excellent maxim for legislation in a new country, but would certainly seem to condemn the land-system of England. Locke, however, does not regard positive law as condemned simply because it is not identical with "the law of Nature." The convenient fiction of a "tacit agreement" allows him to take positive law out of the range of a too revolutionary criticism. That most land is actually appropriated, and that only the ocean is the "great and still remaining common of mankind" ( $(30)$, are facts due to the Social Compact. Locke does not hold, like Hobbes, that in the state of Nature every man has a right to everything, but only that every man has a right to as much as he can use without depriving others of a similar advantage. Thus, if every one were peaceably disposed and considerate of others, 
mankind might apparently have remained in the state of Nature. But as every one does not obey the law of Nature, the state of Nature has its inconveniences ; there are no judges to pronounce sentence on those who have violated the law of Nature, and no officials to carry out the sentences ( $\$ \$ 87$, I 24126). The aggrieved individual must either be judge and executioner himself, or submit in patience to the encroachments of the covetous and violent. "Every man his own law-court, and every man his own policeman," would be an awkward maxim; and Locke's state of Nature turns out, in the long run, to be not much better than that of Hobbes. To avoid its inconveniences, men have "incorporated" themselves into a body politic, "wherein the majority have a right to act and conclude the rest" (§95). The right of majorities Locke bases simply on the preponderance of force. "It is necessary," he says, "the body should move that way whither the greater force carries it, which is the consent of the majority" ( 996$)$. The admirable phrase of Sir James Fitzjames Stephen, “We agree to try strength by counting heads instead of breaking heads," " suggests that Locke might have based this right of majorities on an express or tacit compact, rather than on mere force, which in many cases does not reside with the numerical majority.

Political societies having come into existence, and having entrusted the power of the communities thus formed to governments (of whatever type) in order 1 Liberty, Equality, Fraternity, p. 3I (Edit. 2). 
to carry out the purposes for which political society exists, might it not seem as if the "property" which should be preserved by governments ought to be the property which is in accordance with the law of Nature? A government that confiscated all land in excess of what the owner could himself " till and use the product of " might seem to be doing more for the preservation of "property" (in Locke's sense of the term) than a government that encouraged the formation of large estates. Locke is not unprepared for this objection, though he never expressly faces it. $\checkmark$ Although men are "by Nature all free, equal and independent" (\$95), yet--

"it is plain that men have agreed to a disproportionate and unequal possession of the earth, they having, by a tacit and voluntary consent, found out a way how a man may fairly possess more land than he himself can use the product of by receiving in exchange for the overplus gold and silver, which may be hoarded up without injury to any one, these metals not spoiling or decaying in the hands of the possessor. This partage of things in an inequality of private possessions men have made practicable out of the bounds of society and without compact, only by putting a value on gold and silver, and tacitly agreeing in the use of money; for in Governments the laws regulate the right of property, and the possession of land is determined by positive constitutions" $\left(\$ 5^{\circ}\right){ }^{1}$

This appears to mean that, apart from the social compact and from the positive laws of any given community, gold and silver possess a value as

1 In the original edition of Locke's Treatise (followed, apparently, by Professor Morley in his edition of 1884 , in the "Universal Library" Series), this passage is in great confusion. In the preface to the collected edition of Locke's Works of 17 I4 
money ${ }^{1}$ by the consent of mankind; and since money makes it possible to enlarge possessions without offending "against the common laws of Nature" ( $\S 36,37)$, as is done by accumulating perishable goods, such as rotting fruits or putrefying venison, it would seem that inequality of property is not contrary to the law of Nature. But such inequality as leaves to some persons an insufficient amount must be contrary to the law of Nature as understood by Locke; it cannot be supposed to be due to a general consent of mankind, and must therefore be entirely due to the action or inaction of the governments to which mankind have entrusted the preservation of their lives, liberties, and estates. Now, Locke accepts the existing institutions of any given society as binding on those who enjoy its

it is said that the Treatises on Civil Government are for the first time printed from a copy corrected by himself. I have quoted the passage according to this revised version (which is followed by Professor Morley in his edition of Book II. in Cassell's "National Library"-r889). In the clause immediately preceding the words quoted, Locke says, "Since gold and silver . . . has its value only from the consent of men, whereof labour yet makes, in great part, the measure." I suppose that "whereof" refers to "value." Locke seems to mean that the value of money is not entirely arbitrary or conventional, but depends partly on the labour of procuring the precious metals. The greater scarcity of gold would, I suppose, be expressed by him as the greater "labour" or difficulty of finding it.

1 Money is defined in $\$ 47$ as "some lasting thing that men might keep without spoiling, and that, by mutual consent, men would take in exchange for the truly useful but perishable supports of life." 
privileges, even where these institutions deviate very considerably from the law of Nature. Thus he holds that, by the law of Nature, a man's children (when of full age) are "as free as himself, or any of his ancestors ever were, to choose what society they will join themselves to, what commonwealth they will put themselves under" (\$73); and he holds also that, by the law of Nature, children have a right to inherit the goods of their parents (Book I. $\$ 88)$ : nevertheless, he allows that a government may make political allegiance a necessary condition of the inheritance of property (II. $\$ 73$ ), so that the " natural rights" of children "vanish into thin air" before the positive law of particular societies. The right of inheritance Locke bases on the instinct of self-preservation and the instinct of propagating the species. "Men being by a like obligation bound to preserve what they have begotten, as to preserve themselves, their issue come to have a right in the goods they are possessed of " (Book I. $§ 88) .{ }^{1} \quad$ It is not said whether, by the law of Nature, all children inherit equally, as we should suppose must be the case. "Every man," we are told in Book II. § I90, " is born with a double right. First, a right of freedom to his person, which no other man has a power over, but the free disposal of it lies in himself. Secondly, a right, before any other man, to inherit, with his brethren, his father's goods."

1 All the other references in this article are to Book II. Book I. is entirely occupied with the refutation of Filmer's Patriarcha. 
Whether " with" means " equally with," Locke does not say; he certainly wishes to exclude primogeniture from the law of Nature, in opposition to Sir Robert Filmer's argument for the Divine right of kings. But on the analogy of the passage in Book II. $§ 73$, we should infer that Locke does not consider primogeniture a sufficient departure from the law of Nature to justify revolution. Those who do not like it may go elsewhere. The landless, the portionless, and the disinherited must find what consolation they can in this natural birthright of exile.

To deal fairly with the fictitious formulas in which the thinkers of the seventeenth century clothe their political principles, we must translate their phrases back into the political feelings to which these phrases give an abstract intellectual expression ; we must replace their theories in their original setting of facts. Thus when Hobbes says, availing himself of etymology, that Rebellion is a return to the state of Nature which is the war of all against all, what he feels is that any strong established government which will secure peace is to be preferred to the possible risk of anarchy. When Locke lays down that government exists for the preservation of the natural rights of man, he is not bringing the fierce light of the law of Nature to bear on the intricate mysteries of the law of England ; he has no grievance against "promulgated standing laws and known authorised judges," but only against "extemporary arbitrary decrees" (Cf. II. § I 36). His theory of revolution does not 
go beyond the quarrel of Parliament with the King. It is true he suggests a reform of the "gross absurdities" of a parliamentary representation which allowed "the bare name of a town, of which there remains not so much as the ruins," to "send as many representatives to the grand assembly of law-makers as a whole county numerous in people and powerful in riches" ( $(\mathrm{r} 57)$. His remedy, curiously enough, is a stretch of the royal prerogative "for the public good" (\$ 158$)$. He does not seem to think that Parliament could or would reform itself. But when a revolution is needed to secure a parliamentary government at all and an impartial administration of the customary law of the land, it is hardly to be expected that either practical statesmen or political philosophers should be much occupied with the perfecting of valuable institutions whose very existence was at stake. The distribution of property in England might or might not be in accordance with the common good, but it was better that it should be in the hands of an English Parliament needing reform, and of English judges administering antiquated law, than at the arbitrary disposal of the pensioner of a foreign king or the submissive penitent of foreign priests.

Let us return, however, to Locke's derivation of the right of property from labour, and consider some further points in the way he works it out. It might, indeed, be suggested that such inquiries are a mere waste of time; that the historical method alone can give fruitful results, and that it would be more profit- 
able to examine the practices of primitive societies and the vestiges of primitive law, in the endeavour to discover the actual origin of the right of property among different portions of the human race. But there is a meaning in the philosophical question that Locke attempts to answer-a question, not as to the historical origin, but as to the logical basis of the institution. It is not a properly relevant criticism of the Social Contract theory to say that no such contract ever did take place, that (as Carlyle puts it) the date has not been fixed by Jean Jacques. Hume, with his usual acuteness, saw that a logical refutation of the theory was needed as well; and his argument, that it is absurd to base the obligation to obey the laws on the obligation not to break one's word, is more fatal to the value of this famous and hard-dying theory than the observation that the early stages of a political society are just those in which there is least scope for contract. ${ }^{1}$ Locke indeed rather lays himself open to the historical criticism by bringing in "examples of history" (\$§ I02-104); but we should not be treating him fairly, if we laid much stress on the imperfections of the argument from "the beginning of Rome and Venice," beyond pointing out that the original settlers of a city community must be removed by several degrees from a state of Nature.

And so with the theory of property. We must treat it as a logical analysis of the right of property, undertaken with a view to discover its basis in the

${ }^{1}$ See Hume's Essay, Of the Original Contract. 
law of Nature, and we must understand by the state of Nature, not some actual state antecedent in time to existing societies, but the abstraction which would remain were we to strip off from mankind all the positive institutions of society. "The state of Nature," says Locke, "has a law of Nature to govern it, which obliges every one; and reason, which is that law, teaches all mankind who will but consult it, that, being all equal and independent, no one ought to harm another in his life, health, liberty, or possessions" ( $(6)$. This means that Locke's political thinking starts with the abstract individual as a basis. The individual is supposed to exist apart from society, and yet to be possessed of rights of person and property, such as are only intelligible in society, unless by "rights" we simply mean "mights." Locke's individuals in the state of Nature are really members of a sort of society, if their right to liberty and property is limited by a consideration for others. The "state of Nature" of Hobbes and Spinoza is a conception that is at least not self-contradictory ; "right" in it is "might," and nothing else. Locke's "state of Nature" is neither a correct representation of what would exist if we abstract from all society ; nor, again, is it an ideal to which he would demand conformity on the part of actual societies (which is what is generally meant by those who talk about their "natural rights "). Locke's "state of Nature" is a hopeless mongrel of the two. It is more plausible than a more consistent conception, just because it contains 
nothing to startle ordinary thinking, which always avoids the trouble of being thorough. Put a few Englishmen, not being confirmed criminals, on a desert island, without any definite authority to govern them, and the probability is that, even if they are rather a rough lot, they will act on the whole according to Locke's law of Nature. They will divide the island among themselves, so that each has some share; they will each think it right to defend his own life and goods against the rest ; but they will be ready to help each other in sickness or danger, and they will probably let a man's son inherit his father's lot. They will do all this just because they are not, and never were, in a state of Nature, but are Englishmen, the products of centuries of social evolution. Theories which attempt to explain society on the basis of individual rights presuppose the society they profess to explain.

The most instructive difficulty in Locke's account of property remains to be noticed. He sees that property is not all the product of labour: he claims, however, on " a very modest computation," that " of the products of the earth useful to the life of man, nine-tenths are the effect of labour"-though in most cases he would put ninety-nine hundredths "to the account of labour" ( $(40)$. The exact proportion does not, indeed, matter, because Locke holds that to have "mixed his labour with it" $(\$ 27)$ is enough to turn into a man's own property what was previously the gift of God to mankind in common $(\S 25)$. 
Nature, however, will not dispute ownership with man, not at least in the same sense in which his fellow-men may; and how is this dispute between man and man to be avoided?

"'Tis not barely the ploughman's pains, the reaper's and thresher's toil, and the baker's sweat is to be counted into the bread we eat; the labour of those who broke the oxen, who digged and wrought the iron and stones, who felled and framed the timber employed about the plough, mill, oven, or any other utensils, which are a vast number requisite to this corn, from its sowing to its being made into bread, must all be charged on the account of labour, and received as an effect of that. Nature and the earth furnished only the almost worthless materials as in themselves" (§ 43 ).

Locke sees that we must go even further, and that it would be almost impossible to reckon up all the different forms of industry that directly or indirectly go to the making of a loaf of bread. So many men have "mixed their labour" with Nature. But whose, then, is the loaf?

The solitary hunter may clearly be said to acquire a natural right to the game he secures by his strength and skill: he did not make the bird or beast, but he makes it "his." This is the simplest case of the acquisition of property. Here man is nearest to the mere animals. But what of the weapons the hunter uses? These he may also have himself made out of the materials with which Nature provides him; but they may be made by others, and in a more advanced stage of human life they are certain to be the product of many men's work. 
Whose, then, are they? The maker's or the user's? Implements of hunting, including horses and dogs, were in ancient Lacedæmon available for common use ; and this is a recognition as "right" of what is always true as "fact," viz. the social character of almost all products of human effort among human beings living in any sort of society. Locke, as we have seen, enumerates some of the various forms of labour which go to the making of a loaf of bread. But others might be added even to the indefinite list of handicrafts that he suggests. The soldiers that guard a country from invasion, so that harvests can be reaped in peace; the magistrates who are a terror to evil-doers; all those who increase the knowledge, quicken the intelligence, and raise the character of the community, and so make complicated industrial relations more possible between human beings;---all these might claim a part in the making even of a loaf of bread. That is to say, the loaf is not merely the product of Nature plus Labour, but of Nature plus Social Labour; and this social labour is not merely an aggregate of the labour of various individuals, but it is the labour of individuals working in an organised society. It is not, therefore, the individuals as individuals that have "mixed their labour" with Nature, but the individuals as members of a society. Therefore, if we translate the facts into Locke's phraseology, we must say that, by the law of Nature, i.e. according to reason, apart from any explicit or tacit consent of

${ }^{1}$ Cf. Aristotle, Pol., II. 5, § 7 ; Xen., De Rep. Lac., c. 6. 
the individuals composing the community, the loaf belongs to the society as a whole, and not to this or that individual. To what individual it belongs must depend, not on natural law, but on the positive law of the land; and it is the natural right of the individuals to see to it, that the positive law of the land is in accordance with the common good of the society.

We cannot, therefore, treat "property" as a category independent of society, except by a false abstraction. Whether property belongs to individuals or not, or in what degree, depends on the arrangements of the particular society; and, of course, whatever a society leaves untouched it must be supposed to sanction. And the true criterion by which to judge these arrangements is not the abstraction of natural rights, but, as Locke himself practically recognises, the common good of society. By a happy inconsistency, Locke again and again moves away from the region of metaphysical fictions about Nature to what, in a wide sense of the term, we may call the utilitarian standard of the common good. ${ }^{1} \quad$ Near the outset of the second book of the Treatise on Civil Government we find a safer description of the end of government than is given later on :-

"Political power I take to be a right of making laws with penalties of death, and consequently all less penalties, for the regulating

1 Cf. Leslie Stephen, English Thought in the Eighteenth Century, vol. ii. p. $13^{8}$. 
and preserving of property, and of employing the force of the community in the execution of such laws, and in the defence of the commonwealth from foreign injury, and all this only for the public good" ( $(3)$.

Property is not merely to be preserved, but regulated; not the maintenance of individual rights, but the common good, is the ultimate end of law and government.

Locke has received great praise for his theory of property. M'Culloch says of him that " he has given a far more distinct and comprehensive statement of the fundamental principle that labour is the grand source of value, and consequently of wealth, than is to be found even in the Wealth of Nations. It was but little attended to by his contemporaries or by subsequent inquirers. He was not himself aware of the vast importance of the principle he had developed ; and three-quarters of a century elapsed before it began to be generally perceived that an inquiry into the means by which labour might be rendered -most efficient was the object of that portion of political economy which treats of the production of wealth." I But was Locke's inquiry the same as Adam Smith's? Adam Smith holds that wealth is the result of labour; Locke was dealing, not with wealth in general, but with property, i.e. with wealth appropriated. And we have seen how little indi-

1 Literature of Political Economy (p. 4), quoted by Professor Fraser, in his valuable little book on Locke (in the series of Philosophical Classics for English Readers) which appeared just two hundred years after the publication of Locke's chief works [1890].

D. $\mathbf{H}$. 
vidual labour explains private property. To have stimulated the thought of Adam Smith is indeed to have rendered a greater service than if Locke had avoided some difficulties and inconsistencies by keeping within the limits of the theory of property which he inherited from Grotius and Puffendorf. But I think that Hallam has said what is the reverse of the truth, when he speaks of "the superiority in good sense and satisfactory elucidation of his principle, which Locke has manifested in this important chapter," over these writers. ${ }^{1}$ Grotius and Puffendorf do not attempt to go behind the theory of an agreement or pact, express or tacit, by which men consent to a division of what was originally common. ${ }^{2}$ Locke, seeking to get further back, has treated the matter too slightly, whether from the point of view of history or of logical analysis; and has, in the meantime, lost sight of the valuable element of truth contained in this theory of compact. The theory, applied to government, gave a convenient expression to the conviction that rulers are not responsible to God alone, in any sense which excludes their responsibility to human society. This was the political principle that had to be fought for with sword and pen in the sixteenth and seventeenth centuries. Constitutional questions are less urgent now than economic; but may we hope that the social nature of wealth, and

1 Hallam, Introd. to the Literature of Europe in the Fifteenth, Sixteenth, and Seventeenth Centuries, III., p. $44^{2}$ (4th edit.).

${ }^{2}$ Grotius, De Jure Belli et Pacis, II., cap. ii., $\S$ ii. 5 ; Puffendorf, De Jure Natura et Gentium, IV. iv., $§ 4$. 
the responsibility to the community of those who hold the means of its production, will become a part of the general conscience without the necessity of so severe a struggle? Moral conviction, however, is not quite enough; constitutional safeguards are necessary against the misgovernment of rulers who might be inclined to say, "L'état, c'est moi," and so may legal safeguards be necessary against the selfishness of those who claim a "right" to do what they like with what they call "their own." 

THE SOCIAL CONTRACT THEORY. ${ }^{1}$

I.

THE theory of the social contract belongs in an especial manner to the political philosophers of the seventeenth and eighteenth centuries. But it did not originate with them. It had its roots in the popular consciousness of mediæval society. As a philosophical theory it had already been anticipated by the Greek Sophists.

The intellectual movement of Hellas in the period following the Persian war, though more rudimentary and less complex, is of the same type with the reawakening of the spirit of rationalism and criticism after the slumber of the middle ages-a slumber less profound than we are sometimes apt to imagine. Institutions come to be questioned instead of being simply accepted; the rights of the individual are made the measure and standard of their value. Aristotle ${ }^{2}$ refers to Lycophron the Sophist as having

1 Reprinted, with some corrections, from the Political Science Quarterly, December, I89i.

2 Politics, III. 9, $\S 8$. 
held that law is merely a "contract," a surety for the mutual respecting of rights, and not capable of making the citizens good and just. Here we have in germ what used to be called the theory of the Rechtsstat ${ }^{1}$ the theory that the function of government is limited to the protection of the rights of individuals. This is the doctrine which Professor Huxley, criticising Mr. Herbert Spencer, has called "Administrative Nihilism." In the second book of Plato's Republic, Glaucon, representing the opinion of the new enlightenment, gives an account of the origin of civil society which is identical with part of the theory of Hobbes. ${ }^{2}$ All men, according to Glaucon, naturally try to get as much as they can for themselves- " to encroach," in the phrase of Hobbes. To escape the evils that arise from this mutual aggression, they make a compact to abstain from injuring each other, and this compact constitutes what we call "justice," or law. Socrates, in Plato's Crito, refuses to listen to his friends who urge him to escape from prison: he argues that the Athenian citizen, through having enjoyed the privileges of protection from Athenian law, has made a practical agreement (a "tacit con-

1 Cf. Bluntschli, Theory of the State, Book V. ch. iii. (English translation, Edit. 2), p. 315 ; Holtzendorf, Principien der Politik, p. 21 3. Holtzendorff distinguishes clearly from this use of the term Rechtsstat the frequent modern use of it simply in the sense of "constitutional" as distinct from "arbitrary" government.

2 The views of Thrasymachus the Sophist, in the first book, are identical with the other part of Hobbes's theory, namely, the conception of right as based on the command of the sovereign.

3 Republic, 359. 
tract," we might call it) to obey the laws of Athens, even when he considers them unjust.

"The laws will say : Consider, Socrates, if we are speaking truly, that in your present attempt you are going to do us an injury. For, after having brought you into the world, and nurtured and educated you, and given you and every other citizen a share in every good which we had to give, we further proclaim to every Athenian that if he does not like us, when he has come of age and has seen the ways of the city and made our acquaintance, he may go where he pleases and take his goods with him. . . . But he who has experience of the manner in which we order justice and administer the state, and still remains, has entered into an implied contract [literally, 'has agreed in fact'] that he will do as we command him." 1

The argument, that the citizen is bound to obey a law he may dislike because he is free to leave the state if he choose, is exactly similar to that of Locke :

"Every man's children being by nature as free as himself or any of his ancestors ever were, may, whilst they are in that freedom, choose what society they will join themselves to, what commonwealth they will put themselves under. But if they will enjoy the inheritance of their ancestors, they must take it on the same terms their ancestors had it, and submit to all the conditions annexed to such possession." "2

Hume, in his essay of the Original Contract, ignores the passage I have referred to in Plato's Republic, saying :

"The only passage I meet with in antiquity where the obligation of obedience to government is ascribed to a promise, is in Plato's

1 Crito, 5 I, Jowett's translation.

2 Locke, Treatise of Civil Government, II., § 73. 
Crito, where Socrates refuses to escape from prison because he had tacitly promised to obey the laws. Thus he builds a Fory consequence of passive obedience on a Whig foundation of the original contract."

The whole tendency of the political philosophy of Plato and Aristotle is to get beyond this artificial way of regarding society, Neither of them uses the phrase "social organism," but both have the idea. Plato's ideal of society is that all the citizens should be members of one body. ${ }^{1}$ According to Aristotle, the state is not a mere "alliance," which the individual can join or leave without being permanently affected thereby. ${ }^{2}$ When Aristotle says : "Man is by nature a political animal," he embodies a profound meaning in the phrase. The individual separated from his state is not the same as the individual belonging to it. A hand severed from the body is a hand only in a different sense ${ }^{3}$ and so the individual apart from the state is not the individual citizenthe person with rights and duties.

Greek popular philosophy did not, however, remain at the Aristotelian level. Epicurus had ceased to believe in the moral significance of the city-state, which in his time had ceased to be a reality; and in Epicurus we find a return to individualism and the contract theory. Civil society is an association into which men enter to avoid pains. Justice arises from a contract "neither to injure nor to be injured," as in the Sophistic theory represented by Glaucon."
1 Republic, 462.
3 Ibid., I. 2, § 13.
2 Politics, III. 9, § I I.
4 Diog. Laert., X., § 150. 
II.

In the earlier Christian centuries the strictly ecclesiastical mind regarded all civil society as a consequence of the fall of man, Sin brought government into the world $;{ }^{1}$ Cain and Nimrod were its founders. Philosophically regarded, this is the equivalent of the modern anarchist's opinion that government is an evil, at the best a necessary evil. But from the thirteenth century onwards the political philosophy of the middle ages was leavened by a wholesome element of worldly wisdom, introduced through the influence of Aristotle's Politics. That "man is by nature a political animal," we might almost say, became a dogma ; and consequently the Sophistic and Epicurean theory finds a place neither in the $D e$ Regimine Principum of Thomas Aquinas and his followers ${ }^{2}$ nor in the De Monarchia of Dante,neither among the champions of the ecclesiastical nor among the defenders of the imperial power. But in the popular consciousness of the middle ages and among the writers on the ecclesiastical side there grew up that particular form of the contract theory which has fixed itself most prominently in the minds of ordinary men and of politicians struggling with despotism - the idea of a contract between govern-

1 Cf. St. Gregory, quoted by Suarez, De Leg., III. c. i.

2 Ægidius Romanus in his De Reg. Princ., III. i. c. 6, recognises agreement (concordia) as one form of the origin of the state, growth from the family being the "more natural" form; but this is not the social contract theory. 
ment and people. ${ }^{1}$ The Bible and Aristotle supplied the intellectual food of mediæval thinkers. Aristotle, as we have just seen, gave no encouragement to the contract theory; but the same cannot be said of the Old Testament.

"So all the elders of Israel came to the King to Hebron; and King David made a covenant with them in Hebron before the Lord ; and they anointed David King over Israel." 2

Such passages as this furnished a formula under which the mutual obligations of ruler and subject could conveniently be thought of, and under which the responsibility of kings, not only to God but to their subjects, could be asserted and maintained. The Old Testament supplied the mediæval ecclesiastics, as it did the Puritans afterwards, with a corrective to the doctrine of submission to "the powers that be," which had come down from the early Christians who lived under the irresistible despotism of the Cæasars.

Furthermore, in the middle ages men were more prone than at any other time to think in terms of the Roman conception of a "contract quasi ex consensu." $^{3}$ The idea of contract ${ }^{4}$ is the most important of the contributions to the world's

1 For this cf. Th. Aq., De Reg., I. c. 6., where the word "pactum" is used to express the relation between a constitutional king and his people.

22 Samuel v. 3.

3 Cf. Maine, Ancient Law, pp. 343 et seq.

4 I mean, of course, the idea as carefully thought out. In one sense, wherever there have been human beings there have been 
thinking made by Roman Law. A feudal community differs from a true archaic community (such as a Celtic clan) just through this element of contract added to barbaric custom. ${ }^{1}$ The formula according to which the nobles of Aragon are said to have elected their king, even if it be not authentic, represents at least the principle, in an extreme form, of feudal monarchy. "We who are as good as you choose you for our king and lord, provided that you observe our laws and privileges; and if not, not." 2

"Though from the twelfth century [says Hallam] the principle of hereditary succession to the throne superseded in Aragon as well as Castile the original right of choosing a sovereign within the royal family, it was still founded upon one more sacred and fundamental, that of compact. No King of Aragon was entitled to assume that name until he had taken a coronation oath, administered by the justiciary at Saragossa, to observe the laws and liberties of the realm. ${ }^{3}$

Mr. R. L. Poole in his Illustrations of Mediaval Thought (page 232) quotes a very interesting passage from a letter written by Manegold, a priest of Lutterbach in Alsatia, in defence of Pope Gregory VII. :

contracts ; but it is with the Romans that "contract" becomes a conspicuous "category" of thought.

1 Maine, Ancient Law, pp. 364, 365. Cf. Hallam, Middle Ages, chap. ii. pt. 2., vol i. p. 187 , ed. 1878 .

2 Robertson, Charles $V$., "View of the Progress of Society, etc.," note xxxii. ; Hallam, Middle Ages, vol. ii. p. 43.

3 Middle Ages, II. 45. 
"King is not a name of nature but a title of office: nor does the people exalt him so high above it in order to give him the free power of playing the tyrant in its midst, but to defend him from tyranny. So soon as he begins to act the tyrant, is it not plain that he falls from the dignity granted to him? since it is evident that he has first broken that contract by virtue of which he was appointed. If one should engage a man for a fair wage to tend swine, and he find means not to tend but to steal them, would one not remove him from his charge? . . . Since no one can create himself emperor or king, the people elevates a certain one person over itself to this end, that he govern and rule it according to the principle of righteous government; but if in any wise he transgress the contract by virtue of which he is chosen, he absolves the people from the obligation of submission, because he has first broken faith with it."

This mediæval form of the contract theory is that which appears in works of the sixteenth century which were written in defence of the principle that people might depose tyrannical kings, and it finds its way into public and official documents. Thus-

"the Scots, in justification of their deposing Queen Mary, sent ambassadors to Queen Elizabeth, and in a written declaration alleged, that they had used towards her more lenity than she deserved; that their ancestors had heretofore punished their kings by death or banishment ; that the Scots were a free nation, made king whom they freely chose, and with the same freedom unkinged him, if they saw cause, by right of ancient laws and ceremonies yet remaining, and old customs yet among the Highlanders in choosing the head of their clans or families; all which, with many other arguments, bore witness that regal power was nothing else but a mutual covenant or stipulation between king and people."

I quote these words from Milton's Tenure of Kings and Magistrates. Buchanan, in his dialogue 
De Jure Regni apud Scotos and in the speech which, in his History, he puts into the mouth of the Regent Morton, maintains the theory of the Scottish monarchy to which Milton here refers. In fact Milton follows the very words of Buchanan. The coins stamped at the coronation of the infant King James VI., in 1570 , bear on the reverse a drawn dagger and the motto Pro me si Mereor in me-a grim version of the theory of contract. ${ }^{1}$ The phrase is said to have been used by Trajan when handing a sword to the prefect of the Prætorian guard. This story is expressly alluded to in Buchanan's version of Morton's speech. And we may perhaps conjecture that Buchanan had something to do with the use of it as a motto on the coins of the Stuart king, who, being only four years of age, was not yet able to give distinct utterance to his own opinions about government. The True Law of Free Monarchies, which James afterwards wrote in answer to the revolutionary theories of his old tutor, contains very different doctrine. But even King James himself used the phraseology of the contract theory in addressing the English Parliament of I609:

"The king binds himself by a double oath to the observation of the fundamental laws of his kingdom. Tacitly, as by being a king, and so bound to protect as well the people as the laws of his kingdom, and expressly by his oath at his coronation; so as every just king, in a settled kingdom, is bound to observe that paction made to his people by his laws, in framing his government

1 Becoming even more grim in the hands of Milton (Tenure of Kings and Magistrates), who omits the words "Pro me." 
agreeable thereunto, according to that paction which God made with Noah after the deluge. . . . And therefore a king governing in a settled kingdom leaves to be a king and degenerates into a tyrant as soon as he leaves off to rule according to his laws." 1

This phraseology about compact faded from royal and royalist lips before those extreme assertions about "divine right" and the duty of non-resistance, which the Anglican bishops too often made the most prominent part of their religion. But the words came back as a Nemesis upon the last of the Stuart kings, when the Convention Parliament of 1688 declared that James had "endeavoured to subvert the constitution of the kingdom by breaking the original contract between king and people."

III.

Locke published his Treatise of Civil Government in defence of the principles of the revolution of 1688 , and it is very commonly believed that he maintained this theory of a contract between king and people. Locke is not a lucid writer, and misunderstandings of his theory of political obligation, as of his theory of knowledge, are excusable. Thus Josiah Tucker, Dean of Gloucester, ${ }^{2}$ criticises Locke for alleging that there must be an actual contract between king and people. The Dean admits, however, that there is a "quasi-contract,"

1 Quoted by Locke, Treatise of Civil Government, II., § 200.

2 In his Treatise concerning Civil Government (London, I78I), p. 142 . 
because government is to be considered a "trust" to be exercised in the interests of the governed. But this is Locke's very phrase. ${ }^{1}$ As we have seen, Locke quotes King James I. about the "paction" between king and people; but the original compact on which he basis civil government is, just as with Hobbes and with Rousseau, a compact between individual and individual, not between king (or whatever else may be the government) and people.

"Whosoever [he says] out of a state of nature unite into a community must be understood to give up all the power necessary to the ends for which they unite into society, to the majority of the community, unless they expressly agreed in any number greater than the majority. And this is done by barely agreeing to unite into one political society, which is all the compact that is, or needs be, between the individuals that enter into or make up a commonwealth." 2

Civil society is, in Locke's view, "incorporated" for a certain purpose, viz. to secure the rights of the individual better than they can be secured in a state of nature. This is the "original compact." Society, thus formed, retains always a supreme power. ${ }^{3}$ It

1 See Treatise of Civil Government, II., $\S \mathrm{r}_{36} 6$, I42, I56. In $\S$ I 49 he speaks of "the legislative" as "being only a fiduciary power to act for certain ends."

2 Treatise of Civil Government, II., § 99. In a footnote in the English translation of Bluntschli's Theory of the State (Oxford, I885), p. 276-a footnote for which I am responsible-I followed the usual fashion of contrasting Locke and Rousseau. Further study of Locke has convinced me that there is no essential difference between them in this matter. The error has been avoided in the second edition (1892): see p. 294.

3 Treatise of Civil Government, II., § 149. 
does not treat with king, or other form of government, as one of two contracting parties : it entrusts the work of government (legislative, executive, judicial) to this or that person or persons; and if such person or persons fail to do their work to the satisfaction of the whole body of the people (which, as Locke has explained, means the majority), they may be dismissed and others put in place of them. Such an act of "revolution " may be inexpedient, but the people always retains its "supreme power." This seems to me a perfectly fair statement of what is most essential in Locke's theory; and it will be obvious that it is identical with what is most essential in Rousseau's. Rousseau's “inalienable sovereignty of the people" is just Locke's "supreme power that [in spite of the institution of a form of government] remains still in the people." Rousseau says explicitly that the institution of government is not a contract: the social contract by which the sovereign people is constituted excludes every other. ${ }^{1}$ The institution of a government results from a law made by the sovereign that there shall be a government of such and such a form, and from an act of the sovereign nominating certain persons to fill the various magistracies thus created. ${ }^{2}$ What the sovereign people has done it can alter if it sees fit. Rousseau ascribes to his "sovereign," which can only consist of all, the same attributes that Hobbes had bestowed on his, which might consist of one, some, or all-though Hobbes's personal preference
1 Contrat Social, III. 16.
2 Ibid., $\mathrm{x} 7$. 
was obviously for one. But though, as Mr. John Morley has put it, Rousseau has the "temper" of Hobbes-his clear, if somewhat narrow, logical intellect-he has done nothing more than apply this "temper" to the political principles of Locke. It is the custom of English writers to draw a contrast between Locke and Rousseau. There is a contrast between their styles, between their temperaments and between the temperaments of the audiences they addressed. But if we are considering simply their theories of the basis of political society and the grounds of political obligation, and their views about the abstract rightness of revolution, there is no difference between them. And Rousseau has the advantage over Locke, that he avoids altogether the attempt to make out an historical justification for the idea of social contract. ${ }^{1}$

Thus the political philosophers of the seventeenth and eighteenth centuries, who held the social contract theory, held it in the same form as did Epicurus and certain Greek Sophists before him. The position maintained by Socrates in the Crito might seem more comparable with the mediæval and popular theory of a contract between government and people; but the contract Socrates is thinking of is a contract between the individual citizen, on the one hand, and all the citizens, on the other-a conception which has more affinity with the views of Rousseau than with the ideas of feudalism. ${ }^{2}$ Greek political

1 Contrat Social, I. I.

\& When Rousseau says (Contrat Social, II. 6) : "Tout gouverne- 
theory was the product of republican institutions, in which the free citizen felt himself a part of the sovereign body and not a mere subject. In feudal Europe every man found himself somewhere in a scale of subordination; he was some one's "man." This scale mounted up through nobles and kings to emperor and pope ; and emperor and pope were thought of as holding directly of God,-or else the emperor of the pope, and the pope alone directly of God. But allegiance rested everywhere, as we have seen, on mutual obligation. ${ }^{1}$ Even the relation of God to man was thought of in terms of contract. God had bound Himself to man and man to Himself by covenants and solemn promises. The Hebrew idea of covenant was supplemented by the Roman legal idea of contract, and the distinctive theology of the Western Church was the consequence. ${ }^{2}$

The political philosophers of the seventeenth century did not borrow their theories directly from the Greeks. How then did their view of the original contract come to differ from the mediæval, which had

ment légitime est républicain," he only means the same thing which Aristotle expresses when he denies that a tyranny is a "constitution" at all. In the opinion of both a king, as distinct from a tyrant, is subordinate to the law. In Rousseau's language, he is the minister of the sovereign people; for them he governs and from them his power comes.

${ }^{1}$ In 1683 the University of Oxford condemned, along with other subversive opinions, the doctrine that there is a mutual contract between a prince and his people. A contract with all the obligation on the side of the people would have been no political heresy. Cf. Cooke, History of Party, I. $346 \mathrm{seq}$.

${ }^{2}$ Cf. Maine, Ancient Law, pp. 365 et seq.

D. $\mathrm{H}$. 
become the popular, view? The existence of this difference has seldom been clearly pointed out, ${ }^{1}$ and so far as I know, the cause of it has never been fully explained. Attention has been called to the subject in a very interesting article by M. Charles Borgeaud in the Annales de IEcole Libre des Sciences Politiques of April, i89o. He contrasts the Biblical and mediæval form of the theory which we find in the Vindicia contra Tyrannos of "Junius Brutus" (Languet or Duplessis Mornay?) and in the writings of Buchanan and others, with the theory of a contract between individuals which we find in Rousseau, but before him in Locke, in Hobbes and in Hooker. The last-named is apparently the first political writer

1 It has, indeed, been proposed by some recent writers to distinguish the "political contract" between government and people from the "social compact" by which a political society is formed. The distinction is, as I am endeavouring to show, of primary im-portance; but I do not think we gain anything by attempting nowadays to distinguish "contract" and "compact" in discussing the historical aspects of the theory. It may be true, as Professor Clark suggests (Practical Jurisprudence, p. 144), that the word "compact" was preferred by some writers as seeming to avoid the absurd idea that the agreement in question was legally enforceable. But since Hobbes and Rousseau both use the term "contract" for the same agreement which Locke calls "compact," it only introduces confusion to attempt to keep up a distinction between these terms. Furthermore, as I point out, neither Hobbes nor Locke nor Rousseau allows that the relation between government and people is one of "contract," while on the other hand the English Convention Parliament of r688 speaks of "the original contract between king and people." It seems to me, therefore, that an historical solution, and not a mere distinction in words, is necessary to clear up the confusion. 
after the Greeks in whom this form of the theory can be traced.

"Two foundations there are [says Hooker] which bear up public societies: the one, a natural inclination whereby all men desire sociable life and fellowship; the other, an order expressly or secretly agreed upon touching the manner of their union in living together. . . . To take away all such mutual grievances, injuries and wrongs [sc. as prevailed when there were no civil societies], there was no way but only by growing into composition and agreement amongst themselves, by ordaining some kind of government public, and by yielding themselves subject thereunto; that unto whom they granted authority to rule and govern, by them the peace, tranquillity and happy estate of the rest might be procured."l

In the first of these propositions Hooker was probably not conscious of going beyond Aristotle, who in the Politics ${ }^{2}$ recognises the work of the maker of the state ("the legislator") in addition to the natural impulse of mankind towards political society. But he has laid stress on the element of consent or agreement in a way which suggests the theories of Hobbes and Locke. Hooker probably had not particularly in mind the mediæval theories of a compact between ruler and subject, but was unconsciously influenced by the traditional habit of thinking about government under the formula of contract. Again, holding that the church, i.e. society in its religious aspect, has agreed upon its form of government, he naturally conceived of the state as fashioned in the same way. Further, Hooker inherited from the ecclesiastical politicians of the middle ages the doctrine of "the sovereignty of the people," i.e. the doctrine that

1 Ecclesiastical Polity, I., c. ro.

2 I. $2, \S$ I 5 . 
kings and other rulers derive their power from the people. Thomas Aquinas (quoted by the late Dean Church in a note on Hooker) lays it down that " to order anything for the common good belongs either to the whole multitude or to some one acting in place of the whole multitude." In adopting such ideas Hooker uses the words "consent," "agreement," etc., and thus implicitly unites the two distinct theories that political society is based upon a contract and that the people is sovereign-the theories held by Locke and formulated with startling clearness by Rousseau. Hooker, we may say, is the medium through whom the mediæval doctrine of the sovereignty of the people reaches Locke; but he transmits it in words which easily suggest the phraseology of contract. Locke, it is to be observed, purposely bases his political thinking upon Hooker, because Hooker was an authority acceptable to the Anglican Tories against whom Locke had to argue.

But quite apart from the quiet meditations of Hooker, circumstances were already making the idea of a compact between individual and individual familiar to the minds of many men in the early seventeenth century. The Scottish Covenant was a solemn pact made " before God, His angels and the world" by "the noblemen, barons, gentlemen, burgesses, ministers and commons," i.e. by the Scottish people in their various ranks and stations; it was a covenant in which the king might join, but it was not a pact between king and people. The nobility

1 Summa, I, 2, qu. 90, art. 3 . 
and gentry of Scotland, says Mr. Gardiner, ${ }^{1}$ had been in the habit of entering into "bands" or obligations for mutual protection. In I 58 I King James had called on his loyal subjects to enter into such a "band" when the country was threatened by a confederacy of Catholic noblemen. This was the basis of the National Covenant of 1638 . The absence of a firm government in Scotland had driven men to form compacts among themselves in order to escape the evils of perpetual lawlessness and warfare. It was an easy step from this actual condition to the theory that contract is universally the means by which men pass from the non-social state into that of orderly and peaceful society. The comparative powerlessness of the Scottish kings had allowed the mediæval theory, which based kingly authority on contract, to maintain itself; and the turbulence of the Scottish nobility was thus likewise one main source of the more revolutionary theory, which based all society on contract between man and man.

But by far the clearest case of what seemed the actual formation of a political society by a mutual agreement was the action of the emigrants on board the Mayflower, when they found themselves off " the northern parts of Virginia," where there was no existing government under whose authority they would come. Although formally acknowledging themselves "the loyal subjects of our dread sovereign King James," for all the practical and immediate purposes of government they think of themselves

1 History of England, 1603-1640, VIII. 329. 
as constituting a new political society. In the familiar and famous words they declare, that "we do solemnly and mutually, in the presence of God and of one another, covenant and combine ourselves together into a civil body politic." It has become a commonplace to speak of the social contract as "unhistorical "; but it must be admitted that it has more justification of fact and of historical precedent in the declaration of rights of an American stateconstitution than anywhere else in the world. When Carlyle objects that Jean Jacques could not fix the date of the social contract, it would at least be a plausible retort to say that that date was the I Ith of November, I620. ${ }^{1}$

1 The influence of Calvinism, and especially of the "Independent" theory of church government, on the political ideas of the seventeenth century, is traced in Prof. H. L. Osgood's recent articles on "The Political Ideas of the Puritans" in the Political Science Quarterly, March and June, I89I, as well as in the articles by M. Charles Borgeaud, already referred to. (An English translation of M. Borgeaud's articles is in preparation.) Much light is thrown on the various political theories current at the time by the publication of the discussions carried on in the Parliamentary army in 1647 , preserved in the Clarke Papers, which Mr. C. H. Firth has just edited for the Camden Society. While Cromwell speaks of the king being "king by contract," Mr. Pettus gives a version of the contract theory identical with that afterwards maintained by Locke. Men were naturally free, but they "agreed to come into some form of government that they who were chosen might preserve property" (p. 312). Rainborow and Wildman maintain that "all government is in the free consent of the governed." In contrast with them Cromwell and Ireton manifest toward theories of abstract rights a conservative distrust with which Burke might have sympathised. 
While practical needs were driving some men to base orderly government. on mutual agreement, political theory was, in the minds of those friendly to liberty, moving in the same direction. Grotius, living under republican institutions, expresses the doctrine of a social compact in terms which seem to recognise both the forms of the theory.

"Since it is conformable to natural law to observe contracts [stare pactis] . . . civil rights were derived from this source, mutual compact. For those who had joined any community or put themselves in subjection to any man or men, those either expressly promised or from the nature of the case must have been understood to promise tacitly, that they would conform to that which either the majority of the community or those to whom the power was assigned should determine." 1

This passage is rather an adaptation of the mediæval theory to suit the case of republics as well as monarchies, than a clear recognition of the contract between individual and individual. But in the great literary champion of English liberty the theory of Locke and Rousseau is clearly expressed. We have already seen that Milton quotes Buchanan's account of the contractual character of the Scottish monarchy, but Milton's own theory is expounded earlier in his treatise :

"No man who knows aught can be so stupid to deny that all men naturally were born free, being the image and resemblance of God Himself, and were, by privilege above all creatures, born to command and not to obey; and that they lived so, till from the

1 De Jure Belli et Pacis (1625), Proleg. § 15, Whewell's transation. 
root of Adam's transgression falling among themselves to do wrong and violence, and foreseeing that such courses must needs tend to the destruction of them all, they agreed by common league to bind each other from mutual injury and jointly to defend themselves against any that gave disturbance or opposition to such agreement. . . . The power of kings and magistrates is only derivative, transferred and committed to them in trust from the people to the common good of them all, to whom the power yet remains fundamentally, and cannot be taken from them without a violation of their natural birthright." 1

This is precisely Locke's theory; expressed in Milton's impassioned language, it reveals its identity with the theory of Rousseau. Milton, like Locke, gives the theory a setting of Biblical history. Remove this setting, and we have the theory as it appears in Rousseau.

The position of Hobbes becomes clearer if we consider it in the light of what has been said. With peculiar ingenuity he took the theory that had so often served to justify resistance and applied it in such a way as to make it the support of "passive obedience"-nay, of active obedience in almost every case-to " the powers that be." Hobbes did this by explicitly denying the possibility of any "covenant" between king and subject, or of any covenant between man and God (except through the mediation of the sovereign, who is God's lieutenant), and by maintaining that the covenant which constitutes civil society is a covenant of every man with every man. ${ }^{2}$ According to Hobbes men can-

1 For the term "birthright" in this connection, cf. Clarke Papers, pp. lx., lxi., 322-325.

a Leviathan, c. 18. 
not pass from the state of nature, which is a state of war of all against all, into the state of orderly society except by handing over their natural rights (with what seems the inconsistent exception of the right to self-preservation ${ }^{1}$ ) to a sovereign-one, some or all. The sovereign is not a party to the contract, but is created by it. Hence to resist the sovereign is to return to the state of anarchy. If we translate Hobbes's practical thought out of the phraseology of the contract theory, it becomes simply this : Any evils are better than the risk of anarchy. Locke thought that continued misgovernment might be worse than anarchy, "the inconvenience being all as great and as near, but the remedy farther off and more difficult." ${ }^{2}$

The acutest criticism upon Hobbes is that implicitly passed on him by his great contemporary, Spinoza. Spinoza leaves alone the fiction of con tract, but, working with Hobbes's conception of natural right as simply equivalent to might, argues that the right of the sovereign is also simply equivalent to his might. ${ }^{3}$ This theory of government, however inadequate it may be, is at least self-consistent. On Hobbes's theory, whence comes the obligation to abide by the terms of the social con-

1 See Leviathan, c. 14. Many Englishmen of Hobbes's time would have been disposed to argue: "You take my life, if you do take the means whereby I live"; and others did think that the right of worshipping God after what they thought the true fashion was more precious than life itself.

2 Treatise of Civil Government, II., §225.

3 Epistle 50. 
tract? This contract is made not in the civil state but in the state of nature, and is therefore binding only by the law of nature. ${ }^{1}$ Hobbes would probably have defended his theory by arguing that the natural right of self-preservation, which he holds is inalienable-i.e. the natural instinct to strive for self-preservation-constitutes a sufficient obligation to adhere to the terms of the social contract. It might be to a person of Hobbes's own temperament; but how could such an answer be applicable to any one who argued, like Locke, that continued misgovernment might be a worse evil than anarchy itself ?

Again, supposing a successful revolution to take place and a new government to be established, strong enough to maintain itself and to preserve that peace for which Hobbes cared above everything, what is a conscientious Hobbist to do? The new sovereign (one, some or all) is not the sovereign to whom every individual was previously supposed to have handed over his rights irrevocably, and yet this new sovereign is fulfilling the function for which alone men have given up their natural rights. The supposition was for Hobbes himself not altogether an imaginary one ; and perhaps Hobbes was not acting inconsistently with his theories in submitting to the Council of State in $165 \mathrm{I}$, in order to come to London and get his Leviathan published under a government sufficiently tolerant to allow its publication, and sufficiently strong to protect the author. The average royalist showed a wise instinct in re-

1 Cf. T. H. Green, Philosophical Works, II., p. 370. 
garding as a very suspicious ally the intellectual ancestor of both Rousseau and Bentham. ${ }^{1}$

Locke nowhere expressly denies that there is a contract between king and people, but, as I have shown, prefers to use the same phraseology as Milton and to speak of the king as having power intrusted to him by the always sovereign people. Locke's chief difference from Hobbes lies in his insisting that the dissolution of a government is not the same thing as the dissolution of a society. ${ }^{2}$ A "politic society" is constituted by the original compact, and the appointment of this or that set of persons to do the business of government is a subsequent matter. As I have already pointed out, this theory is identical with that of Rousseau. Rousseau, like Hobbes, expressly denies that there is any contract between ruler and people. Hobbes does so in order to repel the claims of the aggrieved subject. Rousseau does so in order to maintain the supremacy of the sovereign people. One particular form of Hobbes's "sovereign" is the only one that Rousseau allowsthe sovereignty of all. Hobbes passes lightly over this form, because he thinks of the sovereign as identical with the government. Rousseau's sovereign is a power perpetually behind every form of government. Hobbes regards civil society as only possible

1 Mr. C. H. Firth has called my attention to a passage in Clarendon's Survey of the Leviathan (1676), p. 92, in which Clarendon alleges that "Mr. Hobbes his book" and still more his conversation induced many persons to submit to Cromwell as to their legitimate sovereign.

2 Treatise of Government, II., $§ 2 \mathrm{I}$ I. 
when the individual surrenders his natural rights. In the less mechanical thinking of Rousseau the individual by the social contract gains for himself the protection of the whole force of the community and yet obeys only himself (i.e., his "common self") and remains as free as before. ${ }^{1}$ When Rousseau goes on to argue as if the sovereign people could only act in a mass assembly, he forgets his own distinction between the volonté génerale and the volonté de tous, and fails to grasp the full meaning of his own formula; for in the words in which he enunciates the nature of the social pact, he has risen, without fully knowing it, to the conception of society as organic ; and in the idea of a "common self" higher than the individual self, he has anticipated the teaching of German idealism, or perhaps I should rather say, he has adopted a practical principle which requires for its explanation a profounder philosophy than his age had as yet provided.

For the purposes of political philosophy the history of the social contract theory ends with Rousseau. Kant and Fichte only repeat the theory in Rousseau's form, with a rather more complete consciousness of what it implies.

"The act [says Kant] by which a people is represented as constituting itself into a state, is termed the original contract. This is properly only an outward mode of representing the idea by which the rightfulness of the process of organising the constitution may be made conceivable. According to this representation, all and each of the people give up their external freedom in order to 
receive it immediately again as members of a commonwealth. The commonwealth is the people viewed as united altogether into a state. And thus it is not to be said that the individual in the state has sacrificed a part of his inborn external freedom for a particular purpose; but he has abandoned his wild lawless freedom wholly, in order to find all his proper freedom again entire and undiminished, but in the form of a regulated order of dependence, that is, in a civil state, regulated by laws of right. This relation of dependence thus arises out of his own regulative law-giving will." 1

In this passage it will be seen that Kant agrees with Rousseau and differs from Locke in recognising that the theory of the original contract is not an historical account of how political society grew up, but a logical analysis of the basis on which political society rests. Hobbes, as has been pointed out by Prof. Croom Robertson, ${ }^{2}$ by calling " natural" the kind of society that is formed by acquisition, "not obscurely suggests that the institutive is first only in the logical, not in the historical, order." Kant, however, takes pains to bring out this unhistorical character of the theory more clearly than any of his predecessors. The "original contract," he says (in his essay $O n$ the saying that a thing may be right in theory, but worthless in practice) -

" is merely an idea of reason; but it has undoubtedly a practical reality. For it ought to bind every legislator by the condition that he shall enact such laws as might have arisen from the united will of the people ; and it will likewise be binding upon every sub-

1 Kant, Rechtslehre, Part ii., \$ 47. (Werke, IX., p. I6I, Ed. Rosenkranz), Mr. W. Hastie's translation (Kant's Philosophy of Laze), pp. 169, 170 .

2 Hobbes, p. 145 . 
ject, in so far as he will be a citizen, so that he shall regard the law as if he had consented to it of his own will." 1

Thus Kant explicitly recognises that the conception of contract is a standard by which to judge institutions, not an account of the manner in which they came into existence. Kant may seem to avoid the assertion of the sovereignty of the people which is prominent in Rousseau; but in his Zum ewigen Frieden he lays down, just as Rousseau does, that "the republican constitution is the only one which arises out of the idea of the original compact upon which all the rightful legislation of a people is founded." 2

Fichte in his Grundlage des Naturrechts (1796) makes the social contract theory in Rousseau's form solve the contradiction between the "thesis" that "whatever does not violate the rights of another each person has the right to do, each person having the right to judge for himself what is the limit of his free action" - the usual assumption of "individualists"- -and the antithesis " that each person must utterly and unconditionally transfer all his power and judgment to a third party, if a legal relation between free persons is to be possible"-which is Hobbes's theory. ${ }^{3}$. Fichte does not mention either Hobbes or Rousseau in this passage; but his own theory

1 Werke (Ed. Rosenkranz), VII., p. 209. Mr. Hastie's translation under title Kant's Principles of Politics, p. 46.

2 Werke, VII., p. 24I. Mr. Hastie's Kant's Principles of Politics, p. 89 .

3 Werke, III., p. ror. Kroeger's transl., Science of Rights, p. 149. 
does not in any essential point differ from that of the latter, to whom he refers elsewhere. His "will which is an infallible power, but only when in conformity with the will of the law," is identical with Rousseau's volonte generale, which cannot err. ${ }^{1}$ Fichte prepares the way for Hegel; but Hegel's recognition of the element of truth in Rousseau's theory can be most conveniently referred to after we have considered the criticism and decline of the theory.

\section{IV.}

The most important and the most instructive criticism passed upon the social contract theory is that of Hume ; for Hume's thinking belongs to the same type as that of Locke. Already in his Treatise of Human Nature (1740) ${ }^{2}$ Hume had assailed the theory, and his criticisms are repeated in his essay Of the Original Contract (1752). Rousseau's Contrat Social did not appear till I762. But history is not the same thing as chronology; and in tracing the growth of ideas we sometimes find that the criticism of an opinion has begun even before the opinion has reached its fullest and completest expression. Hume does not content himself, like many later opponents of the theory, with urging that society did not as a matter of fact originate in contract-an argument which we have seen would be valid against Locke, but not against Hobbes, Rous-

1 Contrat Social, II. 3.

2 The "First Part" was published in 1739; the "Second Part," which deals with ethics and politics, in the following year. 
seau or Kant. Hume does not neglect the historical argument, and what he says about the function of war in the making of nations is in entire accordance with the conclusions of recent sociology. But the more valuable part of Hume's criticism consists in his bringing out the logical inconsistency in a theory which bases allegiance upon promise. Why are we bound to keep our promises? The answer must be: Because otherwise society would not hold together. But does not this same answer explain the need of obedience to the law? The obligation to keep promises must be based either on the law of an already formed society or simply on force.

Bentham, in his Fragment on Government, refers approvingly to Hume's "demolition" of the "chimera"; ${ }^{1}$ but Bentham himself treats the contract theory only in its "mediæval" and popular form of contract between king and people. When asked "to open that page of history in which the solemnisation of this important contract was recorded," the lawyers confess that it is a fiction. But Bentham is impatient of fictions. "I bid adieu to the original contract ; and I left it to those to amuse themselves with this rattle, who could think they needed it.'

History does not refute a theory which is unhistorical. But the growth of the historical spirit and the application of the historical method to the study of institutions diminish our appreciation of a way of representing facts which jars at every mo-

1 The metaphors are Bentham's; see chap. i., $\S 36$. 
ment with ideas that have become commonplaces to us, however unfamiliar to most political thinkers in the last century. The method of Montesquieu predominates over the method of Rousseau, and Sir Henry Maine and others have addressed ears already prepared to accept their arguments.

There is a passage in Burke's Reflections on the Revolution in France, in which he uses the phraseology of the contract theory in order to rise above it to the conception of society as an organic growth :

"Society is indeed a contract. Subordinate contracts for objects of mere occasional interest may be dissolved at pleasure ; but the state ought not to be considered as nothing better than a partnership agreement in a trade of pepper and coffee, calico or tobacco, or some other such low concern, to be taken up for a little temporary interest, and to be dissolved by the fancy of the parties. It is to be looked on with other reverence; because it is not a partnership in things subservient only to the gross animal existence of a temporary and perishable nature. It is a partnership in all science; a partnership in all art; a partnership in every virtue and in all perfection. As the ends of such a partnership cannot be obtained in many generations, it becomes a partnership not only between those who are living, but between those who are living, those who are dead, and those who are to be born."

The idea of organic growth, which is here only suggested, has now become one of the commonplaces about society. Wherever, indeed, there are federal institutions the phraseology of the contract theory is more natural ${ }^{1}$ and in such institutions we

1 Through the kindness of the editors of the Political Science Quarterly I have been enabled to see an interesting dissertation by Mr. J. F. Fenton, The Theory of the Social Compact and its

D. $\mathrm{H}$. 
find the political justification of the theory as representing that side of the truth about human society which the historical antiquarian and the evolutionary sociologist are apt to ignore. Hegel, in his Philosophie des Rechts, ${ }^{1}$ recognises fully the merit of Rousseau's theory in making will (consent) the principle of the state. A merely historical account of what has been in the past is no sufficient philosophical explanation of a political society. M. Alfred Fouillée $^{2}$ has endeavoured to express the truth of both ways of regarding society by saying that the highest form of it must be an "organisme contractuel"-a formula that may perhaps gain more general acceptance than anything expressed in the phraseology of German idealism. The time has surely come when we can be just to Montesquieu and Burke without being unjust to Locke and Rousseau.

Influence upon the American Revolution. The chief matter in which I should be inclined to disagree with Mr. Fenton is in what concerns the distinction between Locke and Rousseau. Locke, as I have pointed out, does not speak of "a contract between the people and an hereditary line of kings," and his theory is on the whole identical with "the rabid doctrines of Rousseau."

${ }^{1} \S 258 . \quad 2$ In his Science Sociale Contemporaine. 


\section{VIII.}

\section{ON THE CONCEPTION OF SOVEREIGNTY. ${ }^{1}$}

Austin's famous definition of sovereignty is expressed by him in the following sentence :

"If a determinate human superior, not in a habit of obedience to a like superior, receive habitual obedience from the bulk of a given society, that determinate superior is sovereign in that society, and the society (including the superior) is a society political and independent."-Lectures on Jurisprudence, Lecture VI., vol. i. p. 226 (Edit. 4, I879).

The definition of a positive law, which is the counterpart of the definition of sovereignty, is given toward the close of the same prolonged "lecture" :

" Every positive law (or every law simply and strictly so called) is set, directly or circuitously, by a sovereign individual or body, to a member or members of the independent political society wherein its author is supreme."-Ibid., p. 339.

It is thus the fundamental assumption of the English school of jurisprudence and of the English writers on political science who follow in the path

1 Read originally before the Aristotelian Society (London), February $3^{\text {rd, }} \mathbf{1 8 9 0}$, and afterwards submitted to the "American Academy of Political and Social Science" (November 13 th, 1890 ), and printed in their Annals, January, I89I. It is here reprinted with considerable alterations. 
228 ON THE CONCEPTION OF SOVEREIGNTY. [VIII.

marked out by Hobbes, Bentham, and Austin, that in every political society sovereign power always resides in certain determinate persons (one, few, or many), and that all true laws (i.e. laws which the law courts would recognise as such) may be regarded as the commands of this sovereign. A consequence of this conception of sovereignty is that the classification of the forms of government becomes rigidly precise, simple, and, it must be added, quite remote from the ordinary use of language either among practical politicians or among the most scientific of political historians. The phrases "mixed government" and "limited monarchy" are abominations to Austin and Cornewall Lewis, as much as the facts supposed to correspond to these phrases were to their great precursor, Hobbes. Hobbes had political prejudices, as well as logical reasons, for his antipathy. In the case of Austin the motive force is the intense disgust provoked by that vagueness and obscurity of Blackstone which had already called forth Bentham's Fragment on Government. Vague uses of the term "law" and traditional laudations of mixed government and of the surpassing perfection of the British Constitution inevitably caused a reaction; and the confused prolixity of Blackstone must serve as the excuse for the seemingly precise prolixity of Austin.

The Austinian jurisprudence, which, in spite of Austin's German studies, is thoroughly English in its antecedents (except in so far as we regard the theories of Hobbes as due to the influence of Bodin), 
VIII.] ON THE CONCEPTION OF SOVEREIGNTY. 229

has produced a great effect on English legal and political thinking; but outside of England and some British colonies it has produced no effect whatever -none certainly, in France or Germany or Italy ; none in Scotland, nor, with very slight exceptions, in the United States of America. ${ }^{1}$ Its dominant authority in England has finally begun to be weakened by the introduction of the historical method into the study of law-above all by the great work done and the ideas suggested by the late Sir Henry Maine. Sir Henry Maine has pointed out, that throughout the greater part of the world and during the greater part of human history there have been no such sovereign legislating bodies as Austin supposes; and that, where we might consider all the conditions of sovereignty, according to Austin's conception, to be found, as, for instance, in the case of Runjeet Singh, the Sikh despot of the Punjaub, such a sovereign ruler never made a single law in Austin's sense. (Early History of Institutions, p. 380.) As Professor Clark puts it: "That the sovereign makes, or sets, such rules in the first instance is contrary alike to philology, history, and legal tradition, all of which indicate an element of original approval or consent by the whole community." (Practical Jurisprudence: A Comment on Austin, pp. 167, r68.) "If we look at the history of all early

1 Cf. an article on "National Sovereignty," in the Political Science Quarterly [New York] for June, I89o, by Mr. J. A. Jameson, who mentions only two American writers as followers of the "analytical jurists." 
societies," says Sir William Markby, who is not unfriendly to Austin (Elements of Law, edit. 2, p. 24), "we find that the principal duty of the sovereign, in time of peace, is not the making of law, but the decision of law-suits." Law is older than sovereignty; primitive law is the custom of the tribe, and the earliest type of sovereignty is exhibited, apart from leadership in battle, in pronouncing judgments, not in making laws. That one person or a determinate body of persons should make laws would be a profane and monstrous idea in the eyes of the members of primitive societies. The legislative activity of the sovereign comes very late in the process of political development ; and the great historical interest of the writings of Bentham and Austin is just that they are contemporary with, and supply a theoretical justification for, the quickening of legislative activity in England.

Historical considerations are, however, in themselves no argument against the Austinian conceptions of law and sovereignty-any more than it is an argument against the social contract theory to point out that the date of the original contract has not been fixed by Jean Jacques. A perfectly unhistorical theory may be useful as a means of analysis. Hobbes supplied the principle according to which the Austinian conception must be interpreted. "The legislator is he (not by whose authority the law was first made, but) by whose authority it continues to be law" (quoted by Austin, Jurisprudence, i. p. 337). Thus, where a rule of 
English common law has not been interfered with by parliamentary statute, we may regard it as "set" by Parliament, because Parliament could interfere with it, should such interference be considered expedient. What is permitted or suffered to continue we may, by a little twisting of language, by one of those fictions so dear to the conservative legal mind, consider to be commanded. Of course, when we extend this principle of interpretation from highly developed political societies, where the sovereign is constantly legislating, to more primitive societies, where there is no legislative activity, the extreme artificiality of the procedure is forced on our notice. It becomes absurd to say that the Great King of Persia at one time commanded the Jews to keep the Sabbath, because he did not forbid them to do so. The application of the historical method and the genuine scientific study of the origins and sources of law do not refute a professedly unhistorical theory, but they tend to weaken our sense of its importance. And yet we must not allow the glamour of the historical method to blind us to the value of the analytic. As Professor Dicey reminds us :

"The possible weakness of the historical method as applied to the growth of institutions, is that it may induce men to think so much of the way in which an institution has come to be what it is, that they cease to consider with sufficient care what it is that an institution has become."-The Law of the Constitution, pref. to first edition.

But the value of the analytic method is not neces- 
232 ON THE CONCEPTION OF SOVEREIGNTY. [VIII.

sarily the same thing with the value of the analytic method as practised by Austin.

"The procedure of the analytical jurists," says Sir Henry Maine (Early History of Institutions, pp. 360, 36r), " is closely analogous to that followed in mathematics and political economy. It is strictly philosophical, but the practical value of all sciences founded on abstractions depends on the relative importance of the elements rejected and the elements retained in the process of abstraction. Tried by this test, mathematical science is of greatly more value than political economy, and both of them than jurisprudence as conceived by the writers I am criticising."

This comparison between the English school of jurisprudence and the characteristically English school of political economy is admirable. If competition be perfectly unfettered by either law or custom or the force of habit or the presence of ordinary human feelings, if capital be absolutely transferable, and if (what is still more impossible) labour be absolutely transferable, then the Ricardian political economy would represent actual facts. But with a sufficient number of "ifs," it would be possible to write any number of scientific works, every sentence in which might be as painfully and uselessly true as the Proverbial Philosophy of Martin Tupper. ${ }^{1}$

But is this method of abstraction inseparable from an analysis of what is? And is Maine right in calling it "strictly philosophical"? Aristotle would

1 Bagehot, in his Postulates of English Political Economy, compares the insularity of the Ricardian political economy and the Austinian jurisprudence. Cf. above, p. 157 note. 
VIII.] ON THE CONCEPTION OF SOVEREIGNTY.

have objected that to be strictly philosophical we must adapt our methods to the subject-matter of our study, and that the methods available in mathematics are not applicable in the study of the science of wealth and of the science of law, which are branches of the great science of human society. If we try to get strict accuracy and precision where the subject-matter does not admit of it, we shall find ourselves left with mere empty words and abstract formulæ which give us no insight into reality, although they may indeed be valuable as a means of criticising the more confused and less conscious abstractions of common talk or of so-called popular philosophy. And, as a mere matter of terminology, is it not rather the business of the "philosopher" to correct the one-sided "abstractions" inevitable in ordinary language and indispensable in the procedure of the various special sciences? At least, we may reasonably expect from a philosophy of law, and even from a science of jurisprudence, that it shall have some applicability, if not to primitive societies, at least to the states which the theorist had before his eyes.

Now, this is the restricted claim made on behalf of Austin by his apologists at the present day. As Professor Holland puts it: "It is convenient to recognise as laws only such rules as are enforced by a sovereign political authority, although there are states of society in which it is difficult to ascertain as a fact what rules answer to this description." (Jurisprudence, edit. 2, p. 43.) Let us see, then, how the 
234 ON THE CONCEPTION OF SOVEREIGNTY. [VIII.

Austinian conception may be applied to the British Constitution. Here there is a noteworthy difference between Austin and his follower, Sir George Cornewall Lewis. Austin finds the sovereign in the United Kingdom in king, lords, and commonsmeaning by "commons" the electors of the House of Commons. "Speaking accurately," he says (i. p. 253), " the members of the commons' house are merely trustees for the body by which they are elected and appointed; and consequently, the sovereignty always resides in the king and the peers, with the electoral body of the commons." Lewis, on the other hand, agrees with Blackstone that "the sovereignty of the British Constitution is lodged in the three branches of the Parliament" (Use and Abuse of Political Terms, ed. by Sir R. K. Wilson, p. 49), i.e., in the King, the House of Lords, and the House of Commons. As we are here expressly dealing with a question of jurisprudence and not of history, it would be idle to discuss the question sometimes debated between lawyers and historians whether the king is or is not a part of parliament. The historian would indeed find it difficult to write of the political struggles of the seventeenth century, if he might not follow ordinary usage and speak of parliament as a body distinct from and excluding the king. But the constitutional lawyer must be allowed to retain the phraseology of Blackstone, and to define parliament as including all the parties whose assent is necessary in legislation, so that he can speak accurately of " the sovereignty of parliament" 
(cf. Dicey, Law of the Constitution, ed. 3, p. 37). ${ }^{1}$ Lewis's editor, Sir R. K. Wilson, points out that what Lewis himself has laid down as one of the "marks of sovereignty," viz. "irresponsibility," is most certainly to be found in the body of the electors (Use and Abuse of Political Terms, p. 47, note). "Irresponsibility" does certainly seem in a fuller sense to belong to the elector than to the member of Parliament. Neither is indeed legally responsible for the way in which he uses his right of voting: the "moral" responsibility of the member to his constituents is forcibly brought home to him when a dissolution is at hand, whereas no determinate persons (unless it be landlords or employers who "put on the screw") force his responsibility on the notice of the free and independent elector. There is always a penalty in the former case, but not always (fortunately) in the latter. But the other

1 The lawyer, moreover, as the late Mr. Freeman pointed out to me, can claim in this matter to have on his side the original meaning of the word "parliament"; it is "a talking" between the king and the wise men whom he has summoned to advise him. On the question whether the king is a part of parliament, see the translators' note in the second edition of Bluntschli's Theory of the State (Engl. edit.), pp. 501, 502. As the British Constitution has only been zeritten in our colonial imitations or adaptations of it, it is interesting to note that, whereas in the written Constitution of the Dominion of Canada (The British North America Act, r 867) Parliament is expressly defined as consisting of "the Queen, an Upper House styled the Senate, and the House of Commons," in Victoria (Australia), by colonial legislation, the two houses are officially designated "The Parliament of Victoria." (See E. Jenks, The Government of Victoria, p. 236.$)$ 
$2 j 6$ ON THE CONCEPTION OF SOVEREIGNTY. [VIII.

mark of sovereignty laid down by Lewis is "necessity of consent." On this his editor remarks : "When the sheriff returns a member as duly elected, is it not a public act to which the consent of the electors is necessary"? This seems a rather forced application of the conception, compared with the fact, on which Lewis insists, that the House of Commons must consent to the passing of a law. The electors need not consent in order that the law should be sufficiently a true law to be enforced by a law court. Thus, one of Lewis's "marks" seems to suit the electors better, and the other, the elected.

This difficulty, and the divergence of view between Austin and Lewis, force on our attention the fundamental confusion in Austin's apparently clear and precise theory. Recent apologists of the English school of jurisprudence have generally put forward the defence that the sovereign body-in Austin's sense-is the body behind which the lawyer quâ lawyer does not look. Mr. Frederic Harrison has summed up Austin's analysis of sovereignty and law in the two following propositions :

"I. The source of all positive law is that definite sovereign authority which exists in every independent political community and therein exercises de facto the supreme power, being itself unlimited, as a matter of fact, by any limits of positive law.

"II. Law is a command relating to the general conduct of the subjects, to which command such sovereign authority has given legal obligation by annexing a sanction, or penalty, in case of neglect." (Art. on "The English School of Jurisprudence," Fortnightly Revieze, vol. xxx. pp. 484, 485.) 
Now, if this is to be the interpretation of Austin, if we are only to consider what the sovereign is for the purposes of the lawyer, Austin is quite wrong in going behind the House of Commons to the electorate. For the lawyer quâa lawyer a law is good law though it were passed by a Parliament which had abolished the Septennial Act and had gone on sitting as long as the Long Parliament, quite as much as if the law were passed by a newlysummoned parliament, of the elected part of which an overwhelming majority had been returned expressly pledged to vote for this very law. With the wishes or feelings of the electors the lawyer as lawyer has nothing whatever to do, however much they may affect him as a politician or as a reasonable man. The luminous exposition of this point by Professor Dicey (Law of the Constitution, ed. 3 , pp. 68-72) makes it unnecessary to say more. As Professor Dicey points out, Austin's doctrine is "absolutely inconsistent with the validity of the Septennial Act." " Nothing," he adds, " is more certain than that no English judge ever conceded, or under the present Constitution can concede, that Parliament is in any legal sense a 'trustee' for the electors." (P. 7 I.)

If any one were to object that our supposition is an impossible one, and to urge that no Parliament, now at least, could prolong its existence indefinitely - nay, that no Parliament now, elected under a Triennial Act, could pass a Septennial Act, without first "going to the country" on that very question, 
and if we were to ask such an objector "Why?" would not the answer be: "Because the country would not stand it"? That is to say, behind the sovereign which the lawyer recognises there is another sovereign to whom the legal sovereign must bow. The "legally despotic" sovereign, if that means our "omnipotent" Parliament, is very strictly limited in some ways. It is essential, therefore, to distinguish between the "legal sovereign" and the "ultimate political sovereign." Or, rather, to make the distinction complete at once, let us distinguish (I) the nominal sovereign, (2) the legal, and (3) the political. This distinction would serve to obviate a great many ambiguities. It is no new distinction : it is to be found formulated in Locke's second Treatise of Civil Government, ch. xiii. \$\$ I 49, I $5 \mathrm{I}$.

"Though in a constituted commonwealth, standing upon its own basis, and acting according to its own nature-that is, acting for the perservation of the community-there can be but one supreme power, which is the legislative, to which all the rest are and must be subordinate; yet the legislative being only a fiduciary power to act for certain ends, there remains still in the people a supreme power to remove or alter the legislative, when they find the legislative act contrary to the trust reposed in them. . . . In some commonwealths, where the legislative is not always in being, and the executive is vested in a single person, who has also a share in the legislative, there that single person, in a very tolerable sense, may also be called supreme, not that he has in himself all the supreme power, which is that of law-making, but because he has in him the supreme execution from whom all inferior magistrates derive all their several subordinate powers, or, at least, the greatest part of them ; having also no legislative superior to him, there being no law to be made without his con- 
sent, which cannot be expected should ever subject him to the other part of the legislative, he is properly enough in this sense supreme."

In these passages we have the distinction between what I have called the legal sovereign, the political sovereign, and the nominal sovereign, expressed in a manner applicable to the English Constitution. Locke, it will be observed, does not shirk the verbal paradox of saying that there are three supremes, and yet these are not one supreme. Here at least he makes an analysis of institutions without adopting a method of abstraction which sacrifices truth and convenience to the mere appearance of precise and consistent terminology.

Hobbes, from whom the Austinian conception of sovereignty comes, purposely identifies all the three meanings of sovereign. I do not wish to deny for a moment the immense value in political philosophy of the unflinching, though narrow, logic of Hobbes. Hobbes's theory of sovereignty is, of course, equally applicable to aristocracies and democracies; but, with regard to England, as is obvious enough from the curious dialogue, or rather catechism, which goes by the name of Behemoth, his theory may be described as that of a political nominalist, in the sense that he argues from names to things. Because the King of England is called "sovereign," therefore there is no other "legal sovereign"-the Parliamentarian lawyers were only talking what Austin would have called "jargon." That there is no other "political sovereign" Hobbes seeks to prove by his 
ingenious adaptation of the social contract theory, which in all other political writers had served the purpose of vindicating the right of a people to resist tyrants. Hobbes, like Thrasymachus in Plato's Republic, makes all laws (legal and moral) dependent on the will of a sovereign; in the phraseology of his own theory he allows no natural rights (with the inconsistent exception of the right of preserving one's life) to persist in civil society. If we translate his thought out of the fictions in which it is formulated, the practical lesson which he wishes to teach is this: There are only two alternatives-a strong government or anarchy. It is better to submit to any kind of authority, however much you dislike it, than to face the worse evils of universal war.

Locke's threefold distinction in the meaning of sovereignty allows him to escape the conclusion of Hobbes, and prepares the way for Rousseau. According to Hobbes, natural rights are transferred to the legal sovereign (and the legal sovereign is identified with the nominal); according to Rousseau, the legal sovereign is only the minister of the sovereign people, to whom the natural rights of each individual are transferred without being lost. ${ }^{1}$

Austin brushes aside the historical use of "sove-

1 " Trouver une forme d'association qui défende et protége de toute la force commune la personne et les biens de chaque associé, et par laquelle chacun, s'unissant à tous, n'obéisse pourtant qu'à lui-même, et reste aussi libre qu'auparavant." Tel est le problème fondamental dont le contrat social donne la solution.-Contr. Soc. I. c. vi. 
VIII.] ON THE CONCEPTION OF SOVEREIGNTY.

reignty" for the sovereignty of a prince. The historically true and very convenient phrase "limited monarchy" makes him and his followers almost angry. As we have seen, his apologists generally understand his sovereign in the sense of the legal sovereign; but he himself, by including the electorate in the sovereign of Great Britain, has gone behind the sovereign for the lawyer quâ lawyer. When Austin speaks of the "bulk" of the community being in the "habit" of obedience, he indicates that a vague consent of an indeterminate number of persons is necessary to the real power of the legal sovereign, thus practically recognising a sovereignty behind the legal sovereign ; but Austin will not apply the term sovereign at all except to a determinate number of persons. Now the electorate of Great Britain is certainly a determinate number; but is it true to say that it is solely by the consent of the electorate that the House of Commons has its power? Can we say that Austin has indicated the ultimate political sovereign in Great Britain? It is, of course, true that the electors have an easy and constitutional way by which to make the members of the House of Commons feel that, though legally irresponsible, they are actually or politically responsible. The electorate has the power of creation and annihilation. It can make a not-M.P. into an M.P., and it can determine that an M.P. shall in future sit-outside the House. But this only represents the constitutional relation of the electorate to the House of Commons. As a matter

D. $\mathrm{H}$. 
242 ON THE CONCEPTION OF SOVEREIGNTY. [VIII.

of fact, can we say that it was to the electorate of the House of Commons that King and Lords gave way in 1832 ? Even persons who are not electors can always make a riot, and sometimes a revolution. But when we pass outside a body such as the electorate, we are no longer dealing with "determinate persons."

If we turn from the British Constitution to the Constitution with which it is always most profitable to compare it - the Constitution of the United States of America-the contrast with regard to the "legal sovereign" is obvious, and has been clearly brought out by Professor Dicey. The lawyer quâ lawyer can go behind an Act of Congress or an act of the legislature of one of the States to the Constitution of the United States, or, in matters affecting a particular State and not reserved to the government of the United States, to the Constitution of that particular State. No English court can set aside an Act of Parliament as bad law; if an Englishman says anything that Parliament does is unconstitutional, he only means that he does not approve of it, or that he thinks it contrary to what he considers "the spirit of the Constitution": he is merely expressing his own private opinion. But an American court can refuse to give judgment in accordance with an Act of Congress which seems to it to violate the Constitution ; and when an American says an Act of Congress is unconstitutional, he is saying something that (whether true or false) has a perfectly definite meaning for the lawyer quâ lawyer. 
Now Austin, on the look-out for determinate persons, could not be content to call the written Constitution sovereign, but finds sovereignty in those persons who have the power of altering or amending the Constitution.

"I believe," he says (Jurisprudence, i. p. 268), "that the common government, or the government consisting of the congress and the president of the united states, is merely a subject minister of the united states' government. I believe that none of the latter is properly sovereign or supreme, even in the state or political society of which it is the immediate chief. And, lastly, I believe that the sovereignty of each of the states, and also of the larger state arising from the federal union, resides in the states' governments as forming one aggregate body : meaning by a state's government, not its ordinary legislature, but the body of its citizens which appoints its ordinary legislature, and which, the union apart, is properly sovereign therein." 1

With regard to the non-sovereignty of Congress and President and of the States' legislatures within each State there is no dispute. If anyone were to point out that within each State the body of the electors is sovereign in all those matters not expressly reserved by the Constitution of the United States, an Austinian would answer that, since the Constitution may conceivably be altered, the makers of State Constitutions are subject to the makers of the Constitution of the United States-which seems a sufficiently good answer, though it would compel one to give up the phraseology of the Federalist,

1 The pedantic absence of capitals is Austin's own, and implies no intention of insult. Austin might have added that the electors in a State are (the Union apart) sovereign, because they can alter the constitution of the State. 
244 ON THE CONCEPTION OF SOVEREIGNTY. [VIII.

according to which a portion of sovereignty remains in the individual States (No. lxii.). Instead of "remains in," we must say " is delegated to." The analytic method would invert the historical theory of the Constitution. That, however, is, as we have already allowed, no argument against its value. But is the body which can alter the Constitution of the United States the legal sovereign behind which the lawyer quâ lawyer cannot go? Austin draws his inference from Article $\mathrm{V}$. of the Constitution, which provides the mechanism for the amendment of the Constitution; but he stops his quotation without giving the last clause of the Article, which is as follows :

"Provided that . . . . no State, without its consent, shall be deprived of its equal suffrage in the Senate."

Now there can be no doubt that those who framed this clause intended that it should be unalterable by that amending body which can make other changes in the Constitution. It was intended that, in this respect at least, a few written words should be legally supreme over those determinate persons whom Austin considers to be the sovereign in the United States of America: so that if an Austinian lawyer objects to speak of a document as the legal sovereign, he must wander about in his search for "determinate persons," until he finds George Washington, Alexander Hamilton, Benjamin Franklin, James Madison, and others-all of whom are now dead. But these makers of the Con- 
stitution, it appears, have provided no mechanism for enforcing legally this intended limitation of the amending power. Each house of the legislature is, by Article I., Sec. 5, constituted supreme judge in regard to the qualifications of its own members : and therefore, if an amendment were carried in the manner sufficient for any other amendment, providing that certain small States should in future have only one member in the Senate, the other States having two or more, and if one of these small States should refuse to consent, such aggrieved State would have no means of bringing its grievance before a court. ${ }^{1}$ Thus this clause in Article $\mathrm{V}$., which served the important purpose of conciliating the smaller States, is out of place in a legal document : it has only a moral force, and is like the clause in the present French Constitution, which declares that the republican form of government shall never be subject to revision (Amendment of August, 1884) - a clause which is condemned by an American writer on Constitutional Law as "a bit of useless verbiage." " Perhaps Austin was aware of the defect in this clause of Article V. of the Ameri-

1 I am indebted to Prof. William A. Dunning, of Columbia College, New York, for pointing this out to me. Misled by English analogies, in a matter so foreign to English political usage, I had thought that the excluded Senator might sue the government for his salary, or in some other way compel a court to decide on the constitutional legality of the amendment which deprived his State of its equal suffrage.

2 Prof. J. W. Burgess in his Political Science and Comparative Constitutional Law, vol. I., p. I 72. 
can Constitution from a legal point of view. But let us suppose that the Constitution did provide some means for enforcing legally the rights of the smaller States here solemnly guaranteed (e.g. by making the Supreme Court the judge in cases of disputed elections), should we not then have to regard as the legal sovereign the written Constitution itself, or, if we must have determinate persons, its original makers or their ghosts?

Of course it may be said that such a violation as I have suggested of the last clause of Article V. is impossible in America, just as the substitution of the Septennial Act for the Triennial Act, without a general election, would now be impossible in England. That may be true; but it is irrelevant, if we are looking for the legal sovereign, as explained by Austin's apologists. Behind the legal sovereign there are such feelings as reverence for the past, imperative needs in the present, and hopes for the future-which feelings, however, are to be found in indeterminate, and not in determinate persons. The ultimate political sovereign is not a determinate body of persons. And we have just seen that there might be cases where legal sovereignty could not be found in a determinate body of persons.

With regard to the nominal sovereign, it must also be clear that this is not always a determinate person. No constitutional monarchy has, indeed, as yet followed the suggestion of Condorcet and employed an automaton on the throne- "to put the dots on the is." In a republic it may be con- 
venient to have an individual at the head of the executive; but there might be a republic without a president. In the Swiss Confederation, the President is practically only the chairman of an executive board. The President of the United States, though more powerful in some respects than any constitutional king, and though he takes a place in public prayers and in the drinking of toasts parallel to that occupied by emperors and kings, is certainly not the nominal sovereign. "The United States of America" is the nominal sovereign in regard to certain matters, and "the Commonwealth of Massachusetts," "the State of New York," etc., in regard to others. "The French Republic" is the nominal sovereign in France, and was so for some time after the First Napoleon and his imitator had called themselves "Emperors," just as in ancient Rome "the Senate and People" was the nominal sovereign during the rule of the Senatorial oligarchy and during the despotism of the Cæsars.

Mr. Herbert Spencer (The Man versus the State, p. 8I), while apparently accepting Austin's conception of sovereignty as residing in certain determinate persons, strongly objects to sovereignty being considered unlimited. "Austin," he remarks, "was originally in the army"; and this serves him as a psychological explanation of Austin's theory. "He assimilates civil authority to military authority." Now, Mr. Spencer seems to me to find fault just with what is permanently valuable in Austin's conception of sovereignty. That a sovereign is supreme is 
248 ON THE CONCEPTION OF SOVEREIGNTY. [VIII.

indeed an identical proposition, but a proposition which it was very important to assert. If, with Austin's apologists, we assume that the attributes of sovereignty belong to the legal sovereign, then the only escape from endless ambiguities, both in theory and practice, is to insist that the sovereign in every state is, in Austin's striking phrase, "legally despotic." I shall consider afterwards, whether in any sense the ultimate political sovereign can be said to be limited. The nominal sovereign need not cause a difficulty, because the nominal sovereign, whether an individual person or a name, is only the representative of the legal and political sovereigns. ${ }^{1}$ The legal despotism of the legal sovereign means only that the legal sovereign cannot be made legally responsible without a contradiction in terms. As Aristotle would say, "Otherwise we must go on to infinity." But this brings out the more clearly the responsibility of the legal sovereign to moral influences and to physical force. Hobbes did a great service to civil liberty by making men fully aware of what the sovereignty of a monarch implied. And Austin appropriately cites the declaration of Algernon Sidney, that no society can exist without arbitrary powers. "The difference between good and ill governments is not that those of one sort have

${ }^{1}$ As Locke puts it, in the latter part of I $_{5} \mathbf{I}$ of his second Treatise of Civil Government: $\mathrm{He}$ " is to be considered as the image, phantom, or representative of the commonwealth, acted by the will of the society, declared in its laws, and thus he has no will, no power, but that of the law." This is true a fortiori of a nominal sovereign that is not a person or body of persons. 
an arbitrary power, which the others have not; but that in those which are well constituted, this power is so placed as it may be beneficial to the people." (Observe, he does not say merely "exercised beneficially for the people," but "so placed as it may be," etc.) Austin clearly sees what Mr. Spencer is unable to realise, that without the legal restraints enforced by a supreme government there cannot be civil liberty. In Locke's words, "where there is no law there is no freedom." 1

Bluntschli, who by no means shares Mr. Spencer's antipathy to the State, shares his objection to unlimited sovereignty. (Theory of the State, Eng. tran., p. $464 .{ }^{2}$ ) But we may safely say that no one trained in the Austinian jurisprudence could have fallen into the confusions of a passage in Bluntschli (ibid., p. $508^{3}$ ), where he declares that "in no case can an official be bound to render obedience which would violate the higher principles of religion and morality, or make him accomplice in a crime. Such acts can never be the duty of his office. The servant of the State cannot be required to do what a man would refuse from humanity, a believer from religion, or a citizen from regard to the criminal law of the land." What does he mean by "bound"? An official cannot be legally bound to break " the law of the land "; but he cannot legally claim to disobey a command, which, though not contrary to the law

1 Treatise of Civil Government, ii., §57.

2 P. 494 in ed. 2.

3 P. 539 in ed. 2. 
250 ON THE CONCEPTION OF SOVEREIGNTY. [VIII.

of the land, he considers contrary to his morality and his religion, and yet to remain an official. Morally, of course, he may consider himself bound to break the law of the land: and there are even cases where such protest may be made most effective by an official breaking a law which violates the moral feelings of the community, and leaving to the authorities the moral odium of removing or punishing him. Bluntschli's confusion is perhaps more excusable than it appears to an English reader, because of the distinction in Germany between Administrative Law and the ordinary law binding on non-officials. In England, as Professor Dicey has clearly pointed out, we have no droit administratif. But, at the best, such a dictum as Bluntschli's can do no good, theoretical or practical, and only helps to make people more tolerant of tyrannical laws and tyrannical administration than they ought to be. It is only a device of despotism to mix up a little pious talk about morality and religion with an unpalatable legal pill. It is much better that the law in all its harshness and its makers in all their legal irresponsibility should stand out clearly before the eyes of those who are required to obey. For then there is most likelihood of the moral responsibility of the legal sovereign being stringently enforced.

Let us, then, leave to the lawyer quâ lawyer his legal sovereign, and go on to consider, what is a matter not of jurisprudence but of political philosophy - the nature of the ultimate political sovereign. 
VIII.] ON THE CONCEPTION OF SOVEREIGNTY. 25 I

What has kept the Constitution of the United States more unaltered for over a hundred years than that of any country of Europe? What prevents the British Parliament from introducing a Decennial Act in the same fashion in which the Whigs of 1716 introduced the Septennial Act? What restrains the Sultan from ordering his subjects to burn the Koran and eat pork? In every case it is not a determinate person or persons, but opinion.

"As Force is always on the side of the governed, the governors have nothing to support them but opinion. It is therefore on opinion only that government is founded, and this maxim extends to the most despotic and most military governments, as well as to the most free and most popular."-Hume's Essays, Part I., Ess. iv.

With this passage of Hume we may compare the remarks of Professor Bryce in his discussion of "Government by Public Opinion." (The American Commonwealth, chap. 77.)

"Governments have always rested, and, special cases apart, must rest, if not on the affection, then on the reverence or awe, if not on the active approval, then on the silent acquiescence of the numerical majority."

This is the truth which is contained in the famous doctrine of "the sovereignty of the people"-a doctrine which by no means originated in the revolutionary brain of Rousseau, but was well known at the time of the Reformation to both Catholics and Protestants, and was frequently used by one or the other to justify the deposition and even the assassina- 
252 ON THE CONCEPTION OF SOVEREIGNTY. [VIII.

tion of rulers-who belonged to the opposite faith. ${ }^{1}$ It is the doctrine expressed by Locke in the words : "There remains in the people a supreme power to remove or alter the legislative." Austin himself accepts the statement "that every government continues through the people's consent," if interpreted as follows :

"That in every society, political and independent, the people are determined by motives of some description or another, to obey their government habitually; and that, if the bulk of the community ceased to obey it habitually, the government would cease to exist."-Jurisprudence, i. p. 305 .

The "sovereignty of the people" is vague: and it is generally possible for the historian, if not for the contemporary politician, to point out some definite person or body of persons, to whom the bulk of the community are habitually rendering the sort of obedience which in an accepted absolute monarchy is rendered to the titular monarch : e.g. we might speak of the Senate having been practically sovereign in Rome at the time of the Punic wars, or of Augustus being practically sovereign in spite of republican forms. We can often intelligibly, though it may be with some exaggeration, speak of "uncrowned kings" and "unofficial ministers." But in all such cases the person or body of persons rules only as expressing the general will. Still we might conveniently make a further distinction in sovereignty and call the de facto sovereign, as distinct from the

${ }^{1}$ See Janet, Histoire de la Science Politique, Liv. III ch. iii. and iv. 
de jure sovereign (or legal sovereign), that person or body of persons which at any time can effectively obtain and compel obedience in the name of the nation. ${ }^{1}$

The problem of good government is the problem of the proper relation between the legal and the ultimate political sovereign. Under primitive conditions, when the political sovereign is as yet unconscious of his sovereignty, the fitting form of government is the rule of the one, the absolute king, who administers justice according to supposed immemorial or divinely-instituted custom. When a people begins to become conscious of its political existence, a want of harmony may show itself between the mass of the people and the despotic rulers, who will be ruling now in accordance with the opinion of past generations and not of their actual subjects. Then the old system is on the verge of a revolution, peaceable or otherwise. $^{2}$ Representative institutions, petitions, public meetings, a free press, are various means through which the political sovereign can assert itself. When refused such means, and when yet sufficiently vigorous to use them, it will assert itself by armed rebellions, or, if that is not possible, by secret conspiracies and by assassinations, which being approved by the general conscience, are morally different from ordinary murders. Political

1 This distinction was suggested by some remarks in a lecture of Prof. Bryce's. But I must not make him responsible for my way of fitting it into my own theory as here expressed.

${ }^{2}$ Cf. Bryce, The American Commonwealth, iii. pp. I6, I 7, chap. 77 . 
254 ON THE CONCEPTION OH SOVEREIGNTY. [VIII.

assassination is a clumsy and generally ineffective method of moving a vote of censure on the government in countries where the opposition has no constitutional means of expression. When discontent is " driven beneath the surface," if sufficiently strong it will produce political earthquakes. Statesmanship has been defined as "the art of avoiding revolutions," and this is so far true that the wise statesman will make revolution impossible by making it unnecessary, or else certain of failure, because not supported by the "general will." But the "general will," or ultimate force of public opinion, does not reside in a determinate number of persons. Rousseau falls into an error, from which he himself has provided a way of escape, when he inclines to think that the general will (the volonté generale which he expressly distinguishes from the volonté de tous) can only be properly exercised by all the individuals collectively. A great deal may indeed be said on behalf of the direct exercise of political power, as among the citizens of Uri and Appenzell : a great deal may be said on behalf of the democratic device of the referendum as an excellent conservative check upon the "hasty legislation" of an elected assembly; but the sovereignty of the people is not exercised only in direct democracies. It may be and is exercised in many cases through an absolute monarch, or a dictator, or a small assembly of public-spirited and far-sighted nobles or ecclesiastics. Owing to the tendencies of human selfishness, want of imagination, and narrowness of view, the probability is that the interests of 
the unrepresented will not be properly nor systematically cared for. When a prince really cares for his people, when an aristocratic assembly overcomes the prejudices of caste-feeling, there is admiration as at some rare and curious phenomenon. But only a bigoted belief in the forms of democracy can prevent a historian from recognising that the "general will " has frequently found expression through the legal sovereignty of the very few.

The same habit of looking for political sovereignty in determinate persons leads to a great many of the prevalent confusions about majorities and minorities. It seems a plausible argument when it is said that there is very little gain if the tyranny of a majority is substituted for the tyranny of a minority, and a decided loss if the tyranny of an unenlightened majority is substituted for the tyranny of an enlightened minority. Quite true-if the rule of the majority is a tyranny. But "tyranny of the majority" requires definition. "A majority is tyrannical," says Professor Bryce (The American Commonwealth, chap. 85), "when it decides without hearing the minority, when it suppresses fair and temperate criticism on its own acts, when it insists on restraining men in matters where restraint is not required by the common interest, when it forces men to contribute money to objects which they disapprove, and which the common interest does not demand." 1 Apart from such tyranny, the rule of the majority has the import- 
256 ON THE CONCEPTION OF SOVEREIGNTY. [VIII.

ant advantage, pointed out in the memorable phrase : "We count heads to save the trouble of breaking them." Counting heads-even if they be foolish heads-is an invention which, on the whole, has promoted human well-being. The important right of a minority is the right to turi itself into a majority if it can. And if the right of free expression of opinion and of association for the purpose of promoting opinion be secured to a minority, we cannot reasonably say there is tyranny. If a majority believes in the reasonableness of its position, it need not fear the free discussion of it ; and if a minority believes in itself and in the reasonableness of its position, it requires nothing more. To give every elector or every member of an elected assembly an equal vote is a convenient device; it promotes security by preventing the feeling on the part of the majority that there is a grievance, and in the long run it leads to votes being not merely counted, but weighed. Men hold their opinions with very different degrees of strength and conviction. Ten persons who are firmly convinced of the social expediency of their policy can, if they stick together and are allowed freedom of association and of expression, very speedily turn themselves into ten thousand, when they have only lukewarm and half-hearted antagonists. (Of course, I am not referring to scientific opinion as to what is, but to practical opinion as to what ought to be done.) We talk of people having opinions; in the majority of cases it is the opinions that have the people. A political idea, a national sentiment, the 
spirit of the age, do not, certainly, float about like clouds in the air; they san only exist in the minds of individuals, but they exist in the minds of individuals with very different degrees of intensity, and the individuals differ very much in the degree in which they are conscious of them. The man in whom an idea, that is only vaguely present in the minds of others, rises into distinct consciousness, and who can give expression to that idea in such a way as to awaken others to the consciousness of it and of its importance-such an one is a leader of men. The practical leader, as is often noticed by historians and politicians, must not be too much in advance of his contemporaries ; but if he have not a more distinct consciousness of the aims for which others are blindly or half-blindly striving, he is in no sense a leader. Sir Robert Peel, a statesman not incapable of popular sympathies, described "public opinion" (in a letter written in 1820) as "that great compound of folly, weakness, prejudice, wrong feeling, right feeling, obstinacy, and newspaper paragraphs." In the same generation Hegel said: "In public opinion are contained all sorts of falsehood and truth." So far he only says the same thing as Peel; but he goes on to add: "To find the truth in it is the business of the great man. He who tells his age what it wills and expresses, and brings that to fulfilment, is the great man of the age." (Phil. des Rechts, § 31 8, p. 404.) The great man must be able to discern between the real and growing forces in public opinion, and the mere seeming and transitory or decaying elements in

D. $\mathrm{H}$. 
258 ON THE CONCEPtion OF SOVEREIGNTy. [VIII.

it. $^{1}$ But the man whose ideas and sentiments are out of all relation to those of his own age cannot exercise any effect upon it.

When we say that the legally irresponsible legal sovereign is, as a matter of fact, responsible (morally and physically) to the ultimate political sovereign, does not this mean that the ultimate political sovereign is the mere incarnation of the force of the majority? Physical force may be disguised behind the mechanism of voting; but it is force in the last resort. As Locke puts it, "It is necessary that the body should move whither the greater force carries it, which is the consent of the majority." (Civil Goverment, II., c. viii., \$96.) This force may be guided by wise or by foolish leaders ; but it is force nevertheless. Whether a government maintains itself or is overthrown, it is force that decides. Well, so it is. All ultimate questions of political, as distinct from mere legal, right are questions of might. The repugnance to this conclusion arises simply from the ambiguity of language. The word "force" seems to suggest mere brute strength, exclusive of spiritual elements. But the force which can operate among human beings successfully and continuously is never mere brute strength. Discipline, skill, self-control, fidelity, are elements necessary. to the success even of what we call "the force of arms"; and these are

1 This is what is implied in the words in Hegel which follow those quoted: "He does and makes real what is the inner essence of his age: and he who does not know how to despise public opinion, as he hears it here and there, will never attain to what is great." 
all spiritual elements. And a great deal more than these is necessary in order to establish a secure government. "You can do anything with bayonets -except sit on them." All government must have force at its disposal; but no government can last which has merely force at its disposal, even the force of a veteran army of professional soldiers. All government implies consent as well as force. ${ }^{1}$ These are the two elements which are recognised separately and in one-sided fashion in the theory of social contract on the one hand, and in the theory of law and sovereignty maintained by Thrasymachus, Hobbes, and Austin on the other. A law, to be a law in the true sense, must have the regulated force of the community behind it; but in order to be habitually obeyed and permanently enforced, it must be recognised not merely as "good law" (in the lawyer's sense), but as $a$ good law (in the layman's sense), i.e., it must be in accordance with the "general will," it must be thought to promote the common good; or, at least, its tendency to injure the common good must not yet be recognised. It is not necessary that every law should be explicitly approved by everyone who obeys it ; that is the impossible demand of individualism, which, carried to its logical issues, is anarchy, and makes all law alike impossible or superfluous. But the great majority of those who habitually obey must recognise the general expedi-

1 Cf. Rousseau, Contrat Social, I., c.iii. “Le plus fort n'est jamais assez fort pour être toujours le maître, s'il ne transforme sa force en droit, et l'obéissance en devoir." 
ency of the law, or, if not, they must feel themselves able to obtain its alteration, or else they must not yet have awakened to the need of any alteration.

Is there no limitation to this ultimate political sovereignty? Within the nation it might be said there was such in the responsibility of a people to its own future. But that responsibility is part of what we include in the "general will" : the ultimate political sovereign is not the determinate number of persons now existing in the nation, but the opinions and feelings of these persons ; and of those opinions and feelings the traditions of the past, the needs of the present, the hopes of the future, all form a part. But may there not be a limitation outside of the nation? We are thus led to consider the external aspect of sovereignty. In Austin's definition, the words " independent" and "not in a habit of obedience to a like superior" were expressly inserted by him to obviate the objections he found to Bentham's definition of a political society, on which his own is based more directly than on any other. The external aspect of sovereignty, however, came to be recognised and debated in modern times before the internal aspect was much considered. The external aspect of sovereignty is a negative aspect (as is sufficiently expressed by Austin's word "independent"), and for that reason allows of precise definition. The Greek term aúróvouos expresses the absence of obedience to any external authority, but it also suggests a self-governing community, and 
VIII.] ON THE CONCEPTION OF SOVEREIGNTY. 261

would not have been applied to the empire of the Persian king. The Greeks started their political life, or, at all events, they started their political thinking with the assumption of the isolated citystate as the true political society. A larger society than the city represents to Aristotle an inferior, and not a higher, stage of political development. Ties of religious observance and of sentiment, as well as a common language and a common culture, bound together the whole Hellenic world as distinct from "the barbarians." But the independence of the city-state was too deeply rooted in Greek ways of thought and life to allow of the absorption of these numerous societies under a strong central government. Such an absorption meant the extinction of freedom. The experiment of federation-the only method of reconciling autonomy and union-came too late, and was not tried under favourable conditions.

The nations of modern Europe, on the other hand, grew up under the shadow, or the ghost, of the Roman Empire, and were held together by the more real unity of the Catholic Church. The modern idea of national sovereignty, i.e., of complete independence of external authority, only gradually won its way, and the assertion of national sovereignty went along with the decay of the Holy Roman Empire and the revolt of the Northern nations against the authority of the Pope. On the external side a "sovereign prince" means a "sovereign nation"; though, of course, a sovereign nation may be a sovereign, i.e., independent, republic. The internal significance of 
sovereignty became a prominent theoretical and practical question only after the external question had been settled.

The recognition of international law may seem in a certain sense a limitation on the absolute sovereignty of the nation; but it is no legal limitation, because it is a limitation which is self-imposed. The independent nation, as Austin and his school rightly insist, has no legal superior. But the recognition on the part of a nation's representatives that the nation is one of a community of nations, with moral, though not legal, claims on one another, which are backed up by the irregular penalties of war, does impose a moral check on the unlimited independence of a nation, in the same sense in which the recognition of the will of the ultimate political sovereign imposes a moral check on the legal sovereign.

When Austin and his followers insist that international law is not law, the plausibility of the remark is mainly due to the fact that the English language possesses no equivalent for Jus, Droit, Recht. International law is not Lex: it is Jus. But the Austinian criticism does good service by indirectly calling attention to the fact that only the growth of international. morality makes possible the growth of international law. International law is law of the primitive type: it is custom. And the sanctions which deter from violating it are the anger and hatred of other nations, which may possibly or very likely result in the use of physical force. In 
VIII.] ON THE CONCEPTION OF SOVEREIGNTY. $26_{3}$

the rudest societies of men there are customs enforced by no regular judicial penalties, but rigidly observed through fear of the consequences of violating them; and so it is in the, as yet, rude society of nations. They are in the pre-political state; and if we call it the "state of nature," we must recognise that that is no longer always the "state of war." The community of nations is as yet only an idea : it has no legal or political existence. But it is an idea, and as such it forms the basis of international law.

The relations of the several nations to the whole of humanity is the problem with which a Philosophy of History attempts to deal, and from which the practical statesman cannot escape. The several nations are not permanent, self-identical, mutually exclusive units. The evolution of humanity causes new groups to form themselves by union and division out of those already existing. Statesmen, trained in despotic ideas, and endeavouring to regulate national boundaries from above and from without, have often separated those whose spirit was seeking unity and united those who could not be fused into a homogeneous people. The history of Europe since the Congress of Vienna is a commentary on the impossibility of fixing, by external authority, what are "independent political societies." A people in becoming conscious of itself insists on marking off its own limits as well as on determining the character of its government.

When we speak of humanity as something behind 
264 ON THE CONCEPTION OF SOVEREIGNTY. [VIII.

every particular sovereign nation, this is no empty phrase. The movements, whether economic, intellectual, moral, religious, or political, going on in one nation, affect the movements going on in others. No nation, for instance, can be freed or enslaved, enriched or impoverished, without other nations feeling the consequences. Thus, in the light of history, no nation is, as a matter of fact, ultimately irresponsible to the future and to other nations. If it is responsible, what, then, is the sanction? It is the penalty of death-the penalty of perishing by internal dissensions or by foreign conquest. "Natural selection" determines in the last resort which nations shall survive, what groupings of mankind are most vigorous, and what organisations are most successful. Die Weltgeschichte ist das Weltgericht.

Just as it is the business of the ordinary statesman so to guide the legal sovereign that it does not provoke the displeasure of the ultimate political sovereign, it is the business of the greatest statesman so to guide the whole people that they may adopt those forms which will insure their continuance and their progress. The really great leader will anticipate on behalf of his people what painful experience might otherwise teach too late. 


\section{IX.}

\section{THE RIGHTS OF MINORITIES. ${ }^{1}$}

In times past government has generally meant the rule of minorities over majorities. Even the most democratic governments of the ancient world were aristocracies of slave-owners. The free citizens of Athens were a democracy among themselves, but an aristocracy, if we think of all the human beings inhabiting Attica. And, even in cases where "inhabitants" and "free citizens" have been nearly convertible terms, cities and states governing themselves democratically have yet denied political rights to subject peoples. The free citizens of Uri allowed their bailiffs to rule despotically the inhabitants of the Ticino valley. Thus, the struggle for freedom has in the past generally been the struggle of the majority against a privileged minority. Where there has been no such struggle, this has been because the majority have acquiesced in their political subordination or have never yet awakened to a sense that anything else is possible except blind obedience to the one or the few. Such

1 Reprinted from the International Journal of Ethics (Philadelphia), January, 1891. The substance of this paper was originally given as a lecture to an Ethical Society. 
political torpor can continue more easily where all alike are the slaves of an absolute despot. Where the practices of free government (i.e., government by discussion, instead of government merely by force) prevail even among a limited number, an example is set, which the many in course of time will desire to imitate. It is therefore more dangerous for a republican than for a monarchical government to practise tyranny or claim exclusive privilege. The history of ancient Rome is the history of a gradual extension of citizenship to those previously excluded,-an extension won by partystruggles.

Democracy, in the full modern sense, means the rule of the majority. For practical purposes the majority must be taken as, for the time being, the representative of all. If all cannot have their wishes gratified, it is the less evil to adopt the view of the greater number. This is democracy in its lowest terms ; in its ideal it means a great deal more than a machine for carrying into effect the wishes of the majority. It may be urged that it is very absurd to expect the whole to yield to the decision of half plus one: and a democracy may limit itself by requiring that important changes can only take place with the consent of two-thirds or three-fourths of the persons voting or even of the persons entitled to vote. But no practical person will go so far as to require unanimity in large bodies. To expect unanimity, as is done in a Russian village community, belongs to a very crude stage of political 
thinking and is apt to mean the tyranny of the most obstinate. In judicial matters it is somewhat different; there may be good arguments for requiring unanimity in a jury, but I am not concerned to defend the English system. Yet, even with regard to that, one has heard of the Irishman who accused the other eleven of being "obstinate"; he knew how to assert the rights of minorities. Obstinacy is a very good thing in its way, as I shall have occasion to point out afterwards; but, on the whole, one is likely to get a more rational expression of opinion by recognising the principle of "counting heads." Thus there inevitably remains a minority whose wishes are overridden. Of course this minority may be a different one on different questions ; but the effect of party government is to make a great number of questions run together.

The claims of a minority to consideration may be merely a survival of claims to exclusive privilege. The dethroned rulers may not "give way with a good grace," and may expect in a changed constitution to retain their old pre-eminence. The extent of the change, which has taken place, may be disguised from them by the way in which it has come about, as in those countries that have been fortunate enough to grow gradually out of one form into . another. Birth and wealth, with the advantages of education and position which they may carry with them, give a person prestige in a community, however formally democratic it may be ; but the person of birth or wealth may go on to demand an express 
recognition of his advantages. Now such a claim on the part of a minority a democracy cannot recognise without defeating its very principle; and it may be questioned how far any such recognition ultimately benefits the minority itself. An express and formal superiority awakens jealousy and dislike $;^{1}$ an actual superiority of any obvious kind gets in a democratic country abundant opportunities of asserting itself,-in the case of wealth only too abundant opportunities.

It is a claim of a very different and more important kind which is made in Mill's Liberty, - a claim for the minority, put forward, however, not so much on behalf of the interests of the minority themselves as on behalf of the future and general well-being of mankind. All great movements of progress, it is pointed out, have begun with minorities; and thus, if the opinions and efforts of a minority are repressed and thwarted, progress may be hindered and future generations suffer. Others, again, go further and, echoing Carlyle's words, urge that, as the population consists mostly of fools, to allow the majority to rule is to allow the fools to rule. Knowledge, except of the loosest and most meagre kind, is the possession only of the few ; and so, it is argued, we must turn to the experts, and disregard the clamour of the many.

1 E.g., the Prussian "three-class system," according to which all primary voters are distributed into three classes according to the amount of direct taxes they pay,-classes of unequal size, but with equal voting power. The system was vigorously denounced by Lassalle. 
On this subject of the authority of the few and the many respectively considerable confusion shows itself every now and then. It may be as well to try to clear it up a little. On the one hand, it is undoubtedly true that scientific truth is scientifically known only by a few experts ; others must accept it on their authority. On the other hand, there has always been a tendency to believe that the mass of mankind cannot be entirely in the wrong; that there must be some truth in what is generally believed. And the actual growth of democracy and of the democratic spirit might seem to have enormously increased the force of the authority of general consent. To escape from this apparent contradiction we must carefully distinguish between the grounds on which we accept scientific truth and the grounds on which we adopt practical maxims. The vast mass of mankind have believed that the sun goes round the earth, have believed in witchcraft, in ghosts, etc. And this universality of belief is sometimes urged as an argument in favour of the truth of such opinions. It does prove that the scientific disbeliever is bound to show, not merely that such beliefs are erroneous, but also how they can have arisen and become prevalent. In the case of the relation of sun and earth, that is easy enough. The popular view, which still survives as often as the most scientifically-minded person talks of sunrise and sunset, is the first obvious interpretation of the impressions of sense. And similarly (though the matter is often much more complex) a knowledge of the mental history of the 
human race-a knowledge enormously increased of late by the careful study of lower races-will explain the wide acceptance of beliefs which the growth of science tends to discredit. But in all such cases the minority of trained minds has an authority that does not belong to the majority of untrained minds.

This legitimate authority of the expert is often used as an argument that government must be in the hands of a select class. It is sometimes even used as an argument for an hereditary aristocracy, which of course it does not support at all. It might seem to support the rule of an intellectual aristocracy, if we could get together such a body,- Plato's " philosopher kings." On the strength of this argument the Fellows of the Royal Society might claim to teach us lessons in the art of government. But the argument rests on a confusion between what is true for the intellect and what is practically expedient. If the majority of a people have a strong, though it may seem to the educated observer a perfectly unreasonable, belief in monarchical institutions, - are ready to die for their king, - then, however superior we many think republican institutions, it would be folly to impose them from without upon an unwilling people. It is of no use to give any people the best constitution (or what we think such) unless we convince them that it is the best, so that it becomes the best for them. All government is based upon opinion. This is the dictum of the cautious conservative Hume as well as of the democratic prophet Rousseau. Matters of detail can 
indeed be best decided by experts, and cannot be properly decided at all except by them (they must, however, be experts in the art of administration, and not merely in some theoretical science). But the mass of a nation must be convinced of the value of the general principle which is being carried out; else what we might judge the most salutary changes will be ineffectual. Of course the existence of an institution is often itself an important factor in producing the opinion favourable to it ; but it is the favourable opinion, and not the mere legal existence of the institution, that makes the institution of any value. If the mass of a people believe a law to be unjust, it matters not that a few highly-cultured gentlemen at the head of affairs are perfectly satisfied of its justice; to the people it is an unjust law, and has none of the binding force of law on their sentiments and conscience. ${ }^{1}$ And laws which people generally (I do not mean a few stray persons here and there) think it right to violate are producing the very opposite moral effect from that which good laws

1 In practice the most difficult cases are those where legislation has to deal with some matter (e.g. of health) on which none but the scientific expert can in the first instance form a sound judgment. It is only too possible that democratic societies may, through popular distrust of scientific opinion, fall in some respects behind societies under enlightened despotisms. The remedy is not despotism, but popular enlightenment. The scientific specialist is bound, therefore, by patriotism as well in the interests of his own science, to lend what aid he can to that popularisation of science from which he is too apt to recoil : it is the sole antidote to ignorance and pseudo-science. Those whom science neglects, fanaticism and quackery will claim for their own. 
ought to produce. That this or that law or institution is suitable for us or the reverse is not a proposition of the same kind with the proposition that such and such things do or do not happen in the course of nature or history. That the Romans lived under such and such a constitution is a proposition, with regard to whose truth or falsehood the opinion of the scientific historian outweighs any amount of popular belief or tradition. But that such and such a law or constitution is good for us is only true if we think it so, after a fair trial. (The qualification is essential.) To use a familiar illustration, it is the wearer of the shoe that knows whether the shoe pinches. The scientific shoemaker alone may know why it pinches, and how to remedy the mischief. But if the scientific shoemaker were to convince you that the shoe did not pinch, he would convince your intellect only, if the shoe continued to hurt your foot; and you would be apt to go in future to the unscientific shoemaker who could give you comfort even without science. So it is with constitutions and laws. Those who have to wear them must judge whether or not they fit; and therefore they must have the decisive voice as to the general principles, though, as already said, details had better be left to experts. Ends must be approved by the feeling of the many ; the means must be chosen by the intellect of the few. This is, in fact, the raison d'être of representative democracy, - the many choose the few to carry out their wishes.

These distinctions-first, between scientific and 
practical matters, secondly, between judgments about ends and about means-may seem almost too obvious to need statement. But obvious distinctions are apt to be overlooked ; and it is worth uttering truisms, if we can get rid of the fallacious argument that because the few may be wiser than the many, therefore the few should rule the many, otherwise than as their ministers and stewards.

Those who are ready for all practical purposes to accept the will of the majority as decisive yet sometimes think it necessary to propose various expedients for securing what is called "the representation of minorities." The danger of the nonrepresentation of minorities seems to me to be a good deal exaggerated by Mill and other advocates of "proportional representation" and similar schemes. It would indeed not be difficult to make out a primâa facie case for the absurdity of the whole system of representative government, if we attended merely to the arithmetical possibilities of its mechanism. Thus, in Great Britain, the determining power lies with the majority of a Cabinet, which is supported by a majority of the House of Commons, which is elected, it may be, by a bare majority of the electors; so that the representative system seems, when carried out, to defeat itself and to put power into the hands of a very small minority of the whole population,-ultimately perhaps into the hands of "the odd man." But this seeming absurdity results from an abstract and artificial way of looking at the matter. The will of these few persons is only effec-

D. $\mathrm{H}$. 
tive because they do represent (or at least did, at some time, represent) something very much more than a small fraction of the population. No scheme that can be constructed by human ingenuity will make a representative chamber a quite perfect mirror of all the various sets of opinion in the community. It is only a question of more or less ; and, what is very important, any arrangement that is adopted must have the merit not merely of being simple to work, but of looking simple. Even the suspicion of trickery must be avoided. This is, of course, the great advantage of the system of equal electoral districts with single members, and "one man one vote." Even so, it may indeed happen that a majority of the elected chamber may represent a minority of the electors, - if one party have extremely large majorities in some places and be defeated by extremely narrow majorities in others. Accidents of that sort will happen in the best regulated constitutions; but the chances are, certainly, against their happening to any very great extent. But when such arithmetical possibilities are insisted on, it is forgotten, in the first place, that each individual member has many other attributes besides being the member for so-and-so, and, in the second place, that there are elements in the living constitution of a country besides those written down by constitutional lawyers. An elected assembly is powerful indeed. It may, like the British Parliament, be legally "omnipotent;" and yet there is a power behind it, a power that acts not merely at the time 
of a general election, but continuously,-the power of public opinion. The newspaper and the public meeting and the petition are real factors in a modern constitution. It is easy enough to see the defects of each of these organs of public opinion, easy enough to throw ridicule upon them. But that is to miss their true significance. The newspaper ought to represent the power of intellect applied to practical matters; it is too apt to represent largely the power of money-not merely the capital that is needed to float it, but the money that comes in through advertisements. The political and moral consequences of advertising would, however, be too long a story to begin now; to have named it may suffice. Then, as to public meetings: there are many people who scoff at them. "Got-up agitations," "power of the strongest lungs," and so on. Those who talk in this way seem to forget that, though you may make a "flare-up" with a few shavings and a lucifer-match, to keep up a steady heat you need coals as well. There cannot be such a thing as an agitation that lasts, grows, and for which people sacrifice a great deal, and which is nevertheless merely "got up." A continuous agitation is not a cause but a symptom of discontent. Public meetings, petitions, pamphlets, newspaper articles, are, however imperfectly, organs of public opinion, and much better and more effective organs than assassination or even than epigrams, which take their place in despotically governed countries. ${ }^{1}$

1 Public meetings, petitions, etc., are indeed very rudimentary 
Where there exist such organs of public opinion and a tolerably sound, even though not ideally perfect, representative system, any minority which has really got life and vigour in it can make itself felt. I do not think that, if it were possible, it would be desirable to construct any political machinery for giving a prominent place to the opinions of minorities that will not take the trouble to assert and to spread these opinions. The all-important and essential right of minorities is the right to turn themselves into majorities if they can; this means freedom of the press, freedom of association, freedom of public meeting. "Give me," said Milton, "the liberty to know, to utter, and to argue freely according to conscience, above all other liberties." Minorities that grumble at the whole world round them and have no desire and no hope of convincing other people are not a valuable factor in political or social life. They are, in all probability, the decaying survivals of a past type, and not the first germs of a new.

In a genuinely democratic government votes are nominally merely counted; in reality they are weighed. Not indeed in the sense that wisdom always weighs the heaviest-in what constitution, outside Utopia, does that happen?-but in the sense that the energy and contagious enthusiasm of a few, who represent some living and growing idea, far

"organs" of popular sovereignty compared with the Swiss "referendum" and "initiative," which seem to work well-in Switzerland, at least. 
outweigh the indifference and apathy of great numbers. Great movements begin with small minorities; but these minorities must consist of persons who wish to make others share their convictions. From this follows all that can be laid down in general terms about the rights and-what we are less apt to think of - the duties of minorities.

The right of spreading one's opinions implies two things, neither of which must be absent : first, certain legal and constitutional securities ; and, secondly, a certain condition of public sentiment. Without the latter the former cannot be obtained unless exceptionally, as, for instance, under an enlightened despotism ; and that is really no exception, for securities dependent on the strong will of one enlightened and big-minded man can hardly be called constitutional, and are an uncertain bulwark of liberty. On the other hand, without explicitly recognised legal safeguards public sentiment is a somewhat fickle protector of liberty. Outbursts of fear, fanaticism, and intolerance are only too possible; and a good deal may be said even for the merely moral force of a formal "declaration of rights." A people in its calm or its generous moments may well protect itself against its own lower moods : it is something to be able to appeal from the people drunk to the people sober. And the strong hand of the state is often needed to protect the individual against undue social pressure.

I do not think that the subject of the ethics of toleration has ever been adequately treated. Tolera- 
tion is often supposed to arise solely from indifference. This is not the case. In fact, indifference makes toleration superfluous. Toleration, shown by those who "care for none of these things," is no virtue, though it may be a public duty in a magistrate "indifferently administering justice." The toleration of contempt may, indeed, be very useful to those who are zealous and in earnest. The kind of toleration which is most valuable, which can only exist in a morally healthy society, and which will help to keep the society healthy and make it healthier, is toleration shown by those who have faith in the reasonableness of their own beliefs and who are, therefore, willing to face the full light of criticism. Persecution, - and by persecution I mean here not what any aggrieved individual may call such, but the forcible suppression of opinions (every society is obliged to use force for the suppression of certain overt actions, and the line between expedient and inexpedient compulsion will be drawn differently by different persons),- - persecution arises mainly from two sources,--fear and a particular form of belief in the supernatural. If people do seriously believe that they and they alone are in possession of truth guaranteed to them by other authority than that of human reason, of course they will not accept the free use of reason as a test; and there is always a risk that, if sufficiently powerful, they will endeavour to repress the spread of what they conscientiously regard as dangerous opinions. Those who believe that Divine truth is something different 
from human truth will be apt to believe that the civil magistrate must defend the Deity by the power of the sword. This type of belief is really a form of fear,-it is fear of human reason; and, only as this belief becomes rarer or weaker by the secularising, or, to speak more correctly, the humanising of politics, does toleration become possible. But fear may make even those who appeal to reason persecutors in self-defence. It is difficult, if we are quite just in our historical judgments, to condemn entirely the harsh measures employed by small societies holding new beliefs, - antagonistic to those of firmly established and powerful communities, - such small societies, for instance, as the Calvinists of Geneva or the founders of the Commonwealth of Massachusetts. ${ }^{1}$ When a society is struggling to exist at all, cohesion is so essential that it may well require uniformity of belief. A rigid bond of custom is necessary to its earlier stages. Only after cohesion has been obtained is freedom of discussion possible and advantageous. Furthermore, complete freedom of discussion is only possible and is only valuable, when there is a general diffusion of education, and when the habit of settling matters by discussion, instead of by force, has become established. In admitting this we must not, however, forget that discussion itself is one of the most important means of education. There are indeed people- " misolo-

1 Even the most rigid sects of Protestants do in some sense professedly appeal to reason instead of ecclesiastical authority, as the interpreter of Scripture. 
gists," Plato would have called them-who say: "Controversy is of no use. Those who take part in it go away holding the same beliefs as before, only holding them more dogmatically as the result of having had to fight for them." If the fighting is physical, this is nearly always the case ; it is not true of intellectual controversy fairly carried on. During the actual discussion, indeed, each may stick to his opinion : it might even be said that, unless people showed some obstinacy, a debate would always be a failure. For minds in a perfectly flabby condition discussion is impossible: it implies a certain amount of mutual resistance. But if people are really in earnest and care more for truth than for victory, it will be found that after any serious discussion both parties have probably modified their opinions, and out of the conflict of two opposing principles may spring a new one, victorious over both. It is by the conflict of ideas that intellectual progress is made.

Professor Bryce in his great work on The American Commonwealth has made clear a very important distinction between "the tyranny of the majority" and "the fatalism of the multitude," which is often confused with it. "A majority is tyrannical," he says (vol. iii. p. I33), "when it decides without hearing the minority, when it suppresses fair and temperate criticism on its own acts, when it insists on restraining men in matters where restraint is not required by the common interest, when it forces men to contribute money to 
objects which they disapprove and which the common interest does not demand. ${ }^{1}$ The element of tyranny lies in the wantonness of the act, - a wantonness springing from the sense of overwhelming power, or in the fact that it is a misuse for one purpose of power granted for another."

Simply because the minority disapprove of the enactments of the majority, they cannot rightly describe the rule of the majority as "tyrannical." In a democratic constitution, with elections recurring sufficiently often, and proper safeguards for liberty of expressing and spreading opinions, the right of the minority is, as I have said, to turn themselves into a majority if they can; and it must be added, it is their duty also, if they continue to believe in themselves. But here comes in that "fatalism," which is so often wrongly described as the tyranny of the majority; the apathy of minorities is one of the frequent weaknesses in democratic communities. As Professor Bryce has put it, "the belief in the rights of the majority lies very near to the belief that the majority must be right" ( $i b$., p. I24). To give way for the time to the legally expressed will of the majority is a necessary and

1 I assume that the "and" is emphatic, and that this clause must be taken as qualifying the previous clause. If a tax is legally imposed by the majority for a purpose which the common interest (in their judgment) demands, a minority may disapprove this purpose, but they have no moral right to refuse payment of the tax, unless they are conscientiously convinced that such an act of rebellion is their duty, as the best means of bringing about what they regard as a better state of affairs. 
salutary consequence of popular government; but to lose heart and give up effort is an illegitimate and evil consequence of it. It is the duty of a minority to obey, unless conscience absolutely forbids ; in which extreme case it may become a duty to resist. If we are using language strictly, there never can be a right. of resistance. Rights are the creation of society, and there can be no right of the individual or of any number of individuals against the society of which they are members. When we speak of "natural rights," we really mean those rights which we think to be the very least that a well-organised society should secure to its members. In the American "Declaration of Independence" the time-honoured phrase about the right of resistance is wisely supplemented by the addition of the better and truer word, "duty."

Resistance may, in extreme cases, be the only way of protesting against what we hold to be an unjust and mischievous law and the only way of getting it altered. But the problems of practical ethics involved in this question are not easy. The limits of justifiable compromise cannot be laid down in any hard and fast $a$ priori rules. If it really goes against a man's conscience to obey a law (I am not speaking of arbitrary, illegal commands, where the right and duty of disobedience are clear enough), he can, if we use language strictly, claim no right to disobey, but it is his duty to disobey, at whatever cost; if he obeys against his conscience, he loses his own self-respect and lowers his cha- 
racter. Only let him be perfectly sure that it is his conscience that urges him and not some merely selfish motive of personal dislike or offended pride. To justify this statement and this distinction, it would of course be necessary to explain what is meant by "conscience." Suffice it to say for the present-and I think the supporters of most ethical systems would agree with this statementthat the dictates of a man's conscience will on the whole correspond to the better spirit of the community round him, or at least to what he regards as such; and therefore the man, who disobeys a law "for conscience' sake," is acting in the interests of what he conceives to be the future well-being of society. Of course a man's conscience may correspond to a superseded social type, but it will not be a superseded type in his own judgment. Posterity may come to disapprove many actions, and yet bestow admiration on the motives of those who did them. Even where an individual has no conscientious objection to render obedience himself, it may occasionally be his duty, in the interests of the future well-being of society, to join others in resisting and even in rebelling, provided that there is no reasonable hope of getting a bad law or a bad constitution altered by peaceable means, and provided also that there is a reasonable hope that the resistance or rebellion will be so successful as to lead to an alteration in the right direction. ${ }^{1}$ Such is the

1 On the Ethics of Resistance, see T. H. Green, Philosophical Works, ii. p. 455 , seq. 
terrible duty that occasionally falls on the shoulders of a minority, to bear the brand of the criminal now that others in time to come may render a willing obedience to better laws. Society is apt to make mistakes, to number the patriot or the saint among transgressors, to crucify a prophet between two thieves. But the individual is apt to make mistakes also, and there have been honest martyrs for bad causes.

If, however, democracies prove at all true to their ideal, if they live according to the ethics of the age of discussion and not according to those of the earlier ages of force, this duty of resistance should become less and less needed. If majorities, while requiring obedience to laws constitutionally passed, after full and free deliberation, in what they sincerely believe to be the interest of the whole community, sacredly preserve the liberty of thought and discussion both by express legal securities and by a general sentiment of toleration, it is the duty of a minority, while yielding a loyal obedience to the opinion that has prevailed for the time (except in those rare cases to which I have referred), if not convinced of its excellence, to continue a peaceable agitation till their own opinion prevails. If we are really in earnest about our opinions, it is a duty to endeavour to get others to accept them by means of the appeal to reason; it is also a duty, and often a very hard one, to give them up candidly, if we are genuinely convinced that we have been in the wrong. It is a duty to assert our opinions, wisely 
of course, and with toleration for others, even if those others be in the majority; but it is a prior duty to use all the care we can to make sure that our opinions are right, that what we assert eagerly and persistently is really worth asserting. It is utterly untrue to say that we are not responsible for our opinions. That was a bad argument used for a good purpose,-the attack upon religious persecution. Opinions are not trivial matters. What is quietly thought and talked about now will affect what is done very soon. The opinions of a few in one generation may, in the next generation, become the sentiments or the prejudices of the many. Ethical legislation is constantly going on in our every-day conversation, wherever two or three are gathered together-to discuss the conduct of their neighbours. And we cannot escape our responsibility for our share in this ethical legislation, however insignificant we may feel ourselves in presence of the great multitudes of our fellow-mortals. To these great multitudes each of us is responsible; and we owe it to them to oppose them, then and then only, when reason and conscience urge us to do so. 



\section{BY THE SAME AUTHOR.}

DARWINISM AND POLITICS. (SECOND Edition.) Crown 8vo, cloth, 2s. $6 d$.

"Mr. Ritchie's book is one of the most suggestive that we have met with for some time past, and we cannot commend it too highly to our readers."-Literary World.

"Short, crisp, argumentative, and practical ; it is excellently written in a manner both scholarly and complete."The Critic.

[Social Science Series.

\section{THE PRINCIPLES OF STATE INTERFER-} ENCE. Crowon 8vo, cloth $2 s .6 d$.

"As a critic, Mr. Ritchie is excellent. To unusual dialectical power he unites a singularly effective style, clear, forcible, pointed and lively."-Economic Journal.

"An able and brilliant volume."-National Reformer. [Social Science Series.

LONDON : SWAN SONNENSCHEIN \& CO. 


$$
3^{2}
$$



(2)

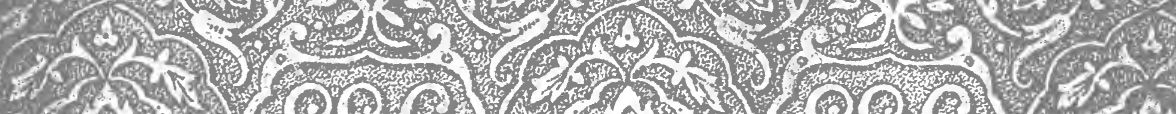

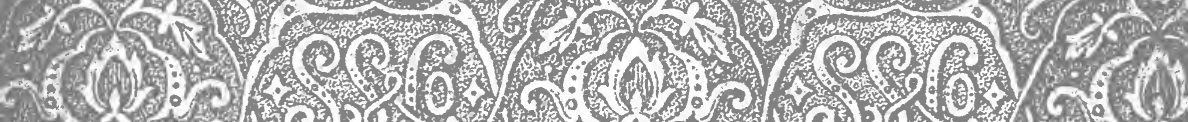

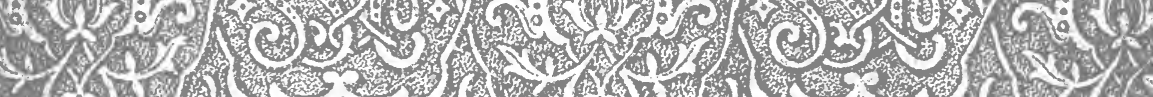

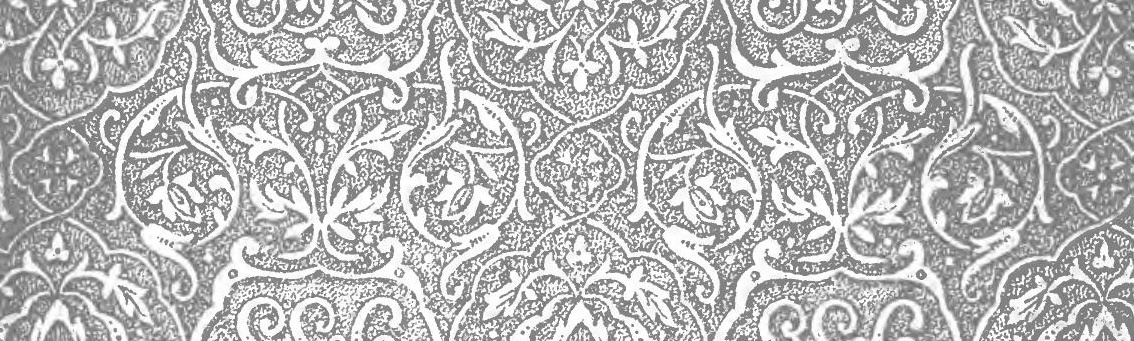

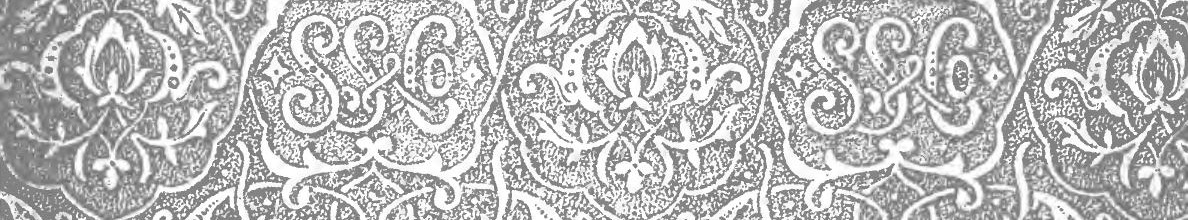

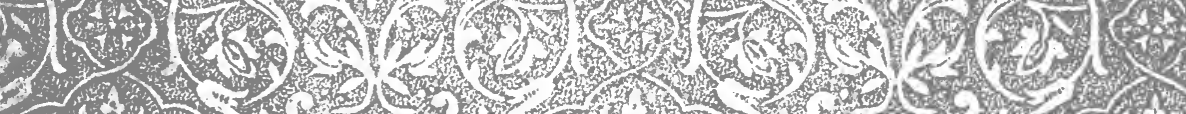
1
1

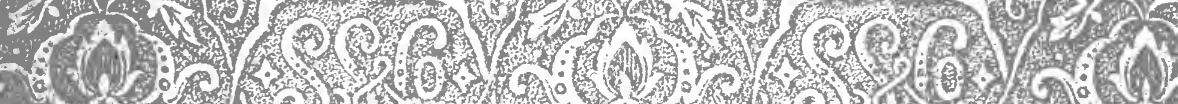

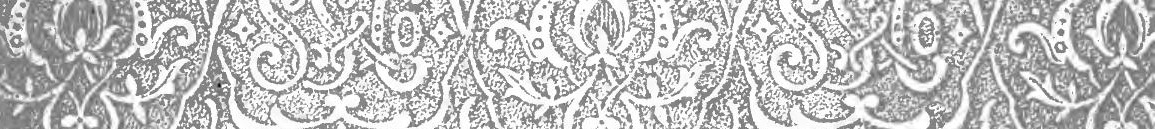
(2) 8.

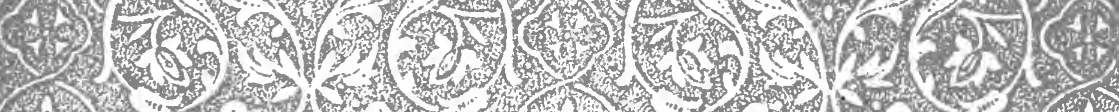

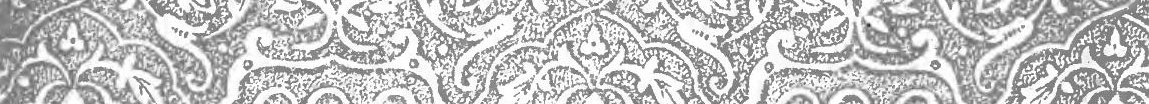

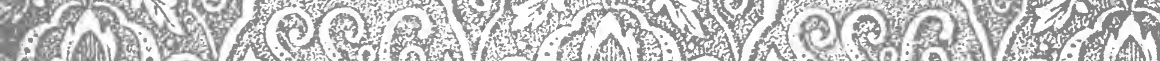

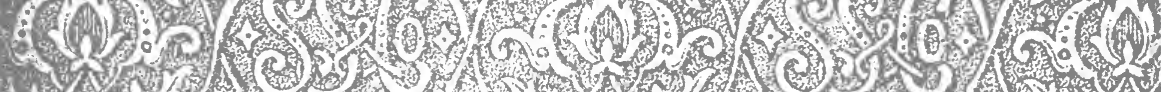
a (6) \% (4) 8.

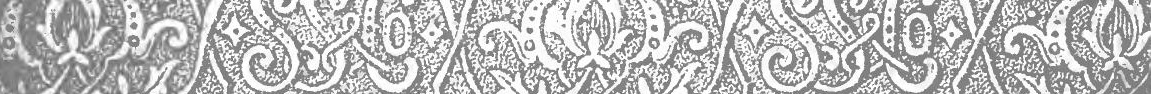
4. 9.1. 


\section{PLEASE DO NOT REMOVE \\ CARDS OR SLIPS FROM THIS POCKET}

\section{UNIVERSITY OF TORONTO LIBRARY}

B

1649

$\mathrm{R} 43037$

1893

C.2

ROBA 


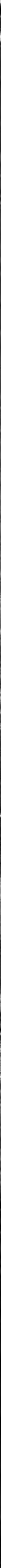

